GLOBAL ALLIANCE FOR

INCINERATOR ALTERNATIVES

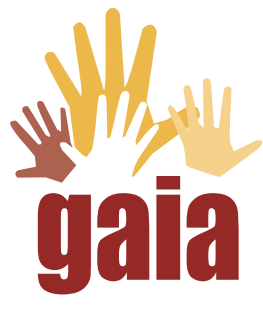

\title{
A Tale of 5 Cities: Plastic Barriers to Zero Waste
}




\section{TABLE OF CONTENTS}

\section{ACKNOWLEDGEMENTS}

Written by Denise Patel. Research provided by Alex Danovitch and Susan Hubbard of Nothing Left To Waste. It was edited by Natasha Naayem and designed by Tigist Kelkay at YolkWorks. Other contributors and reviewers inciude Claire Arkin, Monica Wilson, Doun Moon, Tok Michelle Oyewole at GAIA; as well as KT Andresky of Breathe Free Detroit, Nazir Khan of Minnesota BPOC Table, Whitney Amaya of East Yard Communities for Environmental Justice, Lynn Hoffman of Eureka Recycling, Natalia Figueredo of Ironbound

This report has been made possible in part through funding from Plastic Solutions Fund. The views

expressed in this publication do not necessarily reflect those of Plastic Solutions Fund.

DOI: www.doi.org/10.46556/HEOY6222

Also available at: http://www.no-burn.org/5citie

Cite this report as: Patel, D., Danovitch, A., \& Hubbard. S. A Tale of 5 Cities: Plastic Barriers to Zero Waste. Global Alliance for Incinerator Alternatives. Www.doi.org/10.46556/HEOY6222

\section{ติaia}

(2021 Global Alliance for Incinerator Alternatives

we, Berkeley, CA 94704, USA

www.no-burn.org

GAIA is a global network of more than 800 grassroots groups, NGOs, and individuals. We envision a just, zero waste world built on respect for ecological limits and community rights, where people are free from the burden of toxic polltition, and esources are sustanably conserved, not bumed or dumped. We work to atalyze a global shitt towards environmental
EXECUTIVE SUMMARY

INTRODUCTION

CHAPTER 01: "Garbage in, Garbage out": Why the Lack of Accessibility to Good Data on MSW Holds Cities Back

Good Data Makes Good Policy, but Data on MSW is Both Hard to Get and Dated Strategy 1 : Require Good Data and Transparency

CHAPTER 02: Mythcycling is NOT a Solution for Wishcycling:

Very Little Plastic is Actually Recycled

Finding \#1: Very Little Plastic is Actually Recycled

Strategy: Eliminate Unnecessary Plastic

Finding \#2: Most Recyclable Plastic is Still Left in the Trash

Strategy: Shift the Supply Chain to Reuse, Refillables, and Sharing

Finding \#3: Broken waste management systems drive false solutions

Strategy: Don't Fuel the Myth

CHAPTER 03: Align City Resources with Zero Waste Goals

Strategy 1: Align Mission with Plans, Policies, and Resources

Strategy 2: Improve Legitimate Recycling

Strategy 3: Make Polluters Pay

CONCLUSION

APPENDIX I: TERMINOLOGY

APPENDIX II: METHODOLOGY AND SUMMARY OF DATA

Baltimore

Minneapolis

Newark

Long Beach

Detroit 


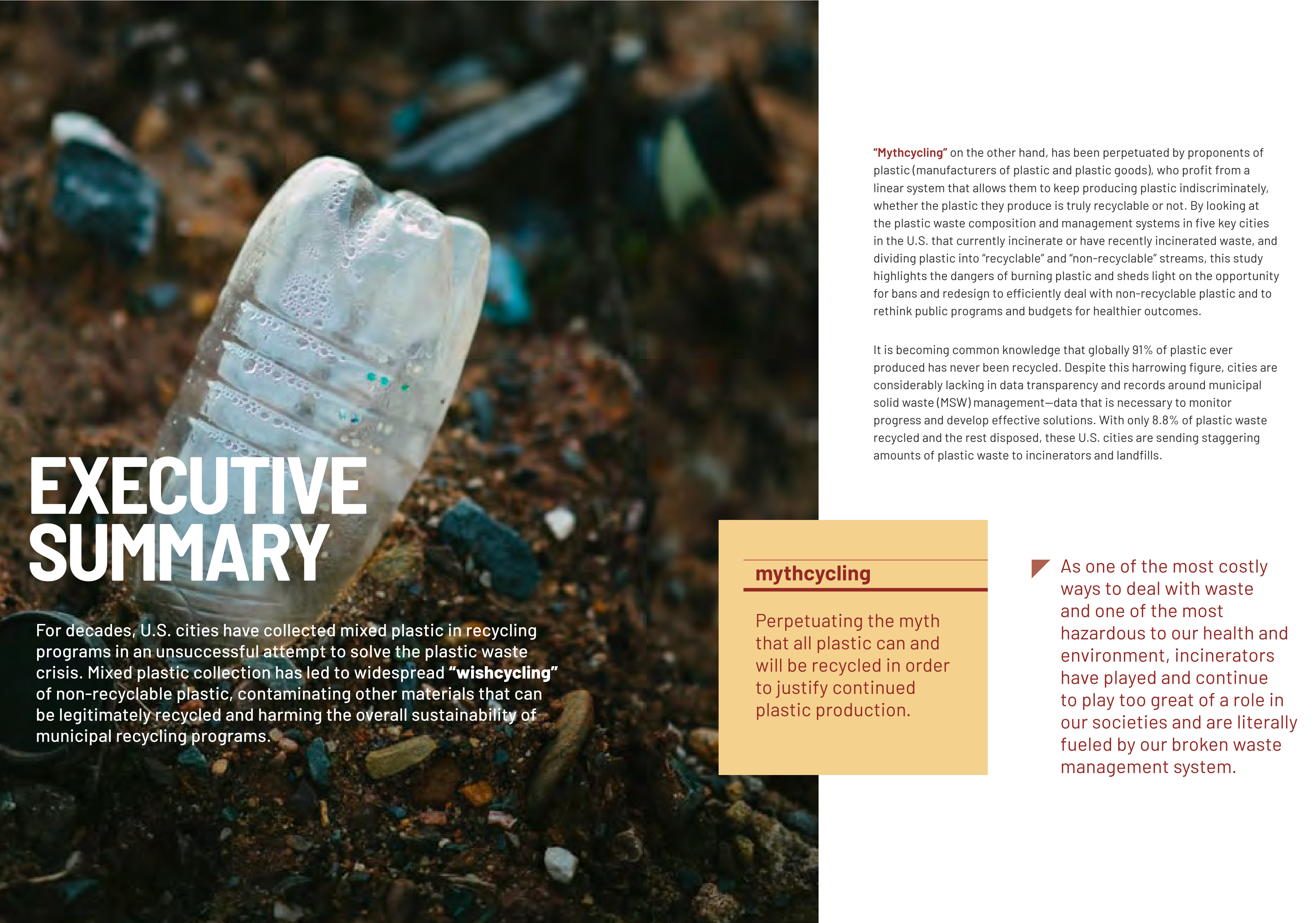


This study found that only $35.7 \%$ of plastic in MSW streams in these five cities has the potential to be recycled, and only $8.8 \%$ actually ends up being recycled through municipal recycling programs and state redemption programs where available. For a plastic to be considered recyclabe, mo recovery facilities (MRF) and municipalities need to have viable access to end markets that purchase the plastic. Misinformation abounds and recycling codes are often used as greenwashing tools by the plastic industry.

Legitimate recycling efforts for paper, metals, glass, and \#1 PET, \#2 HDPE, and \#5 PP are not only technically burdened by the presence of non-recyclables, they are also undermined when citizens become skeptical of truly recyclable materials as a result of being so misled on the recyclability of plastic. Over $65 \%$ of people in the United States are unsure or don't believe their material is getting recycled. To end the plastic crisis, we must separate fact from fiction. By improving legitimate recycling, increasing program access and outreach to residents, and aligning resource allocation to zero waste strategies, municipalities can rebuild trust in recycling programs and efforts.

\section{KEY TAKEAWAYS}

An investigation into the waste characterization of five cities, Baltimore, MD; the Minneapolis area, MN Newark, NJ; Long Beach, CA; and Detroit, Ml, found the following:

Lack of data transparency obstructs solutions. Good data leads to good policy. Data on municipal waste flows is absent, old and difficult to find. This allows the plastic industry to exploit loopholes and push self-serving narratives, and creates challenges for cities and communities that want to shift to true zero waste systems.

\section{Most plastic is designed to be dumped or burned, harming communities. Cities can}

reduce pollution by banning non-recyclable plastic. Only $8.8 \%$ of all plastic in the waste stream in the five cities is actually recycled. The remainder is incinerated, landfilled or could supply plastic-to-fuel or chemical recycling facilities, all of which are harmful to our health and environment.

Recycling rates are low because most plastic produced is not recyclable. Companies not cities, should pay. $64.3 \%$ of all plastic in the waste stream in the five cities is communities are paying for it with their health and their pocketbooks.
People (understandably) don't know what's actually recyclable. Cities should prioritize collecting only plastic that can be recycled. In the five cities, only $24 \%$ of potentially

cocter landfilled. Conversely, $12 \%-55 \%$ of all plastic that ended up in single-stream recycling programs was not recyclable.

Q

While plastic recycling must be improved, it has its limits. Plastic reduction and zero waste systems must be prioritized. Zero waste infrastructure like reuse, refill, and repair provides up to 200x as many jobs as disposal, furthers environmental justice, and improves sustainability.

The simplest and most ethical solution to this problem is to remove all non-recyclable plastic from the system.

It is time for policy and regulations to prioritize reduction and reuse over recycling, in line with integrated waste management hierarchies. By investing and incentivizing the development of alternative systems that allow for reduction and reuse, cities and governments will be solving the plastic problem at source: reducing the production of virgin plastic and the need for harmful end-of-life options such as incinerators and landfills. These systems will also gain public support, as $84 \%$ of Americans already support a national bottle redemption program, and container deposit laws motivate the public to return used containers and result in high recycling rates.

It is important that these solutions be underpinned by significant efforts to bring transparency and reliable data around waste issues-which is considerably lacking and difficult to find-through investments in data collection systems and enforced requirements from waste and recycling service providers. Holding retailers and producers of plastic packaging responsible for reduction and reuse through redesign, bans, and targets is equally crucial, as the health and monetary cost of waste caused by these industries is consistently borne by taxpayers and municipal governments. Cities must also end contracts with incinerators, which serve as toxic escape valves for overproduction of unrecyclable plastic and poor waste management policies.

Today, solid waste disposal continues to eat up the lion's share of resources available. The cities in this study have the potential to be at the forefront of reimagining the system and truly shifting their communities to a circular, zero waste economy. 


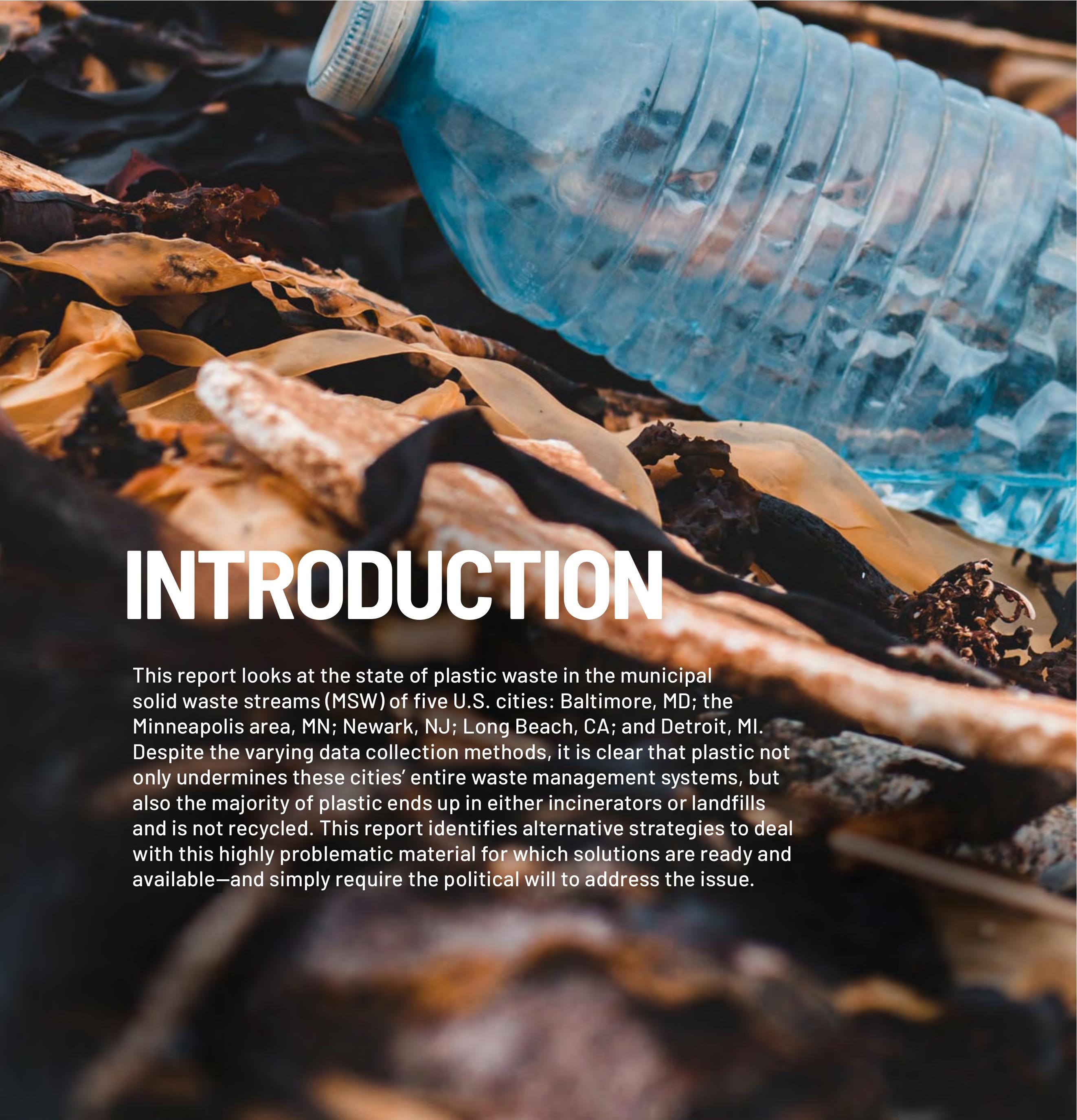

FIGURE 1

State of plastic waste management in $\mathbf{5}$ cities analyzed

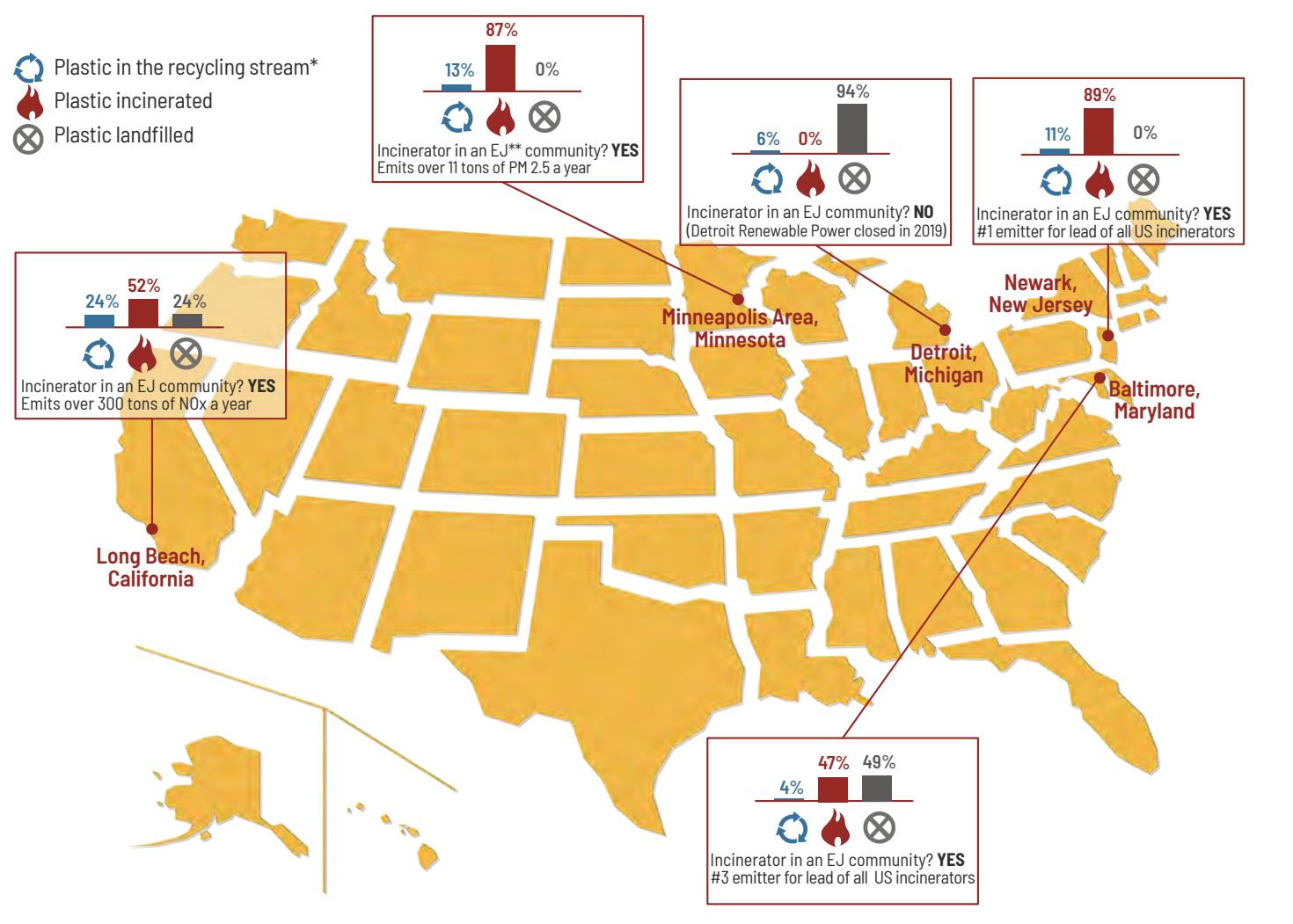

Based on the amount of plastic put into the recycling stream by residents and businesses; data on
the net amount of recycled plastic is not available

${ }^{*}$ *EJ community: Environmental Justice community

Source data for recycling/disposal rates can be found in Appendix II: Methodoloog.

Emissions data and EJ community criteria as described in U.S. Municipal Solid Waste Incinerators

๑) Doun Moon/GAIA

Approaching the data gathered from these five cities with a systems change context in mind revealed the underlying impediments to achieving real zero waste solutions. Waste in general, no matter how it is "managed, has negative impacts on the environment and our health. Each of the

cities included in this report is very familiar with the real impacts of this broken system-79\% of MSW incinerators are located near low-income, predominantly immigrant communities, and communities of color.

U.S. Municipal Solid Waste Incinerators: An Industry in Decline (2019). Global Alliance for Incinerator Alternatives. https://www.no-burn.org/industryindecline/ 
These cities have the potential to be at the forefront of building zero waste systems so that no other community will face the injustice of waste. They have all been or are currently host to incineration, which is one of the most polluting waste disposal systems: incinerators. Often referred to inappropriately as "waste-to-energy," the sole purpose of incinerators is to burn the items that manufacturers make, often after their single-use. Report ${ }^{2}$ after report ${ }^{3}$ verifies what we intuitively know: people who live near incinerators suffer seriously detrimental impacts on their health from respiratory and cardiovascular disease. These incinerators also contribute to global warming, acidification, photochemical ozone (or smog formation), and eutrophication. But what is less commonly known is the impact these incinerators have in limiting the potential 4 for our communities to move towards zero waste approaches: there are 200 times as many jobs in reuse and repair as in burning and burying waste.

Zero waste systems not only create more jobs, they create better jobs.

In the 1970s, many U.S. cities started collecting glass, paper, and metal (materials that are legitimately recyclable into new products), and increasingly more plastic (demonstrably poor at being recycled into new products). While recycling can be an authentically important part of a zero waste solution, it is widely recognized that recycling alone cannot solve the plastic problem. Of all of the plastic materia ever produced, only $9 \%$ has ever been recycled, $12 \%$ has been incinerated, and the remaining $79 \%$ has been landfilled or ended up in our oceans and the environment. ${ }^{6}$ Shipments of plastic waste to other countries for "recycling" are often mixed bales rather than homogenous bales of a single type of plastic, and often contain a large share of unrecyclable plastic and other contaminants that end up being dumped or burned. China and other nations have adopted increasingly stringent policies and regulations to ban all plastic waste imports or otherwise stop the dumping of contaminated plastic in their country. Communities across Asia, and increasingly in Latin America and Africa, continue to be disproportionately burdened, even though most of them are attempting to control that waste. ${ }^{7}$ Some countries have sent plastic waste back to the U.S., where it sits in ports or enters our broken waste stream to be burned or landfilled.

2 Roberts, R. J., \& Chen, M. (2006). Waste incineration-how big is the health risk? A quantitative method to allow comparison with other health risks. Journal of Public Health, 28(3), 261-266. https://doi.org/10.1093/pubmed/fdl037

3 Tait, P. W., Brew, J., Che, A., Costanzo, A., Danyluk, A., Davis, M., Khalaf, A., McMahon, K., Watson, A. Rowcliff, K. \& Bowles, D. (2020). The health impacts of waste incineration: A systematic review. Australian and New Zealand Journal of Public Health. 44(1), 40-48. https://doi.org/10.1111/1753-6405.12939

4 Waste Incinerators: Bad News for Recycling and Waste Reduction (2013). Global Alliance for Incinerator Alternatives. https:// www.no-burn.org/wp-content/uploads/Bad-News-for-Recycling-Final.pd

5 Zero Waste and Economic Recovery: The Job Creation Potential of Zero Waste Solutions (2021). Global Alliance for 6 Geyer, R., Jambeck, J. R., \& Law, K. L. (2017). Production, use, and fate of all plastics ever made. Science Advances, 3(7),
e1700782. https://doi.org/10.1126/sciadv.1700782

7 Discarded: Communities on the Frontlines of the Global Plastic Crisis (2019). Global Alliance for Incinerator Alternatives. https://www.breakfreefromplastic.org/bffp_reports/discarded-communities-on-the-frontlines-of-the-global-plastic-crisis

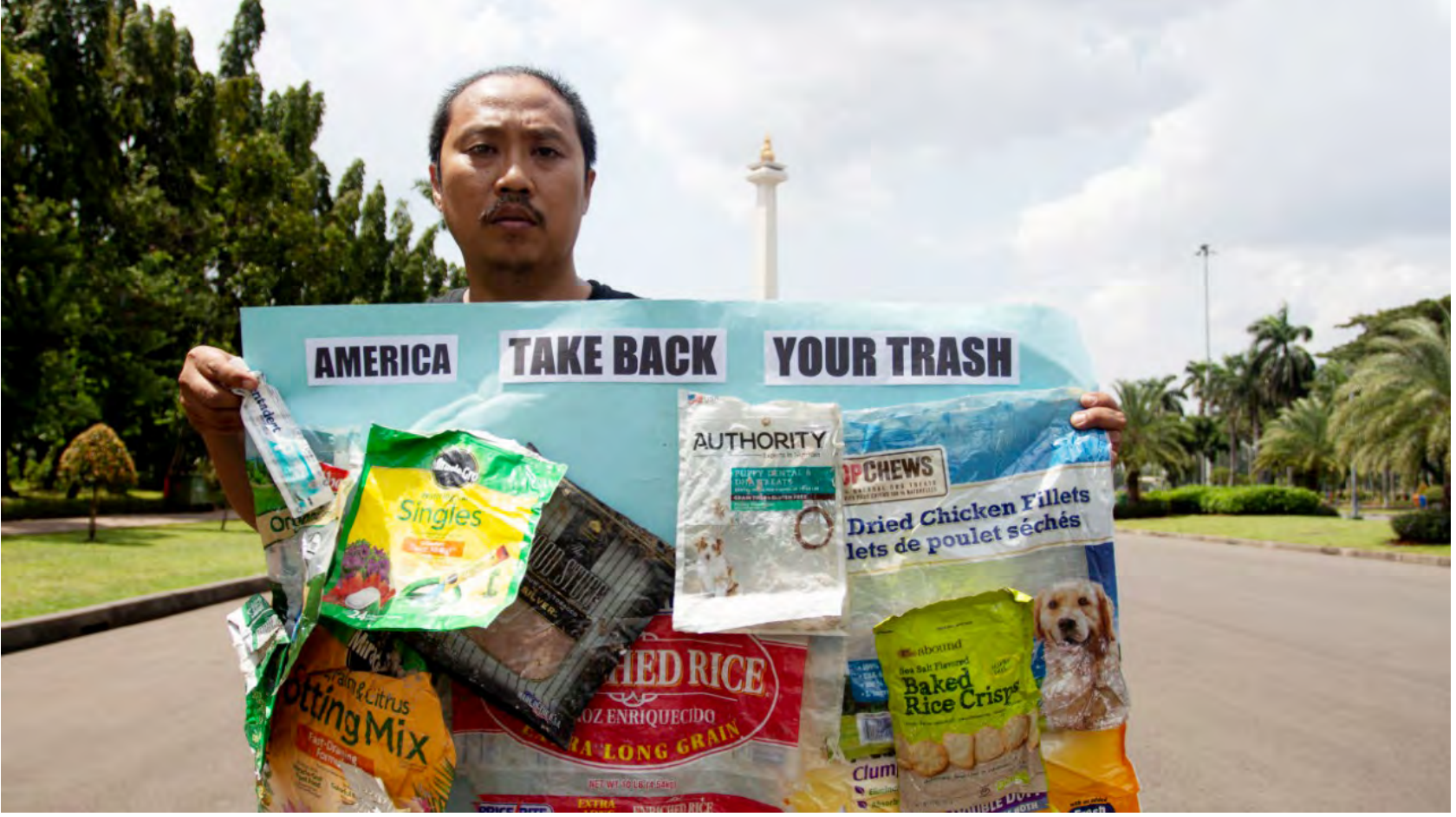

Goldman Environmental Prize-winner Prigi Arisandi of Ecoton fights
back against waste dumping from countries like the U.S. OEcoton

While the plastic industry has long claimed that plastic can be recycled, the reality is that very little is, and the inclusion of non-recyclable plastic in the collection stream occurs at the expense of town and cities across the country. In the end, investments by municipalities, counties, states, and the federal government to collect and recycle materials are undermined by the inclusion of plastic products and packaging. The system is broken and communities are paying for it with their health and their pocketbooks. For far too long, this system has flourished without any accountability for what is really being recycled.

New plastic combinations which could include mixes of two or more of the \#1-7 plastic resins- or which are layered with other materials like aluminum, commonly seen in plastic film pouches-are just a few examples of the growing variety of materials that cannot be recycled. The inherent lack of recyclability, and the cost to sort plastic resins with no end markets, make it virtually impossible and often unaffordable to sustain local recycling programs. Meanwhile, industry has doubled down on recycling as the solution despite the facts:

- There are very few end markets that will purchase and use the bulk of plastic packaging (with the exceptions of \#1 PET, \#2 HDPE, and \#5 PP) to make new products, costing cities even more to collect and dispose of non-recyclable plastic.

- MRFs are unable to efficiently sort and process the proliferation of single-use plastic packaging.

- There are a growing number of people who do not want plastic or its impacts in their life and are willing to pay more to change the system. ${ }^{10}$

Circular Claims Fall Flat: Comprehensive U.S. Survey of Plastics Recyclability (2020). Greenpeace. https://www.greenpeace org/usa/wp-content/uploads/2020/02/Greenpeace-Report-Circular-Claims-Fall-Flat.pdf

Review of Material Flows at MRF's and Reprocessors (2019). Applying Thinking Systems to Recycling (ASTRX). https://astrx.org/ resources/astrx-study-of-material-recoverability/

10 "Most Americans Would Pay More to Avoid Using Plastic, Poll Says"(2019). PBS NewsHour. https://www.pbs.org/newshour/ nation/most-americans-would-pay-more-to-avoid-using-plastic-poll-says 
To build popularity for and perpetuate the myth of recycling as a solution to our waste problem, industry funds grants for misleading education programs and pushes campaigns like "Keep America Beautiful" that put the burden of responsibility on consumers to recycle properly." One of their latest campaigns, "152AndYou" pushes individuals to pick up 152 pieces of litter each to clean up roads, trails, and waterways, but fails to advocate for systemic solutions to prevent waste in the first place.

Meanwhile, the continued extraction of fossil fuels to produce new virgin plastic products and packaging combined with the low value of recyclable materials, if they can even be recycled at all, exacerbates the problem.

Plastic production is forecast to double, plastic leaking into nature to triple, and plastic leakage into the ocean to quadruple by $2040 .{ }^{13}$

The lack of refill/reuse systems and non-plastic packaging alternatives to avoid the production of new virgin plastic is a significant impediment to reducing reliance on fossil fuels and adds to every city's share of greenhouse gas emissions.

11 "How Big Dil Misled the Public into Believing Plastic Would Be Recycled" (2020). National Public Radio. https://www.npr.

12 National Litter Study (2020). Keep America Beautiful. https://kab.org/litter-study/

13 Breaking the Waves of Plastic: A Comprehensive Assessment of Pathways Towards Stopping Ocean Plastic Pollution (2020). The Pew Chartable Trusts, STSTEMIo. https://ww pewtrusts.org/-Imedia
ticwave_summary.pdf

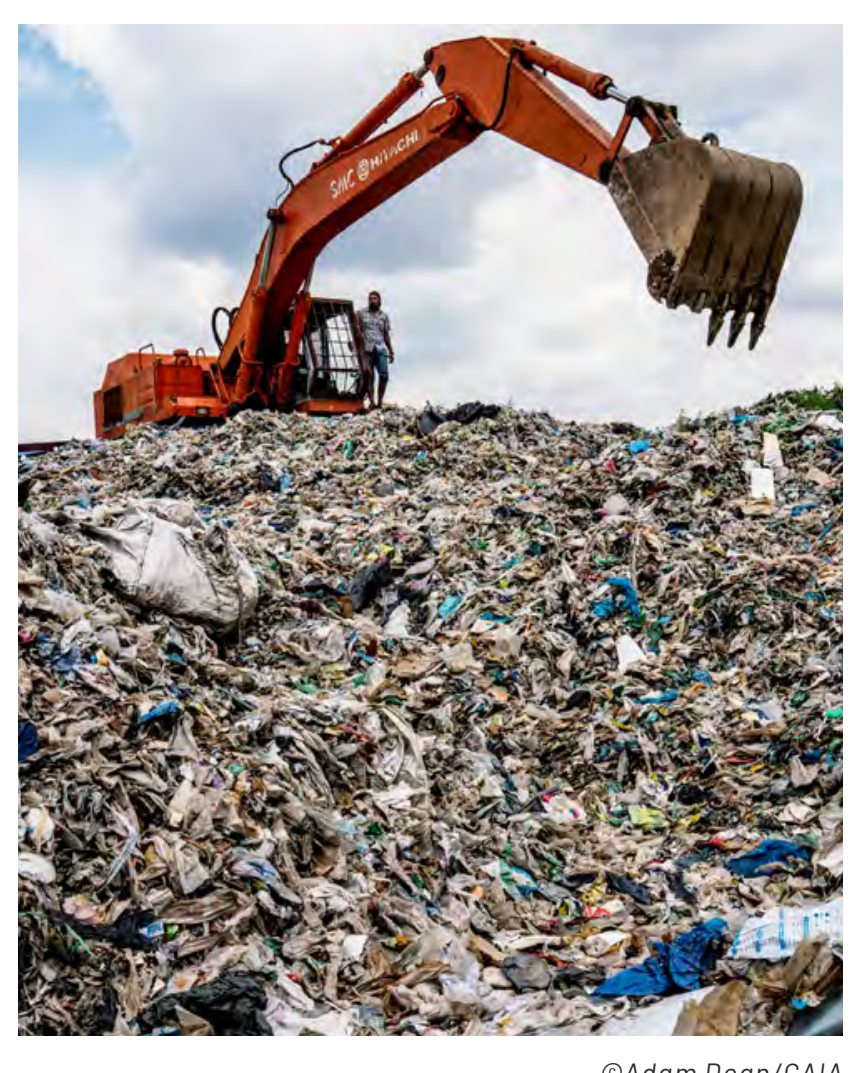

๑Adam Dean/GAIA

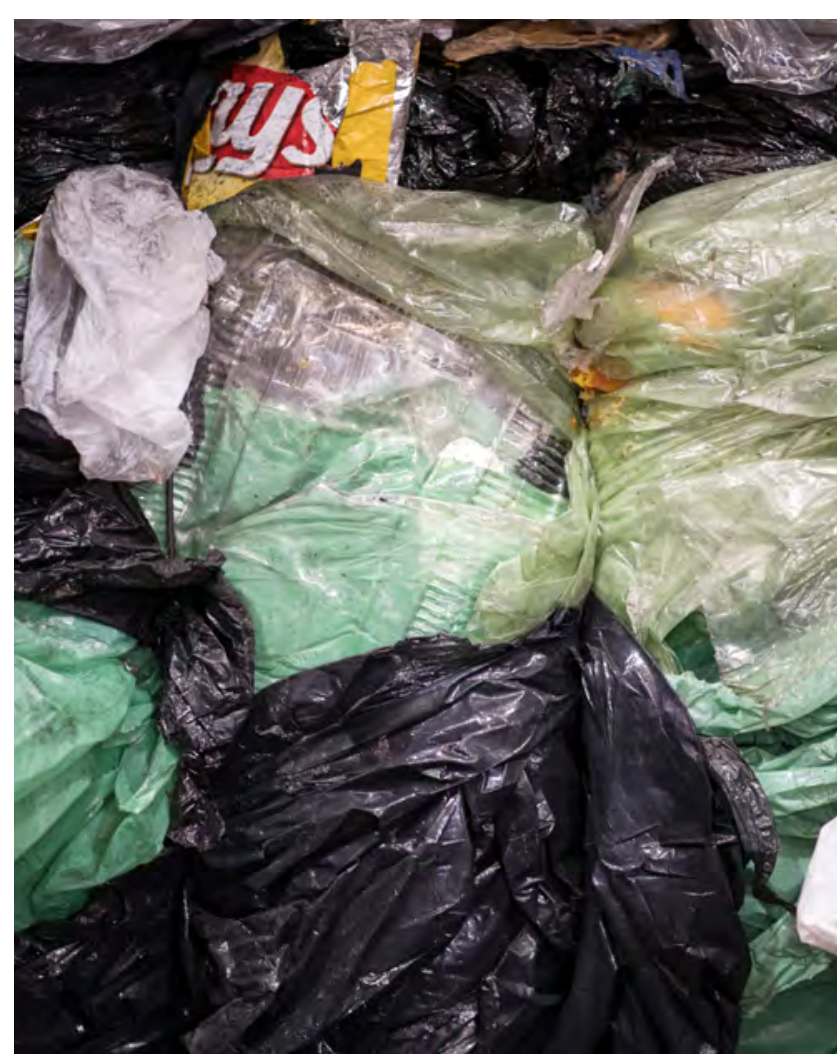

OSantiago Vivacqua/gail
Even more troubling than the industry's denial of the problem is that after decades of dismal recycling rates, the industry is gaining momentum in changing the very definition of recycling so that it includes burning plastic and other equally detrimental schemes, going so far as to call this "chemical recycling." This so-called "chemical recycling"1/4 would best be called mythcycling, as it is just another burn

technology similar to incineration. With the plastic industry attempting to redefine recycling to include the burning of any post-consumer polymers and thus removing these processes from any regulation as a waste process, ${ }^{15}$ real solutions are critical. Investments in such facilities could create the demand for more and more waste plastic that will pollute our communities, damage our health, and compete with authentic solutions to the waste problem.

Some of the methods used in the current linear waste system (often referred to as take, make, waste) should only serve as temporary bridges on the road to zero waste. To protect public health and build truly sustainable, circular zero waste systems, we must turn away from the old system that perpetuates waste, and recognize that the best way to deal with waste is to prevent it from occurring. Creating transparency in our current system will be key, as this will safeguard against greenwashing and support truly impactful solutions. The biggest opportunities for these cities, highlighted by the analysis of the plastic waste data collected, are informed by their communities experiences, plans, and actions.

14 All Talk and No Recycling: An Investigation of the U.S. "Chemical Recycling" Industry. (2020). Global Alliance for Incinerator Alternatives. https://www.no-burn.org/chemical-recycling-us/

5 US Legislation Alert: American Chemistry Council's Effort to Push "Plastic-to-fuel" Bills (2020). Global Alliance for Incinerator Alternatives. https://www.no-burn.org/https-www-no-burn-org-legislativealert/ 


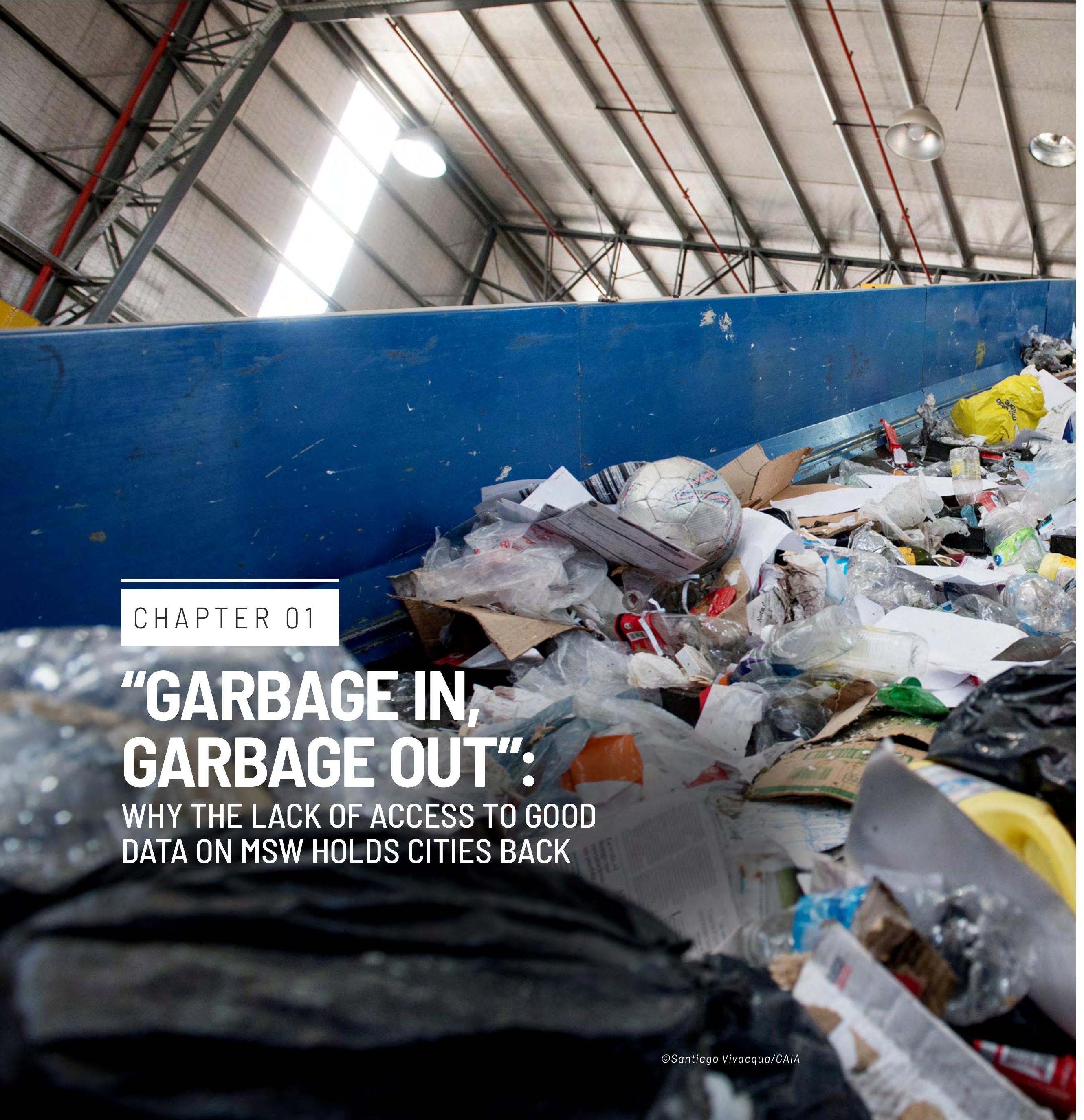

Good Data Makes Good Policy, but Data on MSW is Both Hard to Get and Dated

Understanding how much and where waste is being generated, the types of waste being generated, and what happens to the waste when it is disposed of (incinerated or landfilled) or diverted (recycled or composted) allows cities to make realistic plans, establish important policies, develop dependable budgets and forecast funding needs that are required in order to achieve their zero waste goals. Access to this knowledge also allows communities impacted by the waste system to influence these decisions. Unfortunately, this data can quite commonly be very hard to get, hard to understand, or so old that it is unreliable.

One very important example of this data problem is the complete lack of information on any waste that is not MSW. This means that industrial wastes are not required to be measured or reported, even though they are expected to be at least $97 \%$ of the entire waste stream, with MSW accounting for just $3 \%{ }^{16}$ This report (and almost every report you read on solid waste), therefore, is only a microcosm of a much larger and pressing problem. Yet MSW that ends up in incinerators continues to have profound impacts on the health of communities addressed in the study. Plastic releases persistent organic pollutants such as dioxins, furans, polychlorinated biphenyls (PCBs), and toxic metals such as arsenic, barium, cadmium, mercury, and lead when burned.

Another major information gap is what happens to waste that is exported to other countries for "recycling." It is often non-recyclable, heavily

contaminated with non-recyclable material, may include harmful additives or is inherently hazardous, like polyvinyl chloride (PVC). Plastic exported from the U.S. and other high-income nations cause significant pollution and environmental health impacts on importing nations. ${ }^{18}$

16 MacBride, S. (2012). Recycling Reconsidered: The Present Failure and Future Promise of Environmental Action in the United States. The MIT Press; JSTOR. https://www.jstor.org/ stable/j.ctt5hhfah

17 Plastic and Pollution: The Hidden Costs of a Plastic Planet (2019). Center for Ihternational Environmental Law. https://www.ciel.org/plasticandhealth/

18 Discarded: Communities on the Frontlines of the Global Plastic Crisis (2019). Global discarded-communities-on-the-frontlines-of-the-global-plastic-crisis/ 
Troublingly, most municipalities count exports as part of their recycling rate, despite having no understanding or accountability over what happens to that waste.

How, where, and the type of data collected by a city also skews the picture. Most cities count their recycling rate based on what the recycling hauler picks up at the curb and delivers to the MRF. Once the material arrives at the MRF, what happens to it is often unknown, but all of the material has been counted nonetheless. City reporting on recycling likely includes the non-recyclable material counted as "recycled" because it is often measured by what residents place at the curb, not by what is actually recycled.

FIGURE 2

Impacts of Plastic Throughout the Lifecycle

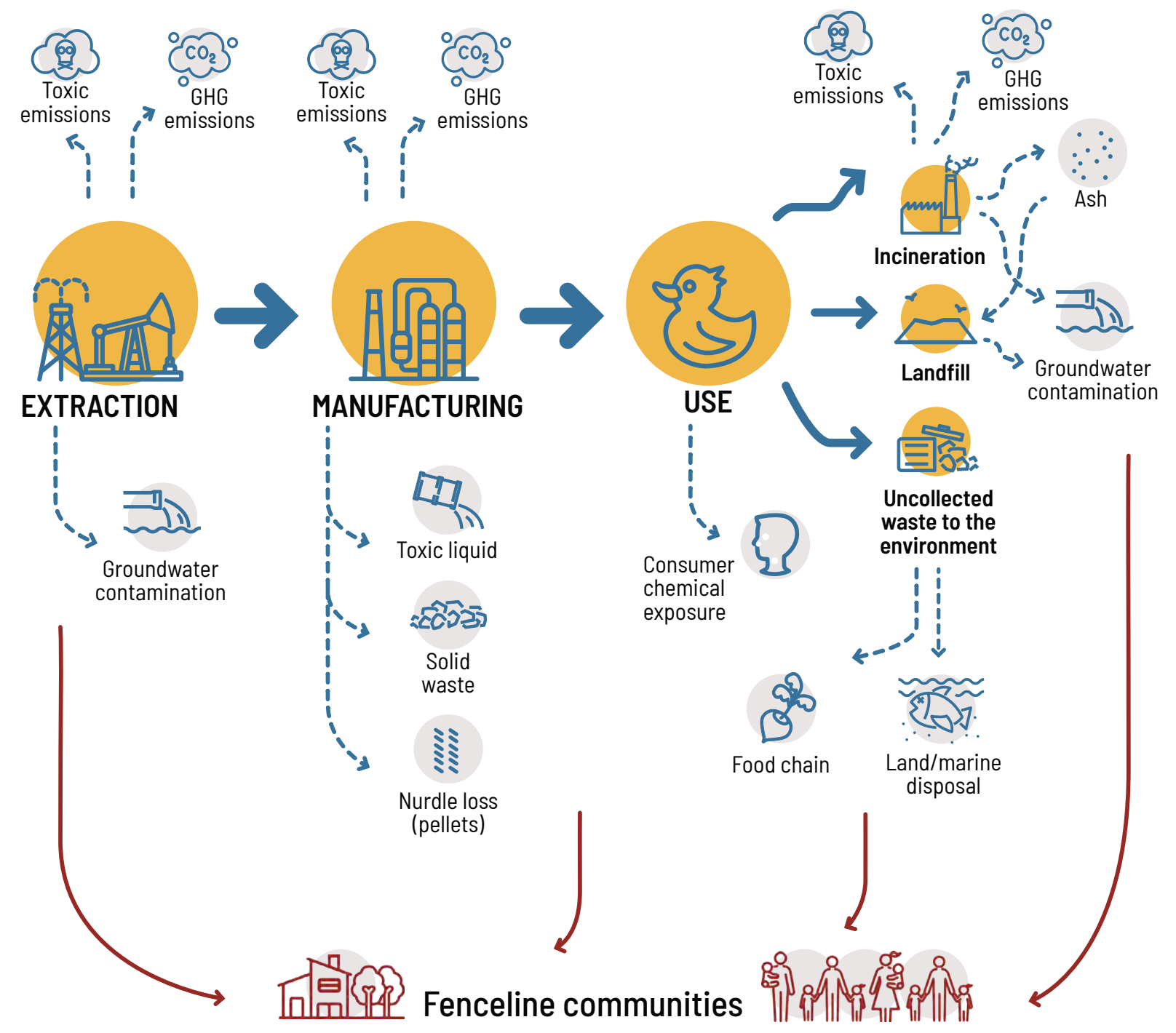

\section{Spotlight on Newark, NJ: Troubles with Access to Waste Data}

In Newark the Essex County Resource Recovery incinerator burns about 2.8 tons of waste per day. It emits more lead into the air than any other U.S. incinerator, in addition to dozen of other toxic chemicals that pollute the air, land, and water. Despite these facts, no published waste characterization study was available specific to Newark, and a 2013 study of Mercer County had to be used as a proxy. A recent report on recycling composition based on facility averages for 14 MRFs in 11 states in the Northeast region was used as a proxy for Newark's recycling composition. Based on this information, we estimate that in Newark, at least $89.2 \%$ of plastic is incinerated. Without more systematic monitoring and reporting in place to facilitate better outcomes for Newark's waste, a large majority ends up in its incinerator. The Ironbound Community Corporation (ICC), founded in 1969, has been fighting incineration and all other major sources of pollution for more than forty years, and has succeeded in stopping 13 proposed incinerators from being built. Last year, ICC succeeded in passing an environmental justice bill for New Jersey designed to prevent the siting of new industrial facilities or the expansion of current facilities in communities like Newark that are already overburdened with pollution. This bill is now being replicated in other states, including Michigan and Minnesota.

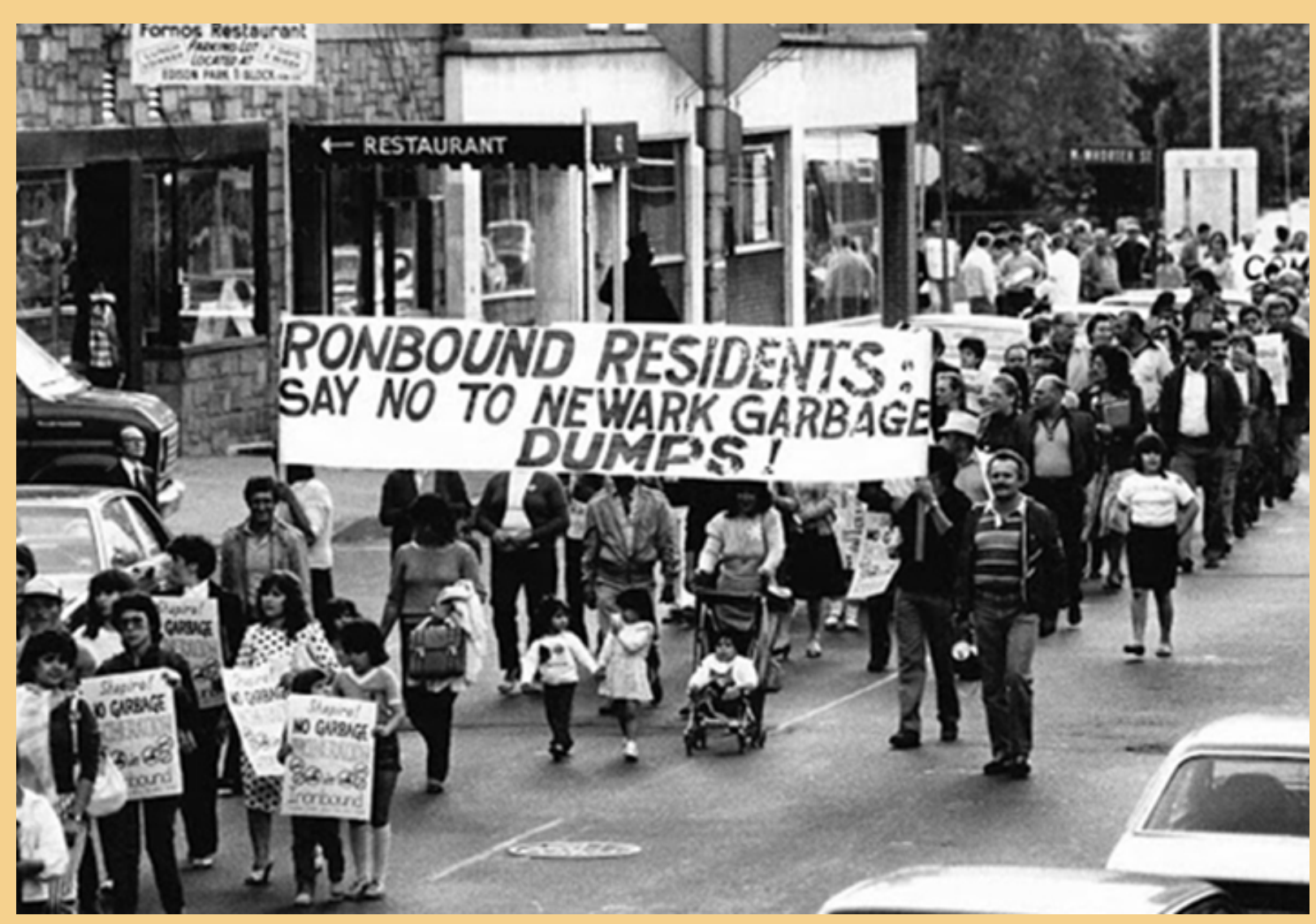

OIronbound Community Corporation 


\section{MSW DATA IS HARD TO GET}

Efforts expended for this report demonstrated that public data is hard to get from local governments because the cities themselves have difficulty getting the proper information from their service providers. Cities are strapped and city employees are covering a lot of bases. It is commonplace that the employee responsible for providing this information at the local level either did not have it or was unsure of where to get it. In some cases, it is unknown whether the city has any legal right to obtain the data from the service provider. Certain cities that had contracts that require reporting were not even aware of this requirement until researchers pointed it out. The cities that do get data are getting what is usually self-reported by the owners/operators of the facilities, and there is no auditing or verification of the validity - especially when it comes to the specifics of materials types, contamination, and end markets.

Some cities do require their service provider to report where the MRF sells the recyclables, but it can easily be the case that the first purchaser of the material could resell the materials as is common for mixed plastic. The result is that cities have hardly any certainty about where the material gets recycled or how it is used.

Most of the cities did not have information on their website that was accessible to their residents about the amount of waste they generated, what is in their waste, or what happens to it. While it was available in some of the cities when requested, there were no cities that made it easy to access or understand. None of the cities provide any information about the sources of the waste coming into the incinerators or the landfills. Citizens living in those communities that want to understand how much waste is imported into their community for disposal are left with the option to go through the process of Freedom of Information requests to get any information which can be time and resource intensive.

\section{MSW DATA IS OLD}

All of the waste composition data found for these programs was dated with the exception of Baltimore's 2019 information; the data from the other cities was at least five and up to eight years old. Much of the waste composition data was extrapolated from the state's data since the city had no specific information about waste composition. Knowing the composition of the waste stream is critical for determining what policy/program tools might best suit the city. In particular, plastic use has been steadily increasing for different packaging applications and aged data on plastic is very likely underestimated. Furthermore, plastic packaging numbers can be complicated to estimate because consumer goods companies and their packaging manufacturers save money by "lightweighting" their products (often using nonrecyclable lightweight flexible packaging).

\section{STRATEGY 1 : REQUIRE GOOD DATA AND TRANSPARENCY}

The historic lack of data and transparency around waste issues is one of the most significan problematic trends. It results in an inability to prioritize efforts, properly allocate funding, or understand how well-intentioned actions might actually be greenwashing, and therefore have little meaningful impact. From a lack of municipal data on the basic waste composition, to misrepresentations of the recycling chasing arrows symbol on non-recyclable packaging, to a lack of transparency on what is made from the products we recycle, the data matters. This becomes even more critical when communities must rely heavily on multinational, for-profit waste haulers to achieve their recycling goals. In general, locally-owned recycling businesses that share the communities' goals provide better access and better data overall.

To make data more accessible and easier to understand to the public:

. Cities should require their service providers to provide information through contracts or business operating license requirements. These requirements should be enforced through liquidated damages and other penalties.

2. Cities should understand what happens to materials at the MRF for use in targeting education, deciding what to include in the recycling program, and analyzing the efficiency of the program by:

a. Requiring MRFs to report the types of commodities that they handle, including plastic by resin type, where they go, what the typical end use is, and what is exported.

b. Requiring MRFs to provide due diligence on secondary processing markets they may use (such as plastic recycling facilities or PRFs) to understand what happens to materials there.

c. Requiring a composition analysis specific to the material delivered by the city, including what is in the residual. This requirement should be included as part of the request for proposa (RFP)/bid process to ensure it is included in program cost.

d. Reporting diversion numbers based on the final destination at the MRF, not what is collected at the curb.

3. States or municipalities can invest in data collection systems to standardize the collection of data and provide more transparent access to information.

4. States should require the city to maintain, collect and report waste data through city operations and municipal vendor contracts. This information should be published on a website quarterly with links to relevant documentation. 
In Baltimore, the South Baltimore Community Land Trust (SBCLT) is working to change North, South, Central, and West Baltimore neighborhoods from dumping grounds surrounded by polluting industries to healthy zero waste communities. A few years ago, SBCLT managed to shut down a proposal for what would have been the largest incinerator in the country, sited to be built in the community already subjected to the worst toxic air emissions in the whole country. Today, SBCLT's city-wide campaign to create a "Just Transition to Zero Waste" is pushing for the closure of the Baltimore Refuse Energy Systems Co. (BRESCO) trash incinerator, one of the city's largest sources of air pollutants. This is the first step in reversing the injustices inflicted on communities located closest to its site: SBCLT is pushing the Baltimore City Government and anchor institutions to replace all polluting waste infrastructure with just, equitable, and safe zero waste systems-beginning with a push for traditional composting infrastructure as there is currently no such infrastructure within 30 miles of the city.

As a result of SBCLT's work, in collaboration with other local organizations and institutions, the Baltimore City Council unanimously adopted the Fair Development Plan for Zero Waste, pledged \$16 million towards its implementation and hired a Department of Public Work Director with operational waste experience. Baltimore's Fair Development Plan for Zero Waste focuses on reduction of non-recyclable plastic as a primary goal, including full implementation of the plastic bag ban, expanding the ban on polystyrene foam, and advocating for a statewide bottle redemption program, alongside improved access and education for the citywide recycling program. By implementing the plan, the city will legitimize and reinforce community power through land ownership, financial resources, good local union jobs, and democratic governanceand begin to reverse the health and economic disparities that have plagued the city's communities for generations.

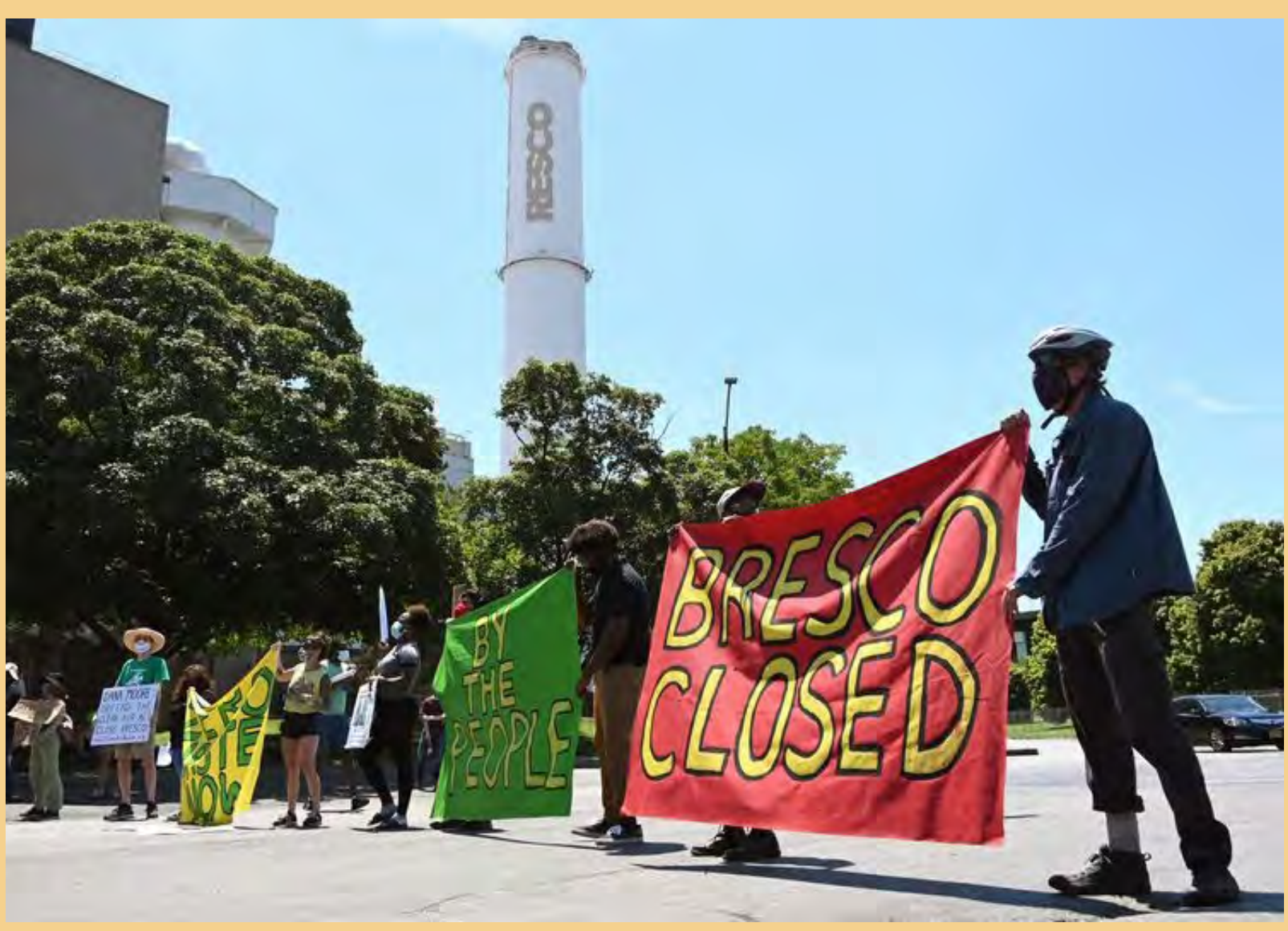

(-) South Baltimore Community Land Trust 


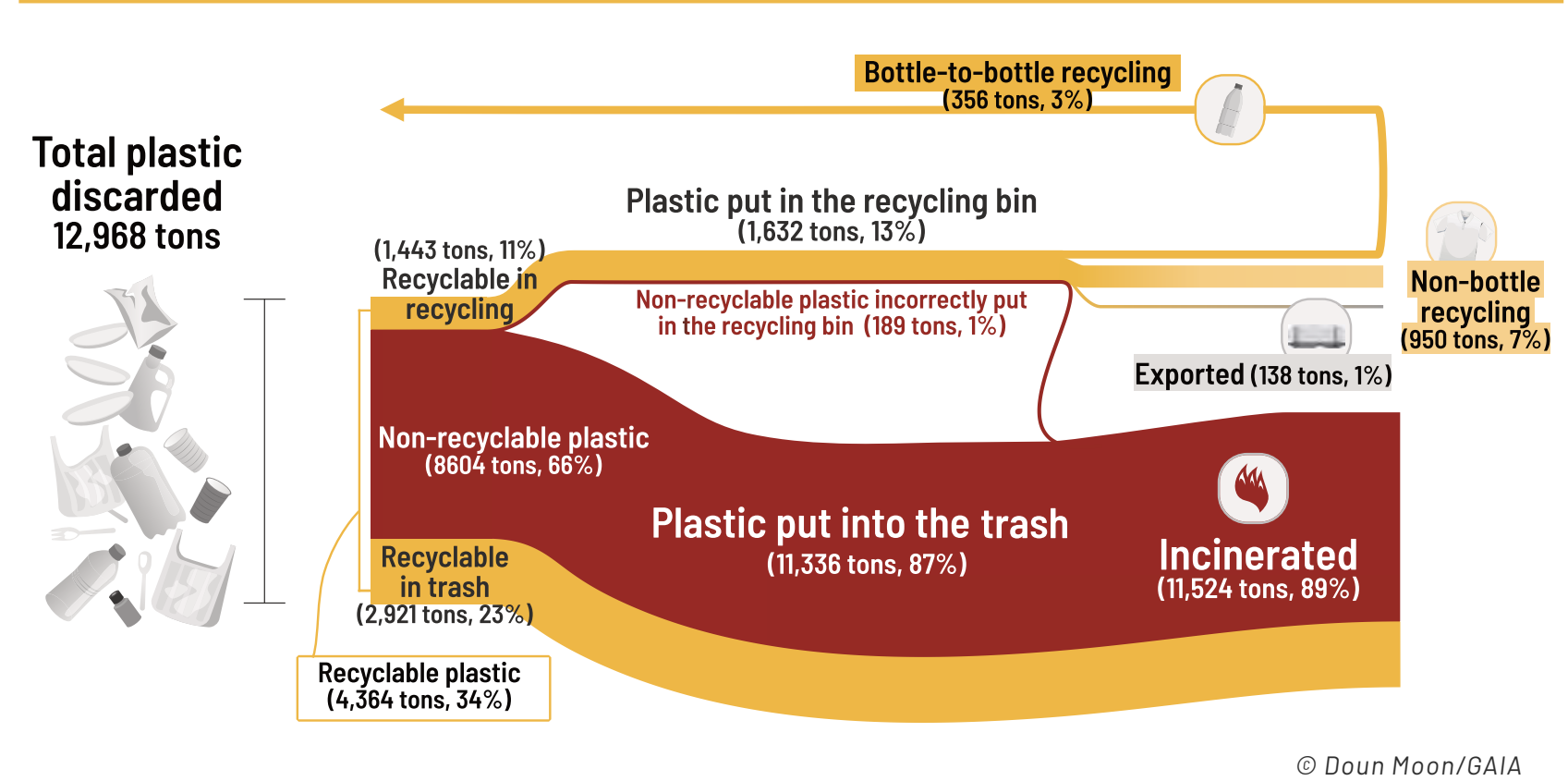

The projected end uses are based on the average national end uses of \#1 PET, \#2 HDPE, and \#5 PP (Closed Loop Partners. A Data Visualization Tool Identifying Opportunities to Recapture Plastics in the U.S. and Canadal.

Data used in the figure includes plastic discarded in containers and non-container durable plastics, such as small household items like toys, tableware or home decor, through the city-serviced recycling program. The analysis only included plastic sorted out specifically in plastic grades and did not include all plastic in the waste stream such as
Of all of the cities in the study, the Minneapolis area has the most effective municipal recycling program, resulting in the highest percentage of plastic actually recycled through curbside and drop off collection programs. This high percentage can be attributed to strong citizen advocates and the work of mission-based recycler Eureka Recycling to highlight the importance of recycling with the goal of waste reduction. Nevertheless, a lot of nonrecyclable plastic is still sent to the incinerator. Built in Downtown Minneapolis in 1989, the Hennepin Energy Resource Center (HERC) incinerator is located near where the majority of Minneapolis' Black population lives, a part of the city that has the highest asthma rate in the state. HERC burns 1,000 tons of trash per day and produces 1.5 million pounds of emissions every year, including heavy metals, carbon monoxide, nitrogen oxide, sulfur dioxide, and dioxin. Hennepin County owns the incinerator and has ignored decades of community opposition to it, but the Minnesota Environmental \& Climate Justice Table-a coalition of environmental and climate justice activists and groups-is working to show them thet Minneapolis doesn't have to choose between burning and dumping its trash because zero waste is possible, feasible, and affordable.

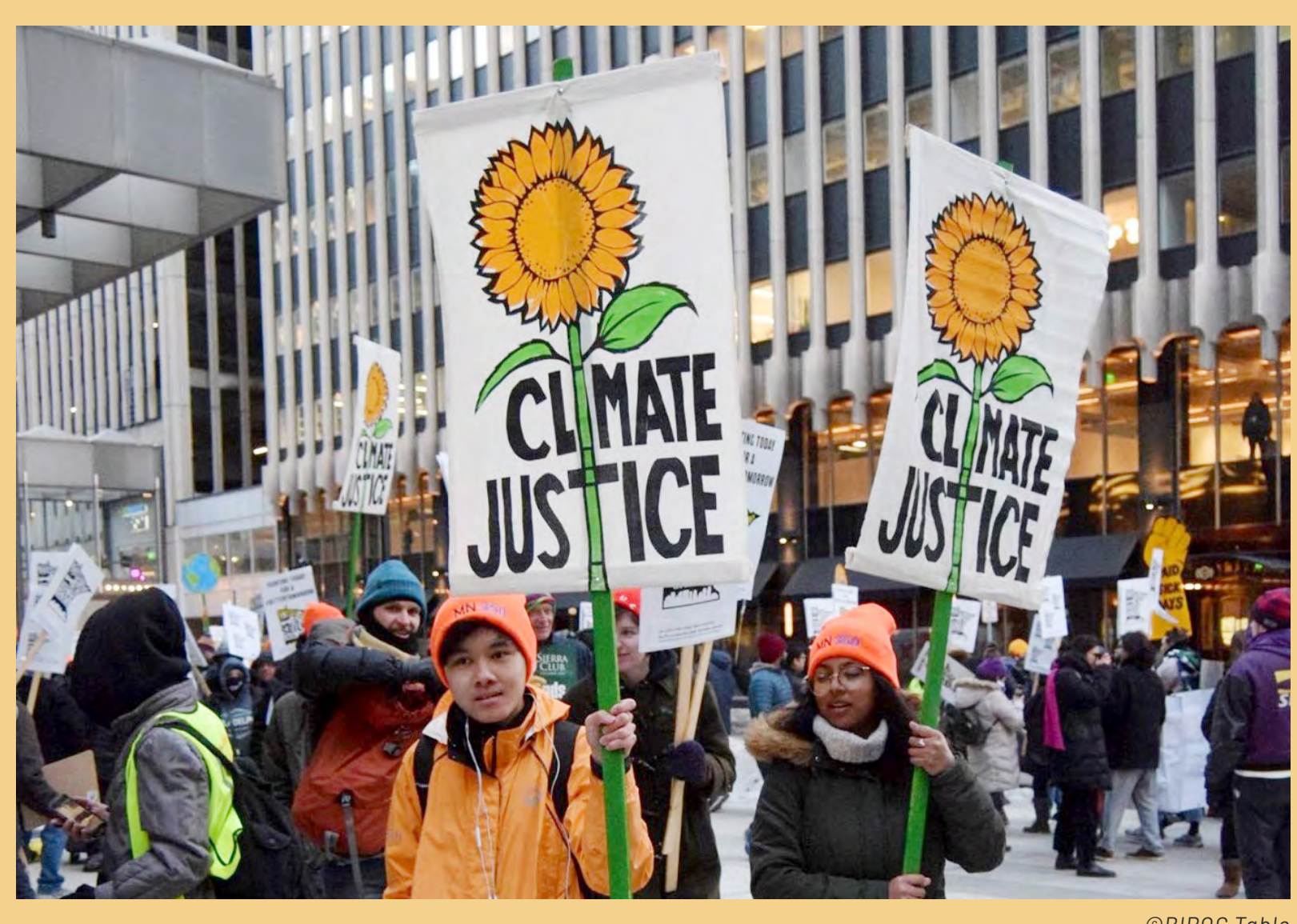




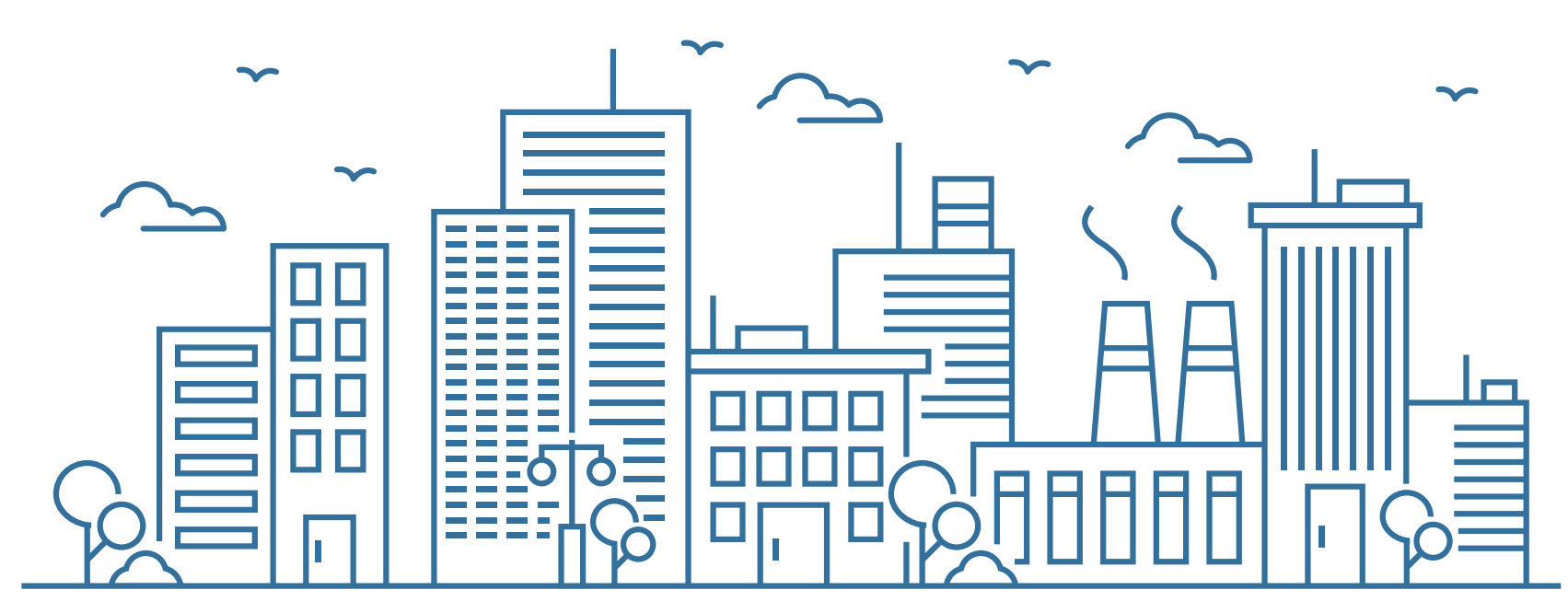

NOTES ON CITY DATA

1. Newark had the least site-specific data, which was substituted with regional estimates. No published waste or recycling characterization studies were found for Newark, and recycling information was not provided by the city's contractor when requested. Therefore, waste

composition data from neighboring Mercer County and MRF composition data published through a study of the Northeast Recycling Council were used as a proxy.

2. No published waste characterization studies were found for the City of Detroit. Statewide data from a Michigan study was used as a proxy. Recycling characterization data was available specific to Detroit from a recent study.

3. Long Beach used a statewide data system for waste composition. Composition and weight data from the city's recycling vendor was provided as part of the city contract requirements.

4. Baltimore had recent data from the city's work to develop the Fair Development Plan for Zero Waste.

5. The Minneapolis area had good numbers as the city either provides the services directly, or requires reporting as part of their contracts and licensing regulations.

6. All cities had data on annual weight recycled/disposed of and data specific to their communities reported within the last 3 years. Data included in the scope of "MSW" varied by city. All cities included residential. Some cities handled commercial and multifamily data differently. To address this, the charts used in this report are specific to residential waste only except as noted.

\section{FINDING \#1}

\section{VERY LITTLE PLASTIC IS ACTUALLY RECYCLED}

All of the data from the cities studied in this report is consistent with national trends on how much plastic is currently recycled or could potentially be recycled in the current recycling system. The results are dismal.

The average data in the cities show:

- $64.3 \%$ of all plastic in the waste stream is not recyclable through municipal recycling or state redemption programs. (see charts "Ultimate Fate of Plastic in Five Cities").

- A wide range of $12-55 \%$ of all plastic that ends up in single-stream recycling is not actually recyclable (see chart "What Happens to Plastic in Single-Stream Recycling?").

- Only $8.8 \%$ of plastic is actually recycled (see chart "State of Plastic in Five Cities").

Plastic packaging is generally required by state laws to be labeled with \#1-7 and chasing arrows to signify the resin used to make that product. These resin numbers lead municipalities and consumers to believe that the plastic they put in their recycling bin or cart can be recycled. In reality, most plastic in the waste stream is not recycled and the \#1-7 codes have become a greenwashing tool for singleuse plastic. Recycling arrows that surround the numbers on plastic packaging are used by consumer goods companies, even when the product packaging is not actually recyclable. ${ }^{22}$

\section{Summary of Methodology}

1. While some data about the five case cities presented follows national trends, the report does not predict national outcomes nor would it be reasonable to do so with the available data.

2. This study only considered \#1 PET, \#2 HDPE, and \#5 PP plastic packaging (including containers) to be recyclable. In order for plastic packaging to be considered recyclable, two requirements needed to be met:

a. current recycling systems serving municipal programs had the technical ability to capture the plastic packaging material

b. MRFs had access to existing markets for this captured plastic waste material.

3. Data for this study was limited to publicly available sources and varied in study methodology, age, and detail provided. Because of the variations in data sets between cities, the data is not always comparable. Averages provide a general picture of findings regarding scenarios in these cities.

See Methodology in Appendix for detail.

22 "Waste Land" (2020). Planet Money, National Public Radio (NPR). https://www.npr.org/2020/09/11/912150085/waste-land 


\section{Spotlight on Long Beach, CA: From Extraction to Reduction}

East Yard Communities for Environmental Justice (EYCEJ) is a community-based environmental health and justice organization serving communities in East Los Angeles, Southeast Los Angeles, and Long Beach, where two of the three incinerators in California were built, as well as several oil and plastic production facilities. In recent years, the organization succeeded in shutting down the incinerator in Commerce, which had plagued communities for 31 years. This win was built off the back of groups organizing together to defeat legislation that would have provided incinerators with much-needed subsidies in the form of renewable energy credits, despite incineration being a significan source of greenhouse gas emissions.

Today, the Long Beach incinerator, Southeast Resource Recovery Facility (SERRF) remains a threat, but the city is governed by great state policies such as beverage container deposit legislation. Long Beach also requires its recycling vendor, Waste Management, to report waste composition and weight data through a state data system. After frustration with changing recycling guidelines and a lack of new markets for certain plastics, the city shifted away from recycling by numeric designation and instead asks residents to recycle by item types in 2020. The city hopes this will result in the collection of high-quality items with post-consumer markets. ${ }^{23}$ Meanwhile, EYCEJ is advocating for a zero waste plan that will eliminate single-use plastic and build a network of reuse, refill, and repair shops across the city and a transition away from fossil fuel extraction, refining and distribution.

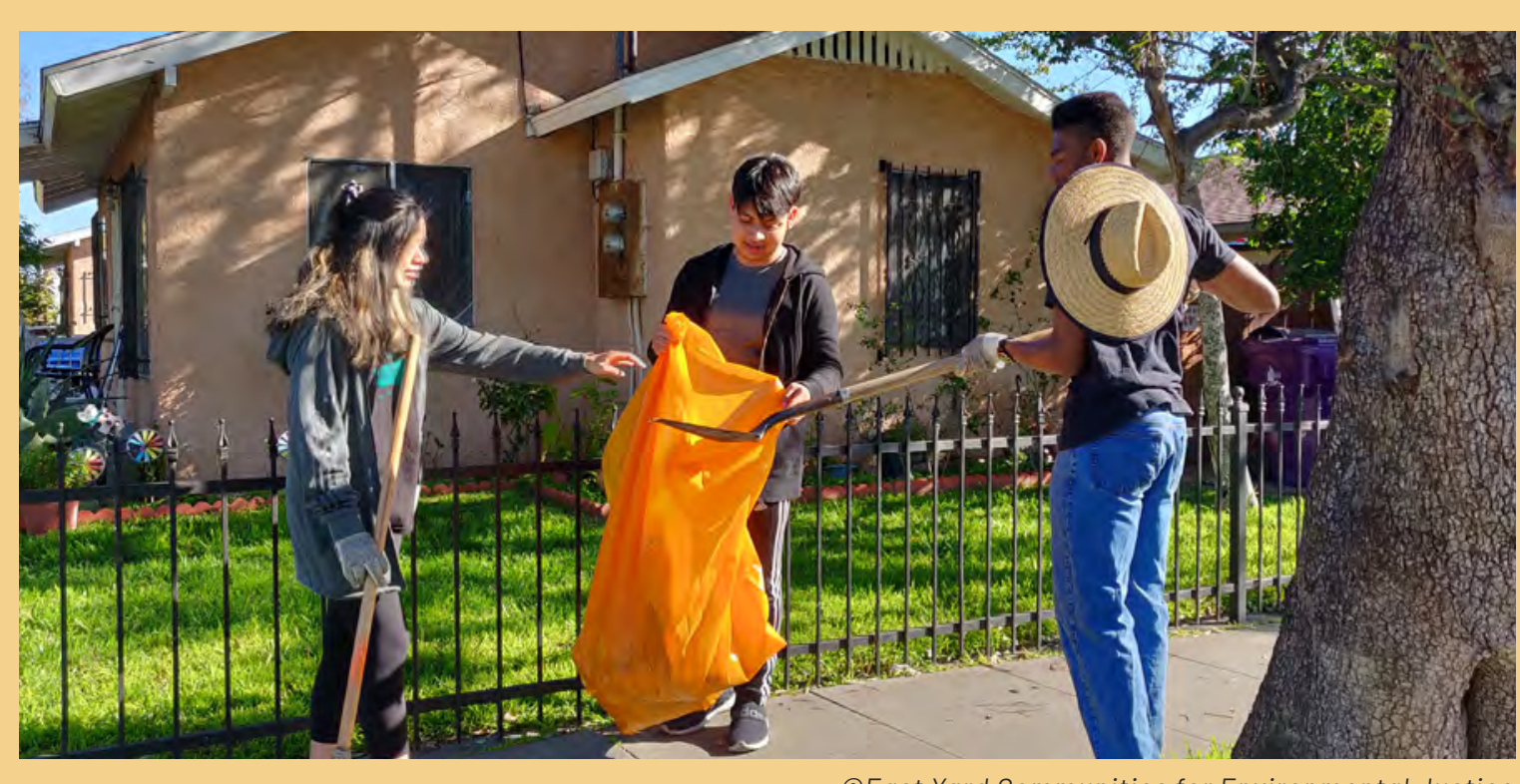

(- East Yard Communities for Environmental Justic 23 "Long Beach, California, Revamps Recycling to Focus on Plastics by Item Type, Not Resin Numbers" (2020).
Waste Dive. Retrieved July 21, 2021, from https://www.wastedive.com/news//long-beach-california-recycling-" mixed-plastic-resin/585328

\section{WHAT PLASTIC HAS MARKET VALUE?}

This report focused on the types of plastic that are able to be processed at a MRF, through each city's single-stream recycling program. In the five cities studied, we only considered plastic with positive market value to be recyclable, which ensures that cities have access to a viable end market and increases the likelihood that the plastic is actually recycled. Based on the market value of the material, it was determined that only some of \#1 PET, \#2 HDPE, and \#5 PP can be recycled, leaving \#3 PVC, \#4 LDPE, \#6 PS, and \#7 other, including plastic film, non-recyclable. Plastic film was left as a separate category to non-recyclable containers to help communities better understand impacts of strategies such as bag bans. Information regarding recycling drop-off programs was not available.

In the five cities studied, there are currently positive market values for grades \#1 PET, \#2 HDPE, and \#5 PP plastic packaging and \$0 or negative market values for commingled \#3 PVC, \#4 LDPE, \#6 PS, and \#7 other plastic. ${ }^{24}$ When materials with negative market values enter the recycling stream, MRFs have to pay to get these materials to market. Those costs are passed onto municipalities. While some film and styrofoam grades have a positive, but significantly lower, market value, they were not included in this analysis as

"recyclable" because they are not acceptable in most MRFs. Films and polystyrene cause serious and costly problems in MRFs, pose dangers to workers responsible for detangling sorting machines, and contaminate sorting systems. While some commercial recycling is viable, in the U.S., only about $24 \%$ of recycled film that is captured is made back into film, $30 \%$ exported, and the remainder is mostly made into lumber. ${ }^{25}$

\section{PROBLEMATIC PLASTIC HAS NO VALUE}

A 2019-2020 survey of 367 U.S. MRFs found very few end markets that will purchase and use the bulk of the plastic packaging to make new products, and this can no longer be hidden because of the refusal of other countries to accept the waste. ${ }^{26}$ Many MRFs sort \#1 PET and \#2 HDPE and directly ship them to end markets. While it's not the case in Minneapolis, in many cities, \#5 PP plastic is mostly shipped with \#3 PVC \#4 LDPE, \#6 PS, and \#7 other, commingled plastic bales to a plastic recycling facility (PRF). At the PRF. \#5 PP's are pulled out and most of the remaining plastic is incinerated or landfilled. Mixing \#5 PP's with \#3-\#7 plastic creates the illusion of economic value for materials that simply have none. The end result is that cities and consumers believe the material is market grade and that they have successfully recycled the material. Meanwhile, PRFs consolidate large amounts of non-recyclable plastic and are under pressure to find an outlet for them. With no viable end markets to turn this plastic into new products, PRFs have a growing incentive to sell their non-recyclable plastic to plastic-to-fuel facilities and cement kilns that would burn the plastic for fuel.

24 Online Commodity Pricing Index for Post-consumer Recovered Materials. Recycling Markets. Retrieved March 10, 2021, from 24 Online Commodity Pricing Index fo

25 A Data Visualization Tool Identifying Opportunities to Recapture Plastic in the US \& Canada (2021). Closed Loop Partners Retrieved July 21, 2021, from https://www.closedlooppartners.com/research/us-and-canada-recycling-infrastructure-and-plasticwaste-map/

26 Circular Claims Fall Flat: Comprehensive U.S. Survey of Plastics Recyclability. (2020). Greenpeace. https://www.greenpeace. org/usa/wp-content/uploads/2020/02/Greenpeace-Report-Circular-Claims-Fall-Flat.pdf 


\begin{tabular}{|c|c|c|c|c|c|c|}
\hline & Baltimore, MD & Minneapolis Area, MN & Newark, NJ & Long Beach, $\mathrm{CA}^{*}$ & Detroit, MI* & Average Across Five Cities \\
\hline & $\begin{array}{l}\text { Total MSW } \\
\text { (primarily residential) }\end{array}$ & $\begin{array}{l}\text { Total MSW } \\
\text { (residential and some } \\
\text { commercial) }\end{array}$ & $\begin{array}{l}\text { Total MSW } \\
\text { (residential, commercial } \\
\text { and institutional) }\end{array}$ & $\begin{array}{l}\text { Total MSW } \\
\text { (primarily residential) }\end{array}$ & $\begin{array}{l}\text { Total MSW } \\
\text { (residential, commercial } \\
\text { and institutional) }\end{array}$ & \\
\hline Population & 593,490 & 420,324 & 277,140 & 475,980 & 674,841 & \\
\hline \% MSW Incinerated in City on Average & $49 \%$ & $100 \%$ & $100 \%$ & $68 \%$ & $0 \%$ & \\
\hline MSW Landfilled or Incinerated & $91.7 \%$ & $61.5 \%$ & $76.9 \%$ & $80.7 \%$ & $91.6 \%$ & \\
\hline MSW Recycled & $7.6 \%$ & $19.4 \%$ & $19.8 \%$ & $19.3 \%$ & $5.0 \%$ & \\
\hline $\begin{array}{l}\text { How much plastic in the plastic stream* is non- } \\
\text { recyclable? }\end{array}$ & $67.3 \%$ & $66.4 \%$ & $61.2 \%$ & $60.3 \%$ & $66.5 \%$ & $64.3 \%$ \\
\hline $\begin{array}{l}\text { How much plastic in the recycling stream actually } \\
\text { gets recycled in through single-stream and } \\
\text { redemption? }\end{array}$ & $2.1 \%$ & $11.1 \%$ & $8.7 \%$ & $16.4 \%$ & $5.6 \%$ & $8.8 \%$ \\
\hline $\begin{array}{l}\text { How much potentially recyclable plastic is in the } \\
\text { trash? }\end{array}$ & $30.6 \%$ & $22.5 \%$ & $30.1 \%$ & $23.3 \%$ & $28.0 \%$ & $26.9 \%$ \\
\hline $\begin{array}{l}\text { What is the maximum potential of recyclable } \\
\text { plastic in the plastic stream? }\end{array}$ & $32.7 \%$ & $33.6 \%$ & $38.8 \%$ & $39.7 \%$ & $33.5 \%$ & $35.7 \%$ \\
\hline \multicolumn{7}{|c|}{ How does plastic get collected for recycling in each city? } \\
\hline Single-stream Recycling & Yes & Yes & Yes & Yes & Yes & \\
\hline State Redemption Program & No & No & No & Yes & Yes & \\
\hline Mission-based Recycler & No & Yes & No & No & No & \\
\hline
\end{tabular}

*Plastic stream is the complete flow of plastic collected for recycling from its source through to recycling

or final disposal in landfill or incinerators and other disposal methods. 


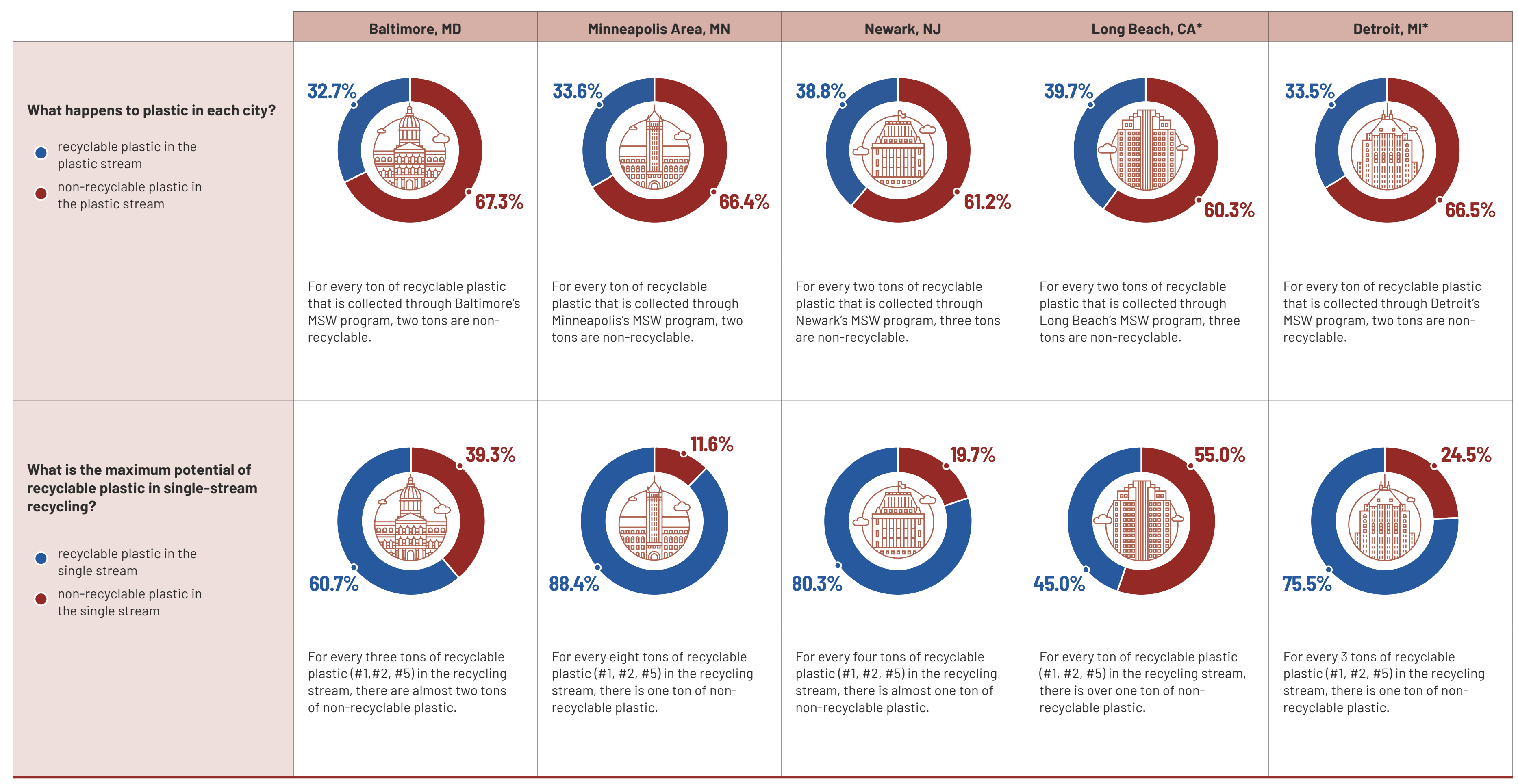

*Located in states with statewide bottle redemption programs 
The data presented in the "Ultimate Fate of Plastic" charts applies the definition of recyclable in this report as "\# PET, \#2 HDPE, and \#5 PP plastic with viable end markets for the MRF or municipality to purchase the plastic." and demonstrates the fullecychaily of plastic in mach city's MSW.

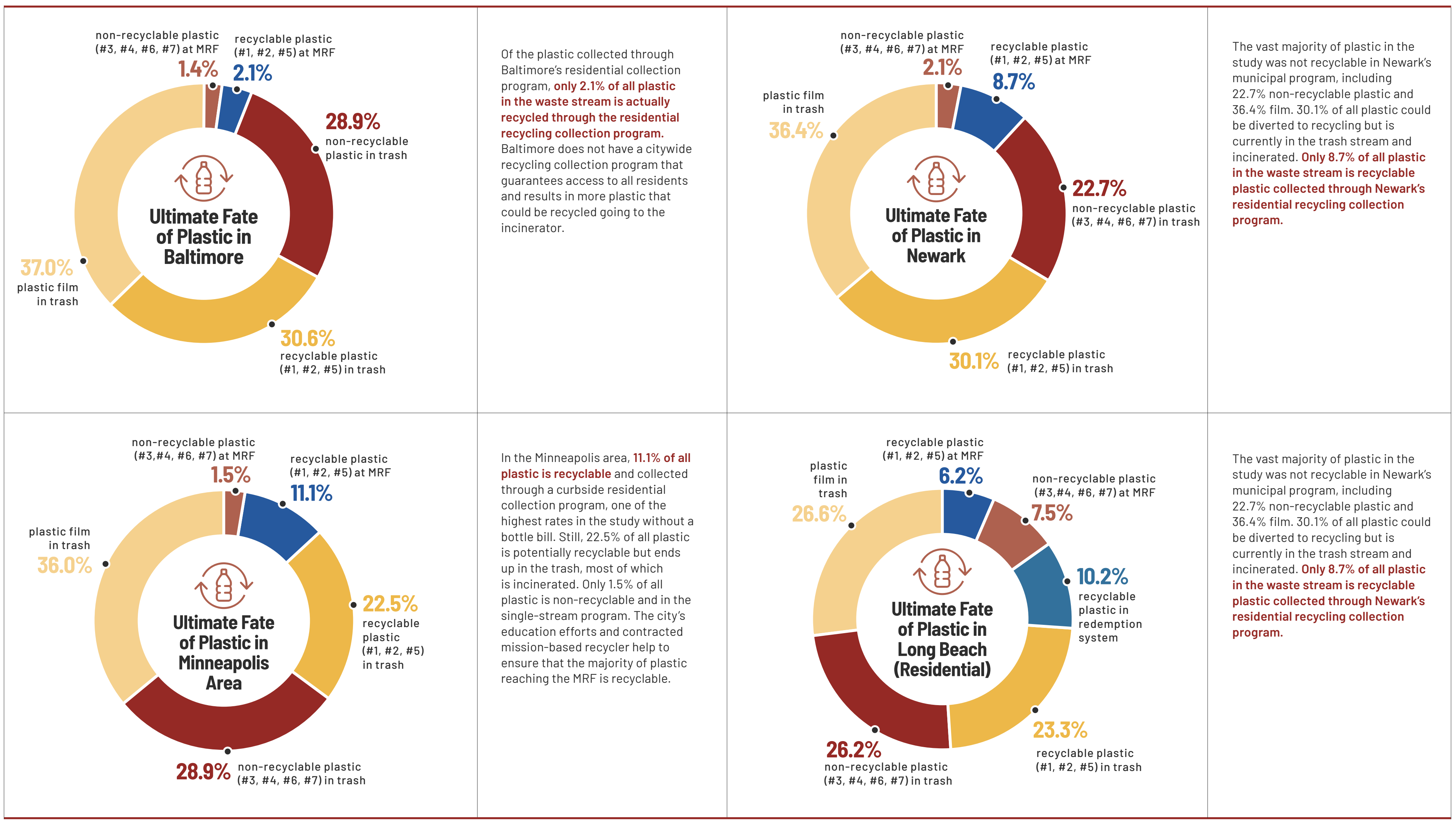




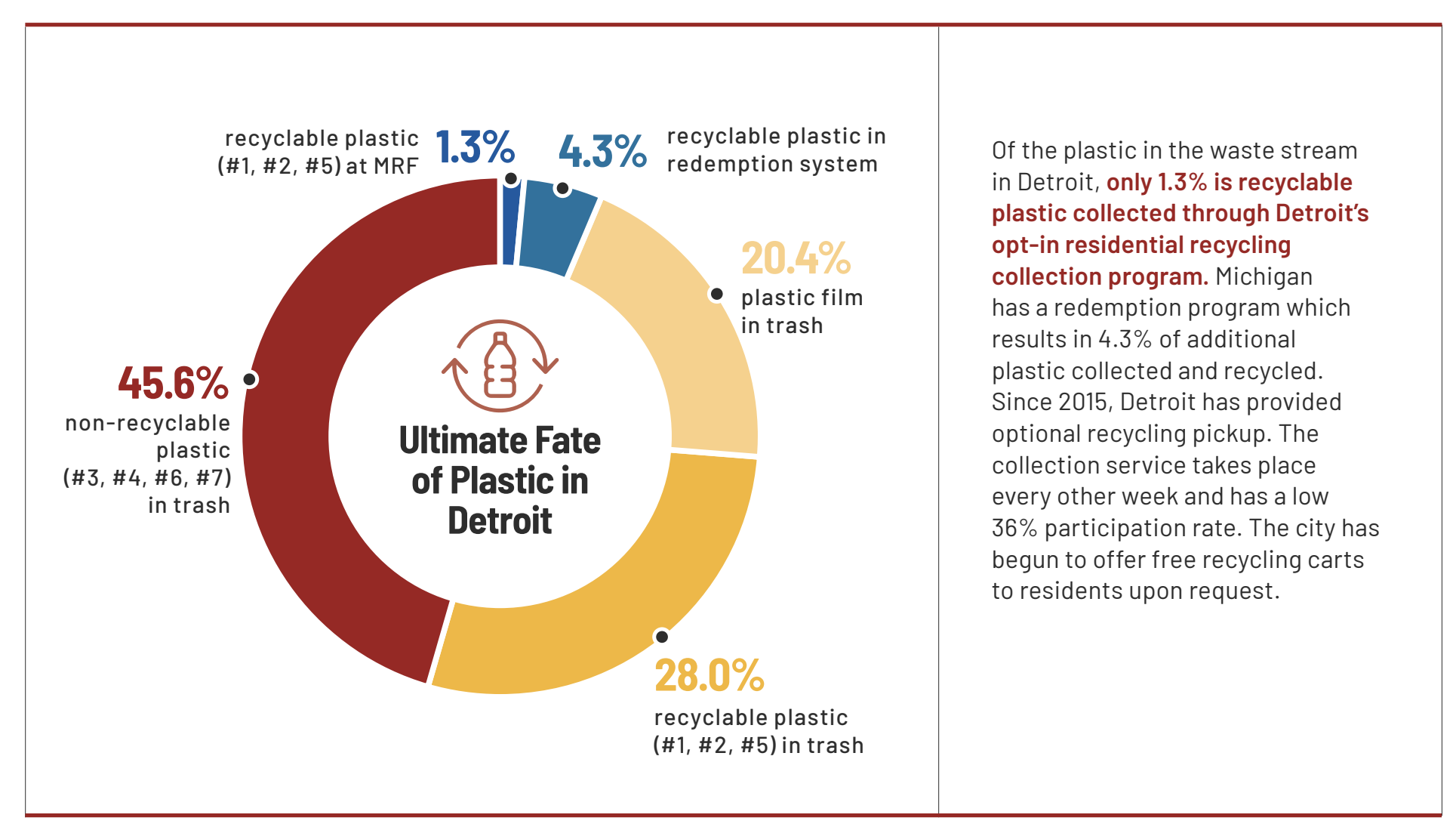

\section{HOW MUCH SINGLE-USE PLASTIC IS RECYCLED?}

The problem with plastic containers and packaging is that despite the majority of plastic being nonrecyclable and in the trash, recycling is still being pushed by industry and misguided policymakers as the primary solution to this single-use plastic.

The "Ultimate Fate of Plastic" charts provide an overall picture of where all plastic ${ }^{27}$ collected through each city's collection program ultimately ends up, according to the publicly available data, and highlights how significant city policy is in determining how much of the plastic that can be recycled actually does get recycled. ${ }^{28}$

7 Of all the plastic included in the study, $64.3 \%$ is non-recyclable (plastic film, containers and other non-recyclable plastic). 27 It is estimated that between $18 \%$ and $25 \%$ of the plastic included in the report analysis included non-single-use packaging
Items that potentially are made from plastic and other materials, such as furniture, electronics, textiles are not included in this plastic analysis. See Methodology in Appendix II for details.

28 Industrial and construction/demolition (C\&D) waste were not included in this analysis.
Each city's current programs affect the amount of the total diversion of plastic. The frequency of and access to collection, statewide redemption programs, and the presence of a mission-based recycler are all factors that impact the overall potential. Still, much of the non-reyclable plastic (\#3 PVC, \#4LDPE \#6 PS, and \#7 other) which most people think is recyclable, ends up in the trash. Overall, the percentage of plastic that actually gets recycled in single-stream and redemption programs across the five cities ranges from $2.1 \%$ in Baltimore to $16.4 \%$ in Long Beach.

While plastic film is not considered a recyclable plastic in this study, isolating it as a category demonstrates the potential for policy to eliminate considerable amounts of plastic that ends up in the trash. In the four cities where plastic film was collected and counted, the amount of plastic film (primarily plastic bags and packaging film) ranges from $20.4 \%-37 \%$ of plastic in the trash. New Jersey and California have already passed plastic bag bans. While the State of Maryland debates banning plastic bags, the City of Baltimore has already passed an ordinance to ban plastic bags. It has not yet been fully implemented.

\section{ONLY MARKETABLE PLASTIC ACTUALLY GETS RECYCLED}

Zooming in on just the plastic that is sorted for recycling and sent to MRFs further sheds light on the realities of our recycling systems. Single-stream recycling is the primary way cities collect and coun recyclable materials. The charts below, "What Happens to Plastic in Single-Stream Recycling in Each City," present data to show how much of the plastic collected through single-stream collection for each city and how much plastic in each city is most likely to be recycled. ${ }^{29}$ Some plastic is diverted from singlestream through state redemption programs available to Detroit and Long Beach.

7 The five cities studied all had varying amounts of non-recyclable plastic included in single-stream recycling, ranging from a low of $12 \%$ in the Minneapolis area to a high of $55 \%$ in Long Beach.

The rate is impacted by differences such as bottle deposits and redemption (where residents put less bottles in curbside programs and recycle them through redemption programs), education efforts (if a city advertises "all plastic recycling" for instance), and how data is reported (where the non-recyclable plastic ends up). Additionally, the Minneapolis area has a mission-based recycler, which contributes to the city's lower rate. For Long Beach (CA) and Detroit (MI), cities in states with bottle deposits and redemption programs, the plastic beverage containers collected in the redemption program counted as $100 \%$ recycled in this study, as the program only accepts \#1 PET, \#2 HDPE, and \#5 PP recyclable packaging.

29 The study assumes only \#1 PET, \#2 HDPE, and \#5 PP plastic have viable end markets in these cities. It is also assumed tha

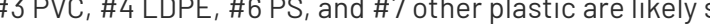
. 
The loads that a MRF must process are also contaminated when people throw materials that are not recyclable into the recycle bin. ${ }^{30}$ This is not only costly to the communities, but sorting the plastic at the MRF is an intensive physical and often dangerous labor practice and/or requires the use of expensive and energy demanding equipment. ${ }^{31}$ Despite the fact that most communities do at least some education that this plastic is unacceptable in the programs, educating residents about the confusing array of plastic packaging is a significant challenge and leads to the predictable trajectory that any increased recycling of plastic that really could be recycled will also result in the collection of more non-recyclable plastic.

\section{PLASTIC END MARKETS}

The highest and best use for clear \#1 PET and natural \#2 HDPE bottles is bottle-to-bottle recycling. But in actuality, today very few of those bottles are recycled back into bottles (24\% of \#1PET and $32 \%$ of \#2 HDPE sorted at a MRF or PRF is currently made back into bottles based on current national averages in the US). ${ }^{32}$ While viable non-bottle markets exist for \#5 PP, these containers are most often used to make other products that are less likely to be recycled again. According to the data, $87 \%$ of PP is made into crates, pipes, buckets, etc. and $13 \%$ is exported. There is no breakdown of "containers" specifically. Prioritizing bottle-to-bottle recycling makes it more likely the plastic will be recycled again. ${ }^{33} 0$ ther plastic is recycled into different uses that can't be easily recycled again (or "downcycled"), like clothing carpet or plastic lumber. While reuse and refill systems should be prioritized over recycling, bottle-tobottle recycling reduces the need for more virgin plastic and promotes sustainability. According to one report, less than $2 \%$ of all plastic packaging can be recycled a second time due to lack of market demand for bottle-to-bottle uses.

Recycling does not inherently reduce the demand for extraction and move the economy to circularity. It is dependent on brands demanding post-consumer content and also on the technical feasibility of the resin types. Unless minimum content standards create more market demand for \#1 PET and \#2 HDPE, the amount of bottle-to-bottle recycling will not increase. The concepts of circularity, closed loop systems, and highest and best use of recyclable materials can be applied to all materials collected in recycling and is further discussed in GAIA's Zero Waste Master Plan.

30 "Pandemic-Driven 'Wishcycling' Is Causing Big Problems At Recycling Centers" (2021). WCCO-CBS Minnesota. https:// (ing-big-prob- lems-at-recycling-centers

31 Sustainable and Safe Recycling: Protecting Workers Who Protect the Planet (2015). Global Alliance for Incinerator Alternatives. https://www.no-burn.org/wp-content/uploads/Safe-Recycling-Report.pdf

32 A Data Visualization Tool Identifying Opportunities to Recapture Plastic in the US \& Canada. (2021). Closed Loop Partners. Retrieved July 21, 2021, from https://www.closedlooppartners.com/research/us-and-canada-recycling-infrastructure-and-plastic-waste-map

33 The 50 States of Recycling: A State-by-State Assessment of Containers and Packaging Recycling Rates (2021). Eunomia. https://www.eunomia.co.uk/measuring-packaging-recycling-rates-across-the-us/

\section{STRATEGY: ELIMINATE UNNECESSARY PLASTIC}

We cannot recycle our way out of the plastic crisis. The most obvious solution taken by 713 state and local jurisdictions is to ban non-recyclable plastic bags, straws, and foam. ${ }^{34} \mathrm{Cities}$ and/or counties can establish waste policies and contracts that protect the integrity of the recycling system for truly recyclable materials, such as aluminum, glass, and paper, while eliminating the problematic plastic that contaminates the system, costs taxpayers money, and harms the health of their communities:

Cities and/or counties can adopt policies and programs such as:

1. Establishing bans and fees on single-use plastic that is not recyclable in the local waste management program. The EPA Transforming and Managing Waste Streams website includes examples. ${ }^{35}$

2. Writing recycling contracts and RFPs that require MRFs that receive municipal or county recycling to only accept materials that are actually recyclable and require material to go to legitimate, traceable recycling markets.

3. Requiring transparency and reporting requirements in contracts to understand where the materia goes, and creating economic incentives or penalties that support new policies to meet the requirements.

4. Not creating or advertising programs to accept all types of plastic in single-stream programs when there are no markets, and working to remove \#3 PVC, \#4 LDPE, \#6 PS, and \#7 other plastic from existing programs.

5. Encouraging or requiring retailers to take back products and/or packaging.

State and federal entities can support city and county efforts by:

1. Restricting State and Federal grants from investments in waste/recycling infrastructure that handle plastic that have no markets.

2. Establishing laws to require that packaging material include a minimum amount of content from recycled materials.

3. Establishing policies that set specific recycling rates that different packaging materials must achieve with deadlines or face being banned from use. California presented two companion bills in the 2019-2020 session to develop a comprehensive framework for reducing plastic pollution and the proliferation of plastic. The bills required significant reductions in the use of disposable products and required manufacturers to make packaging exclusively out of recyclable materials that actually get recycled through existing infrastructure and end markets. The legislation

34 Legislative Datasets and Maps (2021). Plastic Pollution Coalition. Retrieved July 21, 2021, from https://plasticpollutioncoalitionresources.org/resources/maps/

35 Managing and Transforming Waste Streams: A Tool for Communities (2015). US EPA. R. 09. https://www.epa.gow/ transforming-waste-tool 
also required regulations to reduce or recycle at least $75 \%$ of single-use plastic packaging and products by 2030 . The manufacturer would need to demonstrate a recycling rate of not less than

$20 \%$ in the first time frame and not less than $40 \%$ in the next time frame.

4. Establishing laws requiring reusable and refillable options instead of single use packaging items.

\section{FINDING \#2}

MOST RECYCLABLE PLASTIC IS STILL LEFT IN THE TRASH

There are significant amounts of materials that could be legitimately recycled that are in the trash and there is a significant amount of trash in the recycling.

The "Capture Rate" chart of materials below shows how much of each material is collected for recycling out of the total amount available in the five cities studied. The graphs show the percentage of all discarded containers, by type, that are recycled on average in the cities. The majority of all discarded containers are in the trash. The fact that most containers are not being recycled points out a major flaw in the effort to increase plastic recycling - the current recycling systems are not even working very well for the traditional materials like glass and metals in these cities.

\section{FIGURE 5}

Comparing Capture Rate of Different Containers in a Municipal Collection and Redemption System

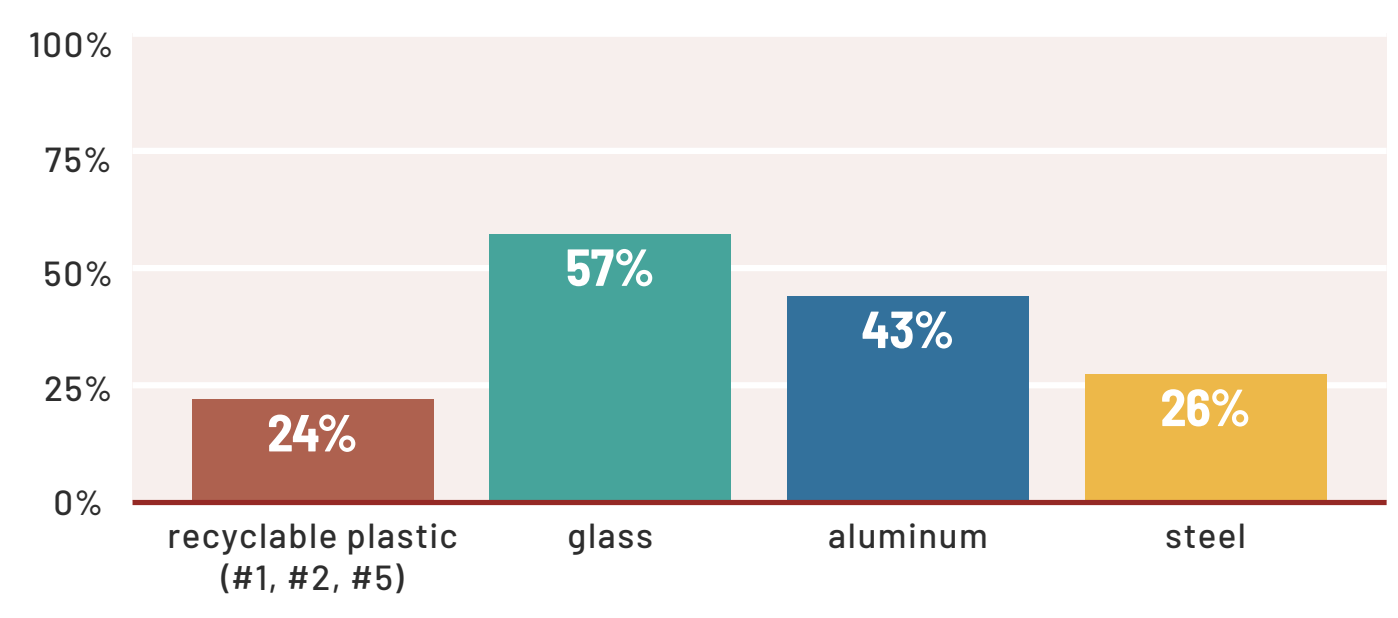

Note: Aluminum is one commodity that has been traditionally captured both inside and outside of a municipal system through scrap yards via canners, pickers, scrapers and gleaners, due to its consistent value. This chart shows only aluminum collected through the recycling and redemption programs.

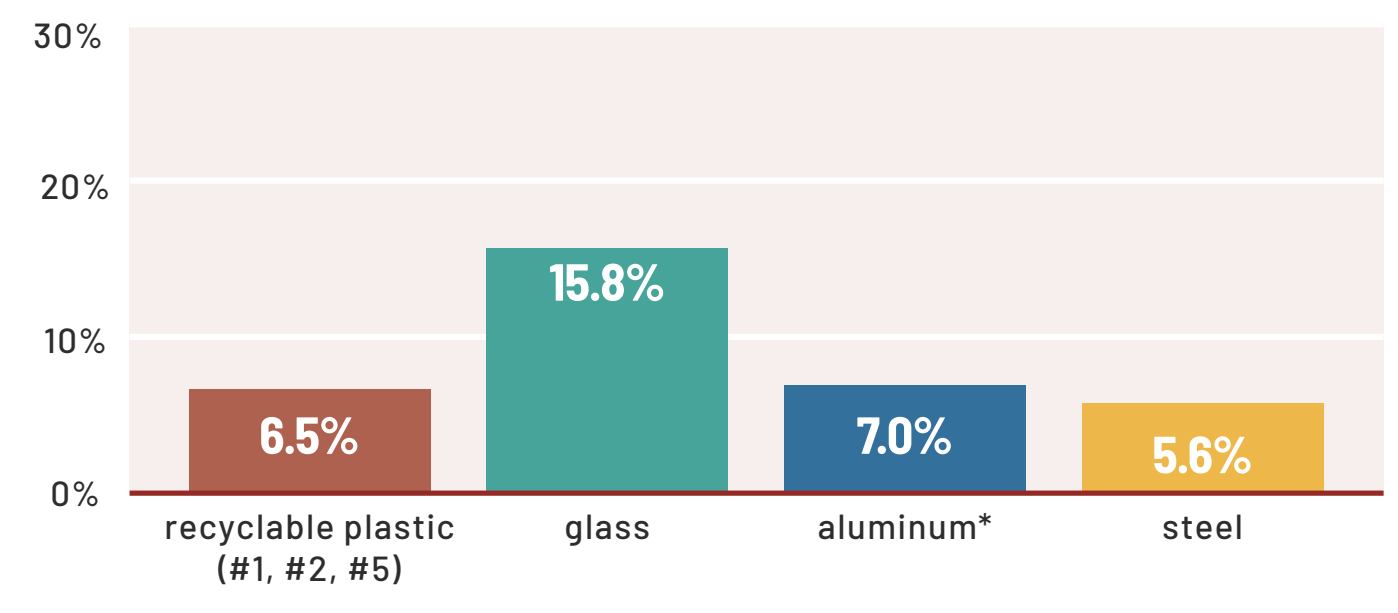

*Curbside only, recovery rate likely higher.

Container Capture Rate by Commodity in the Minneapolis Area

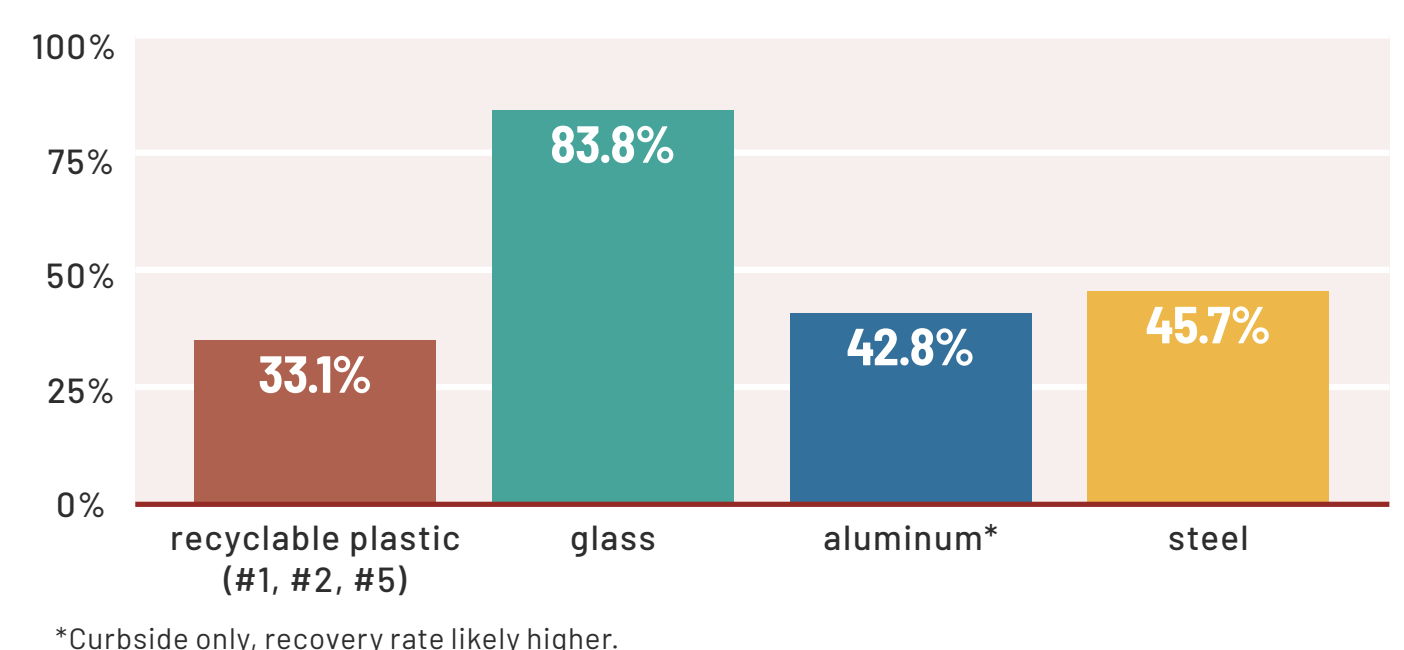

Container Capture Rate by Commodity in Newark

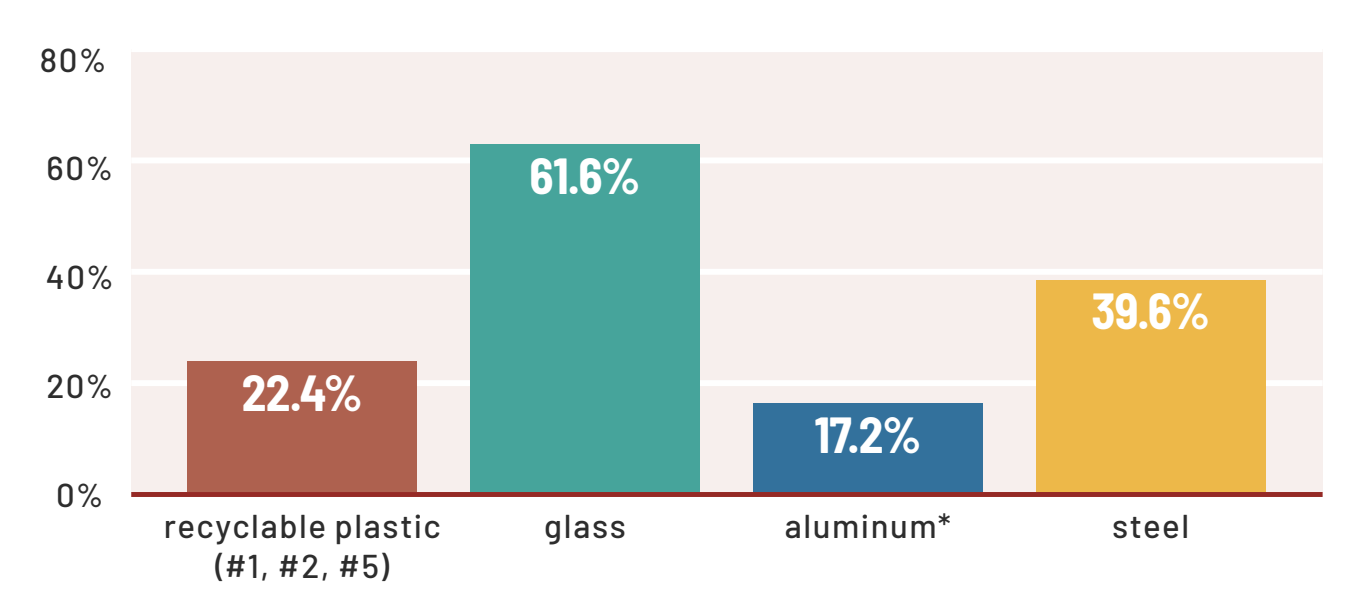

*Curbside only, recovery rate likely higher. 
Container Capture Rate by Commodity in Long Beach

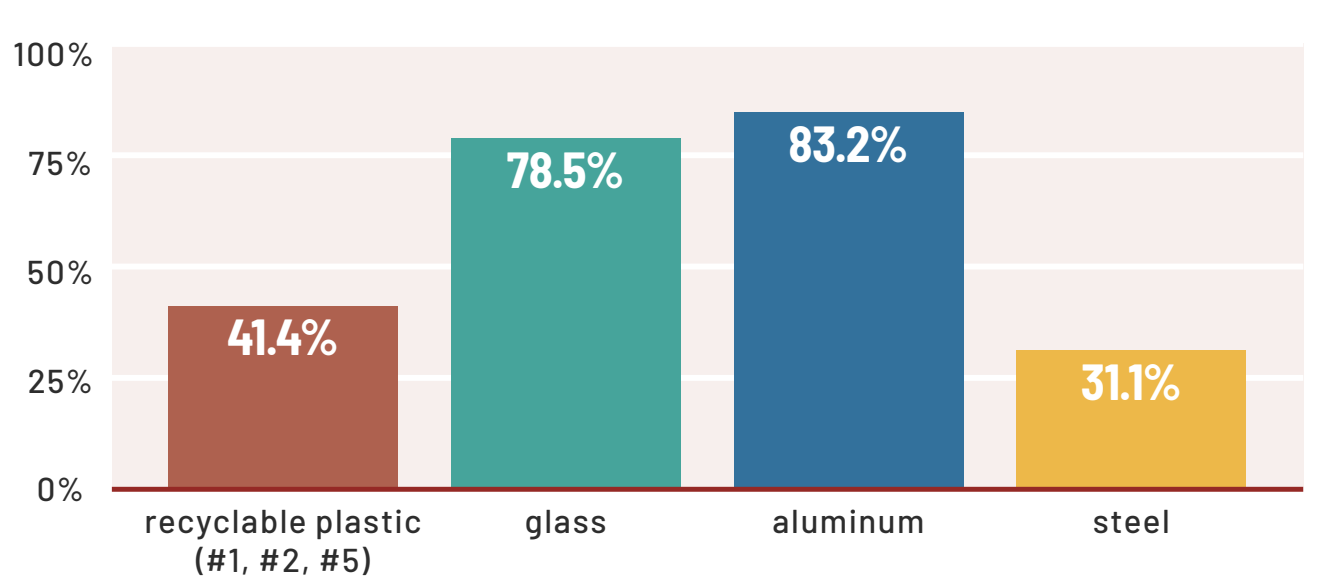

Container Capture Rate by Commodity in Detroit

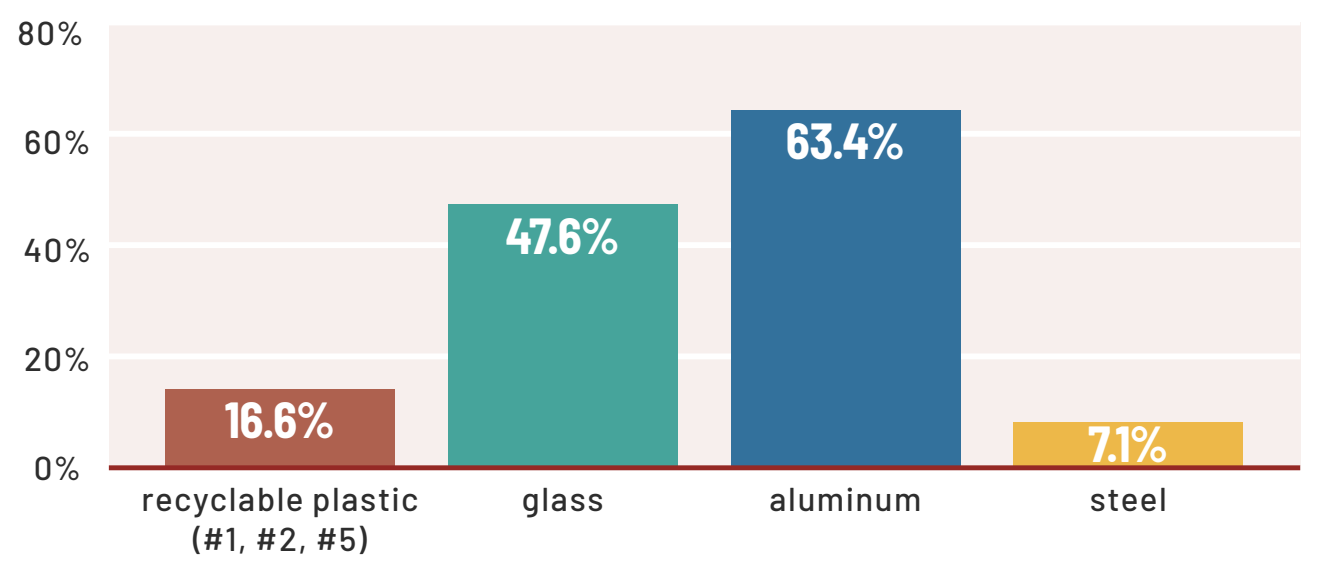

Of all recyclable material, plastic has the worst capture rate. On average recyclable glass and aluminum are recycled at a rate $2-3$ times higher than recyclable plastic. While the plastic industry's focus has been on investing in MRF sorting capacity, it does not address the significant investments in collection programs, economic incentives such as bottle deposits and pay-as-you-throw, and education and consumer motivation that would be needed to increase the capture rate. Even if it is possible to "solve" the plastic recyclability issue, most of the plastic will still be in the trash. The cost of dealing with recyclables in the trash are typically borne by residents through municipal fees and or taxes.

\section{Spotlight on Detroit: Just Recovery After Incineration}

Breathe Free Detroit is a community and grassroots-led campaign that was formed to shu down the Detroit incinerator, Detroit Renewable Power, the largest municipal solid waste incinerator in Michigan with a long history of emissions violations. On March 27th, 2019, after decades of community activism, the Detroit Renewable Power Incinerator announced the facility's immediate closure. Now that an end has been put to municipal waste incineration in Detroit, Breathe Free Detroit in collaboration with grassroots groups across the city is working to fight real estate interests from buying up their neighborhood and to build new zero waste systems for the city. Since 2015, the city of Detroit has provided "opt-in" recycling pickup, with collection every other week and a $36 \%$ participation rate. Carts have been made available to residents at no cost upon request from the city. While Detroit also has a bottle redemption program that recycles $100 \%$ of the recyclable material collected, the program only collects $4.3 \%$ of recyclable plastic from the city. Recyclables, like glass and aluminum are captured at rates $3-4$ times greater than the recyclable plastic in Detroit, $83 \%$ of which (\#1 PET, \#2 HDPE, and \#5 PP) are in the trash and not the recycling.

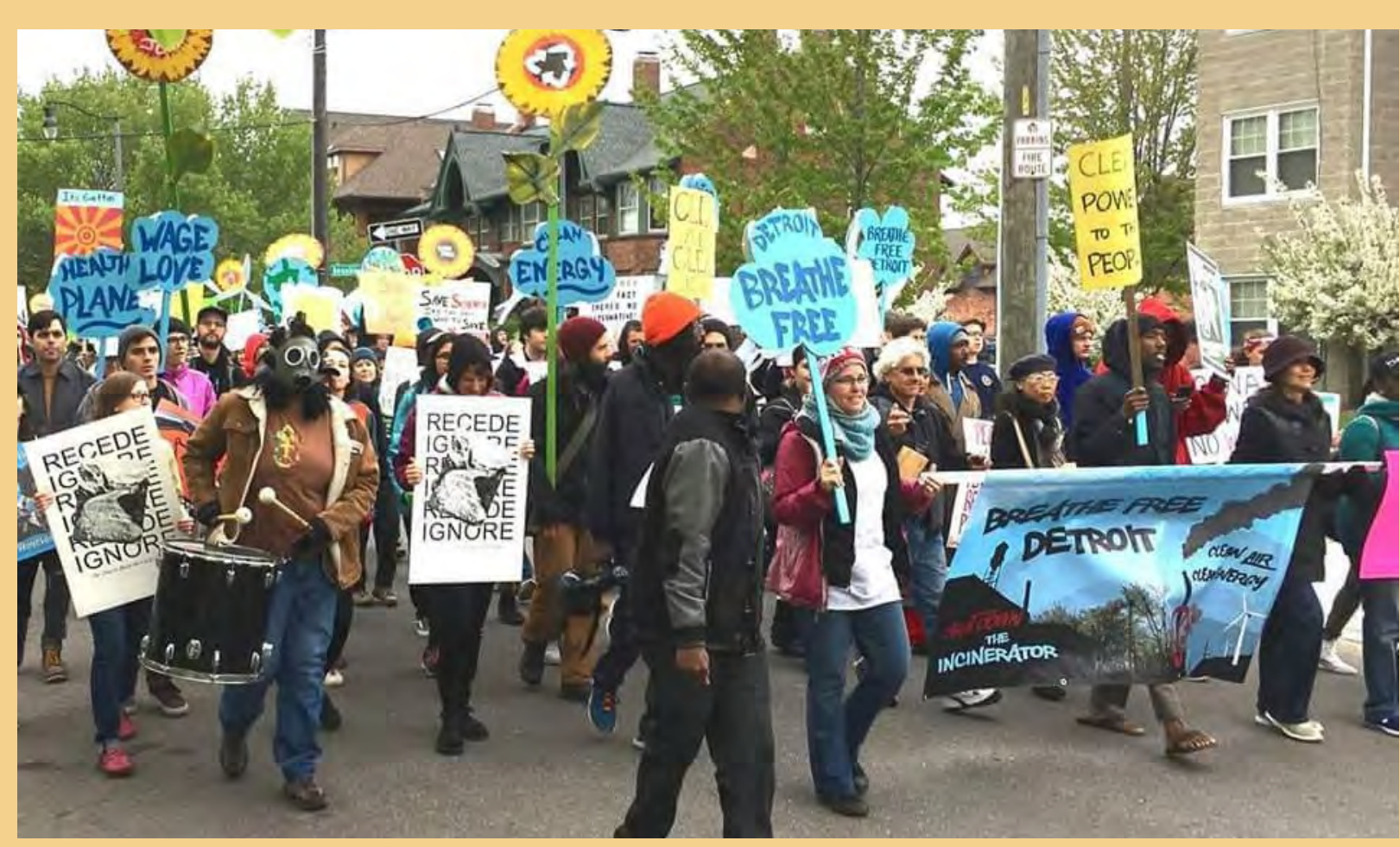


FIGURE 6

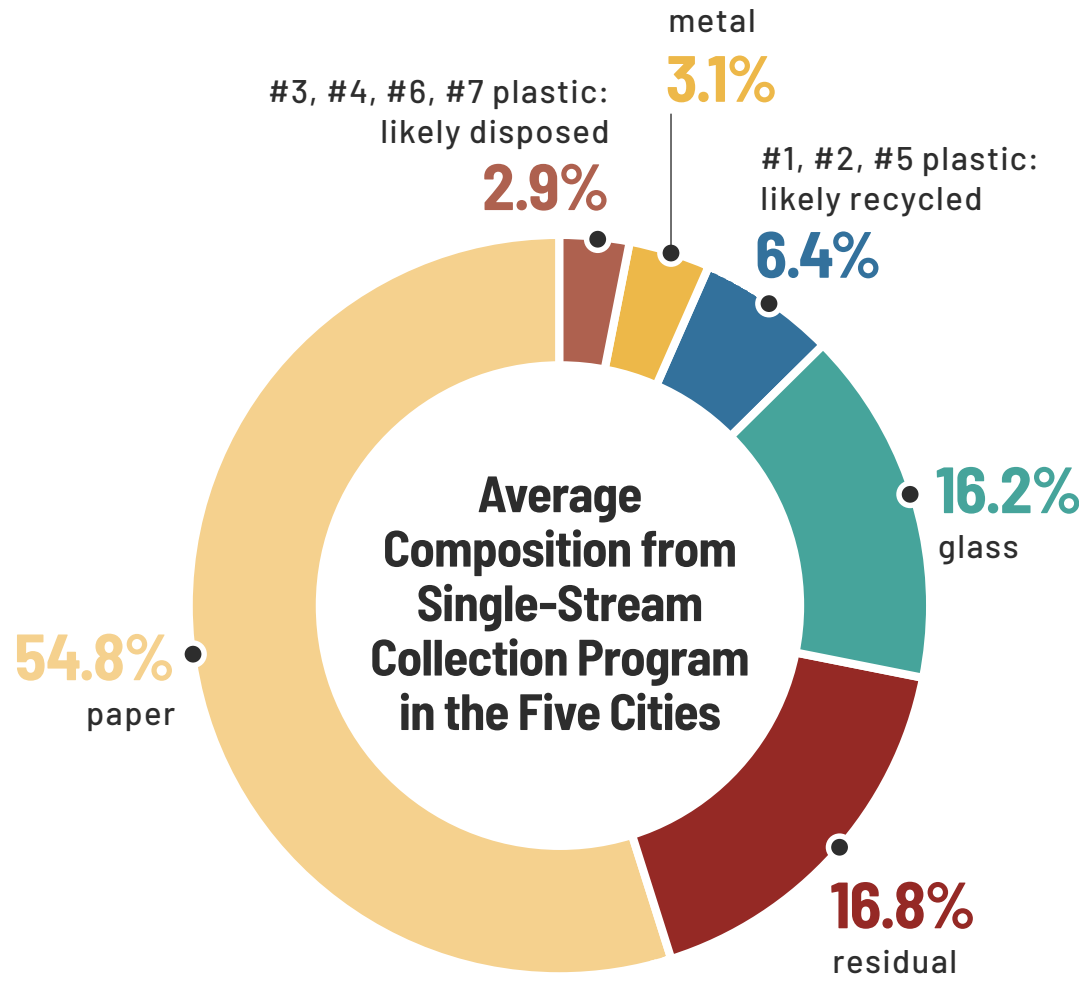

metal

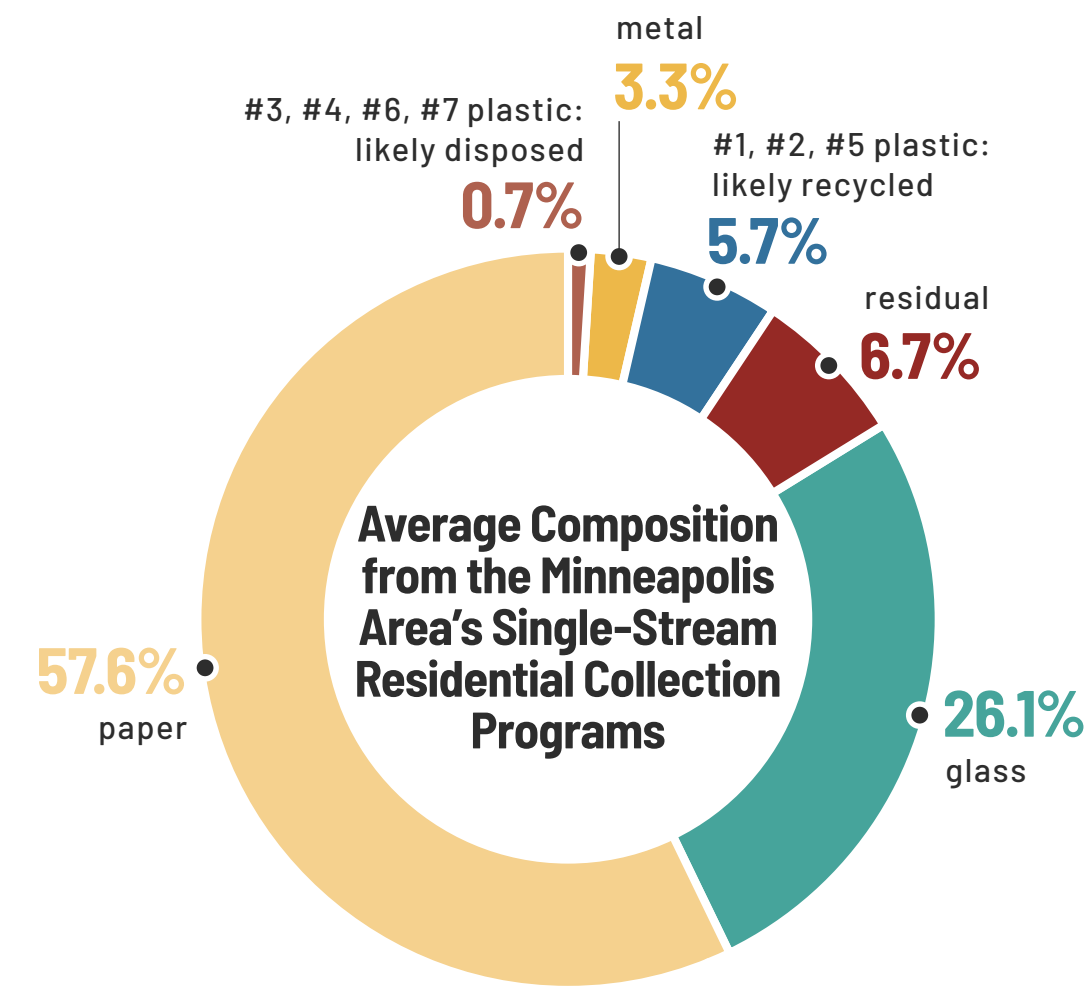

\section{The Minneapolis area had the least amount of residual.}

On average, $19.6 \%$ of material collected for recycling in the five cities is burned or landfilled; either the collection is contaminated by non-recyclable material (including non-recyclable plastic) that was tossed into the recycling bin or because MRFs are unable to sort the material properly. This figure does not include material that is sent to end markets and is disposed of there (which can be another substantial amount of material). By contrast, mission-driven MRFs like Eureka Recycling, where recyclables from the Minneapolis area are processed, have residual rates closer to $10 \%$ because they prioritize strong community education programs and optimize their operations to ensure recyclable materials are

recovered. When excluding the Minneapolis area from the average, the percentage of residuals rises to $22.7 \%$ for the other 4 cities

These factors: the limited capture rate of plastic from the waste stream, the limited amount of that material that can actually be recycled, and the limited potential for it to ever get recycled again (if it is even recycled once), confirm the burden single-use plastic puts on cities' MSW operations.

\section{STRATEGY: SHIFT THE SUPPLY CHAIN TO REUSE, REFILLABLES, AND SHARING}

The data unequivocally points to why recycling cannot be the first line of defense against waste, especially plastic waste.

It is essential for cities to invest in and incentivize the development of alternative systems that solve the problem at the source. Transitioning away from disposability requires a robust reuse economy. Businesses that provide goods in refillable packaging or are package-free, including take out and delivery, and businesses that keep our durable goods in use longer, such as repair, reuse stores, and sharing opportunities, will play a critical role in building local economies and creating jobs. Changing the supply chain to eliminate waste will require a combination of policy, infrastructure investments, economic development and business incubation to be successful. Discover the Reuse Revolution with UPSTREAM Solutions. 
2. Incentivize or require retailers to reduce plastic packaging and foodware and shift to reusables through fees, bans, and requirements. Build in reporting and enforcement mechanisms to track progress.

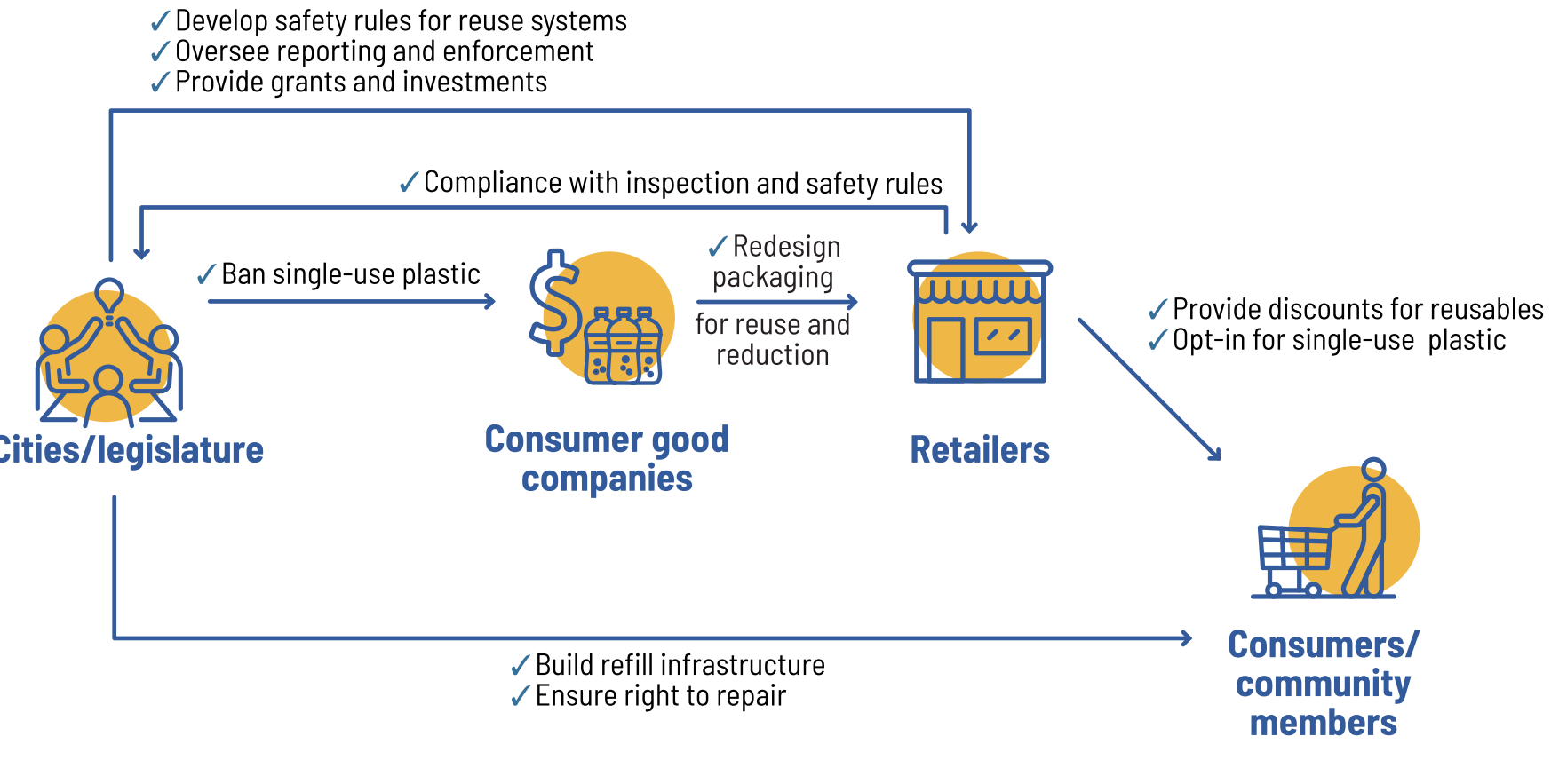

๑) Doun Moon/GAIA

Policies, ordinances, regulations, and legislation should:

1. Prioritize reduction and reuse over recycling and provide state and local investment through grants, loans, and technical support to create the infrastructure necessary to develop reuse and refill systems. For example the Oregon Beverage Recycling Cooperative is a city-supported investment that creates local supply chain logistics for refillables. ${ }^{36}$ Economic Development and Business Incubation programs can provide affordable or subsidized buildings and land for community-based sharing programs and reuse enterprises. The Fair Development Plan for Zero Waste of the City of Baltimore called for $\$ 20$ million annually from municipal economic development bonds or other revenue sources for jobs deconstructing nuisance and vacant properties and reusing/recycling recovered building materials to partner with community land trusts to create community gardens, farms, and reuse and recycling operations from vacant lands and buildings. Many cities have already established programs to support minority and womenowned business enterprises (MWBE) that can be expanded for reuse and refill industries.

36 OBRC Proposes Refillable Bottle Program with Oregon Brewers (2017). Association of Oregon Recyclers. Retrieved July 21 2021, from https://oregonrecyclers.org/blog/obrc-proposes-refillable-bottle-program-oregon-brewers
3. Eliminate possible barriers to reuse in building inspection codes, food safety and bottle deposit and redemption regulations, and other restrictions to allow reusables.

4. Enact right to repair legislation.

\section{FINDING \#3}

\section{BROKEN WASTE MANAGEMENT SYSTEMS DRIVE FALSE SOLUTIONS}

The complex web of waste management systems for different materials and lack of transparency allow the plastic industry to exploit loopholes and push a self-serving narrative about what really happens when plastic is discarded. Policymakers and consumers think when items are accepted in recycling programs they can be and are recycled. Even more damaging is that accepting all plastic can drive what is then declared as the "need" for these unproven technologies that burn or transform plastic. Instead of assuming that the production of non-recyclable single-use plastic needs to be restricted, the industry, at least so far, has been successful in establishing their view that someone else, particularly individual consumers, needs to do something with all of this non-recyclable plastic. The industry uses that dismal potential for any real recycling of the plastic they create as the reason why we need to subsidize, support, or incentivize their next false solution- plastic-to-fuel. ${ }^{37}$ This new technological process for plastic waste, categorized as a type of chemical manufacturing, is being developed without a clear regulatory framework to operate that will ensure the same public health and environmental protections required by other chemical manufacturing facilities ${ }^{38}$

37 All Talk and No Recycling: An Investigation of the U.S. "Chemical Recycling" Industry. (2020). Global Alliance for Incinerator Alternatives. https://www.no-burn.org/chemical-recycling-us/

38 "Furthering Activity with Advanced Recycling and EPR" (2021). Recycling Today https://www recyclingtoday.com/article/ advancing-activity-advanced-recycing-extended-producer-responsibility-laws/ 
Not only does the industry propose continued burning of plastic and other thermal processes that either have been proven to harm human health, the environment, and the climate, or have yet to be tested on human health and the environment, ${ }^{39}$ it also greenwashes these methods with terminology like "advanced recycling" as a way to obfuscate the truth of what is happening. Many states have already passed "advanced recycling" legislation that incentivizes plastic-to-fuel facilities and allows them to be sited without a solid waste permit. ${ }^{40}$ Whether by default or design, the broken waste management system drives false solutions and cities must:

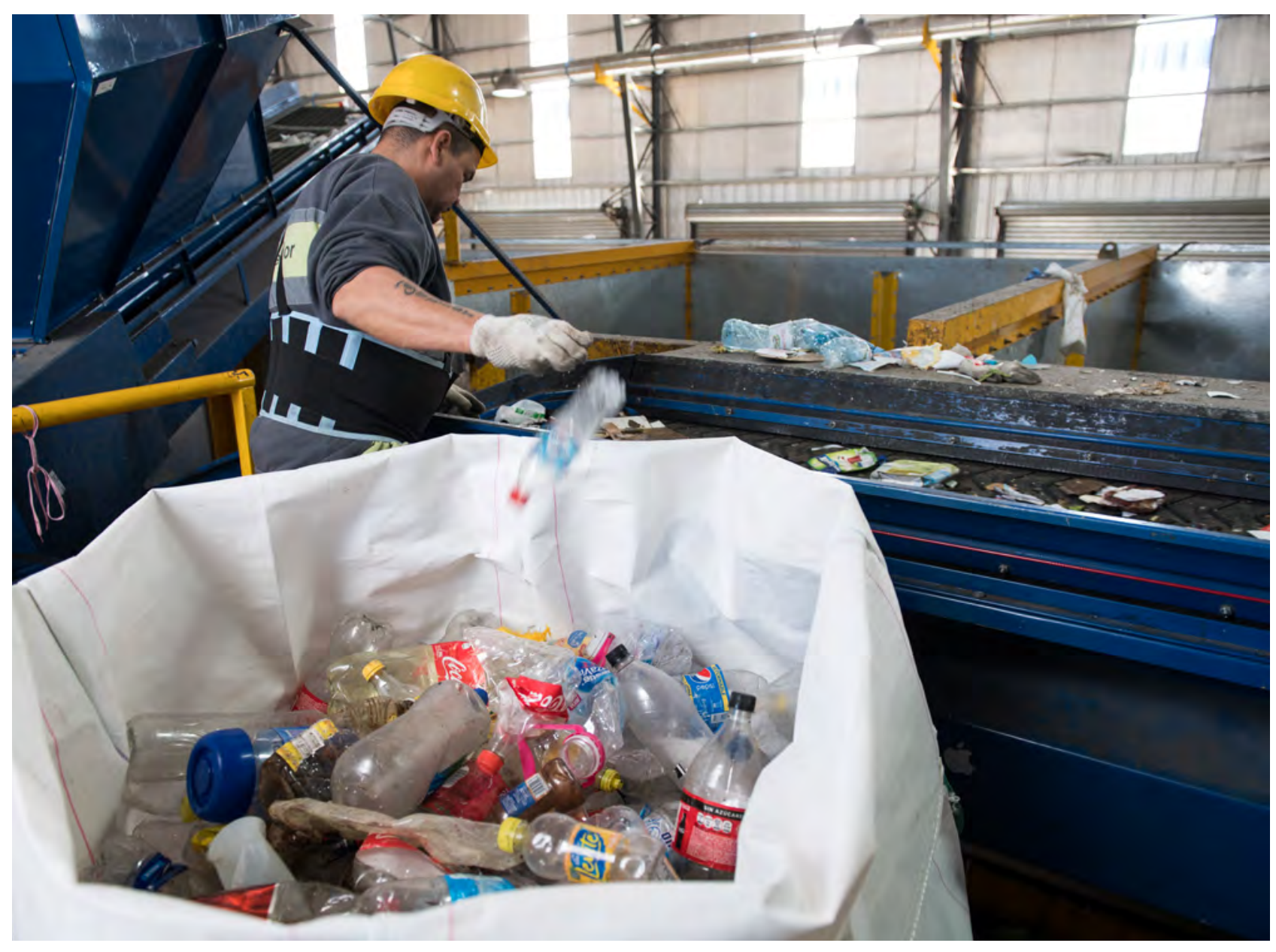

@Santiago Vivacqua/GAlA

\section{STRATEGY: DON'T FUEL THE MYTH}

1. Ban facilities that produce fuels from plastic and mixed waste.

2. Ensure plastic-to-fuel and other burn facilities are not an end market for municipal waste by penalizing residuals or burning for fuel in waste contracts.

3. Refuse to collect \#3 PVC, \#4 LDPE, \#6 PS, \#7 other plastic and work with companies that sort out \#1 PET, \#2 HDPE and potentially \#5 PP directly at the MRF.

4. Hold PRFs accountable for reaching recovery goals and working with transparent recycling markets.

\section{State and federal entities can support city efforts:}

1. Protect the integrity of recycling as the plastic industry pushes "advanced recycling" legislation that redefines recycling to include pyrolysis, gasification and plastic-to-fuel schemes, which often involve burning plastic. Ensure that any "conversion" technology (pyrolysis, gasification), or plasticto-fuels, or plastic-to-energy, or chemical recycling does not qualify as diversion under state and federal solid waste regulations.

2. Restrict State and Federal grants to investments in waste/recycling infrastructure that support actual recycling.

39 Ibid.

40 US Legislation Alert: American Chemistry Council's Effort to Push "Plastic-to-fuel" Bills (2020). Global Alliance for Incinerator Alternatives. https://www.no-burn.org/legislativealert 


\section{CHAPTER 03}

ALIGN CITY RESOURCES WITH ZERO WASTE GOALS:

REMOVING NON-RECYCLABLES TO CREATE
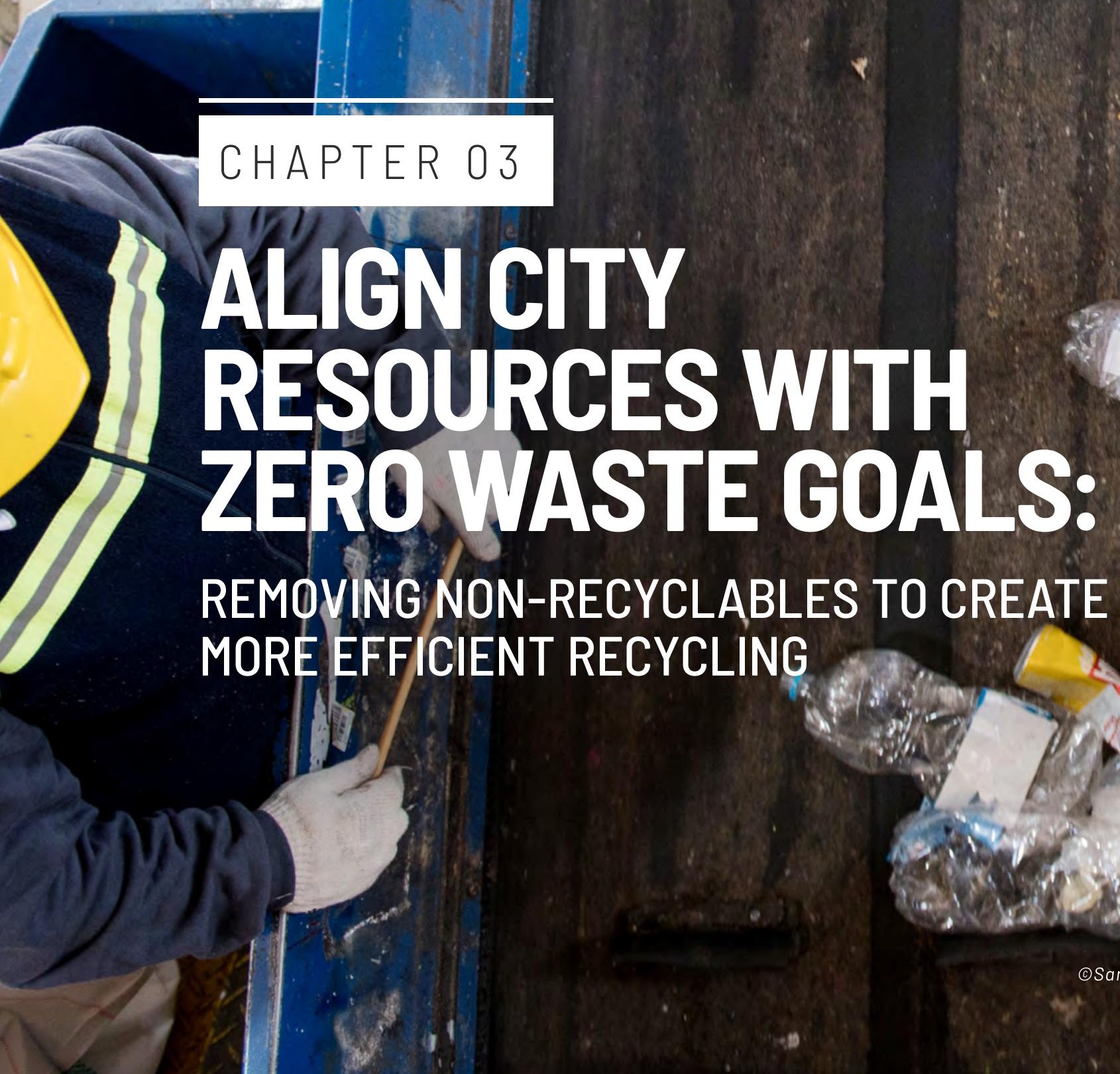

\section{REMOVINGINON-RECYCLABLES
MORE EFFICIENT RECYCLING}

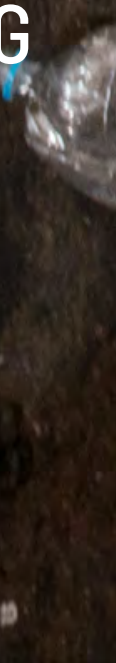

\section{,}
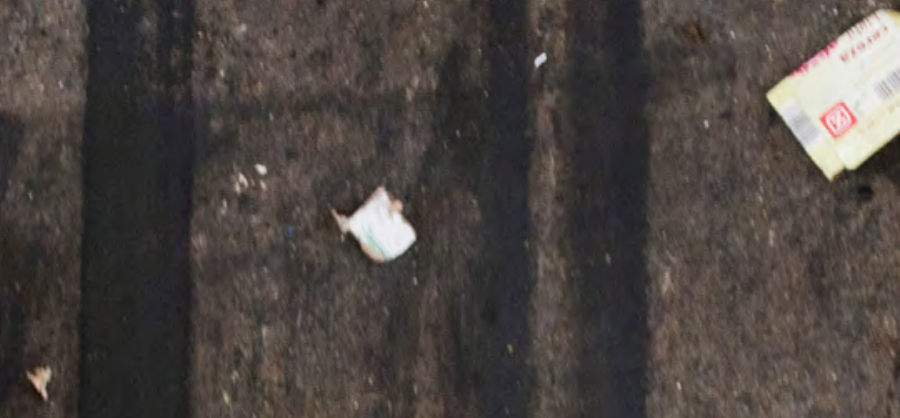

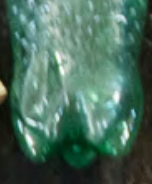

a

$\cos$

Recycling programs are one of the main ways that cities have tried to address plastic waste. Recycling programs are predominantly paid for by the residents, typically through collection fees, property taxes, or with utility fees. Resident fees can be augmented with general funds and/or grants from state funds, but recycling programs are rarely subsidized compared to disposal infrastructure. For example, incinerators are heavily subsidized by renewable energy credits and long-term contracts that require municipalities to supply minimum tonnage of waste annually at a fixed cost to keep the facility profitable. ${ }^{41}$ Meanwhile, the low cost of producing virgin plastic materials due in part to fossil fuel subsidies allowed plastic packaging to take hold of the market and replace glass paper, and steel ${ }^{42}$ Recycling programs were forced to adapt and absorb the increasing costs for collecting and processing the exploding growth of plastic packaging, despite much of it being burned or landfilled in the end. Where packaging is measured in market share the amount of plastic is sizable, but in the waste management sector, weight is the primary measurement used. Plastic, which weighs less than other material, has been able to hide under the radar as a seemingly smaller portion of the problem. Polystyrene foam (commonly referred to as the trademarked name "Styrofoam"), is a typical example of a problematic plastic that takes up a lot of room per unit of weight because it has been expanded 40-to-80 times its original volume.

At the same time that plastic became dominant, multi-national waste hauling companies consolidated, buying up independent providers and taking over what were once municipal and nonprofit recycling programs. In order to become more profitable, these multi-nationals implemented collection efficiencies, but did not invest in systems that maintained the value of the materials they were collecting for recycling. Singlestream recycling is a prime example. It involves putting all the different types of containers and paper in one recycling cart, which, through intense compaction, allows recycling collectors to create efficiency by packing more material into one load. Single-stream recycling, however, contributes to increased wishcycling by leading individuals to hope everything thrown in the bin will be recycled. It also requires

41 U.S. Municipal Solid Waste Incinerators: An Industry in Decline (2019). Global Alliance for Incinerator Alternatives. https://www.no-burn.org/industryindecline/

42 Hopewell, J., Dvorak, R., \& Kosior, E. (2009). Plastics recycling: Challenges and 3641526) 2115-2126. https://doi org/10 1098/stb 20080311 
sophisticated sorting, may cause the material to be damaged beyond recyclability, and includes items too small or made of mixed material that cannot be recycled such as food pouches lined with aluminum. Shifting the programs and practices has not addressed the underlying issues of recyclability and leads consumers and cities to believe that what they are putting in the bin and collecting on curbs is actually being recycled.

When the public finds out that they have been misled about the recyclability of plastic, they can and often do become skeptical of even the materials that do get recycled. Legitimate recycling efforts that can be a real part of the solution end up taking the fall. Cities all over the country are paying for education programs and to collect and process non-recyclable plastic from residents when the simple and cheaper solution is to remove non-recyclable plastic from the system.

\section{FIGURE 8}

\section{What is left in the trash after diversion?}

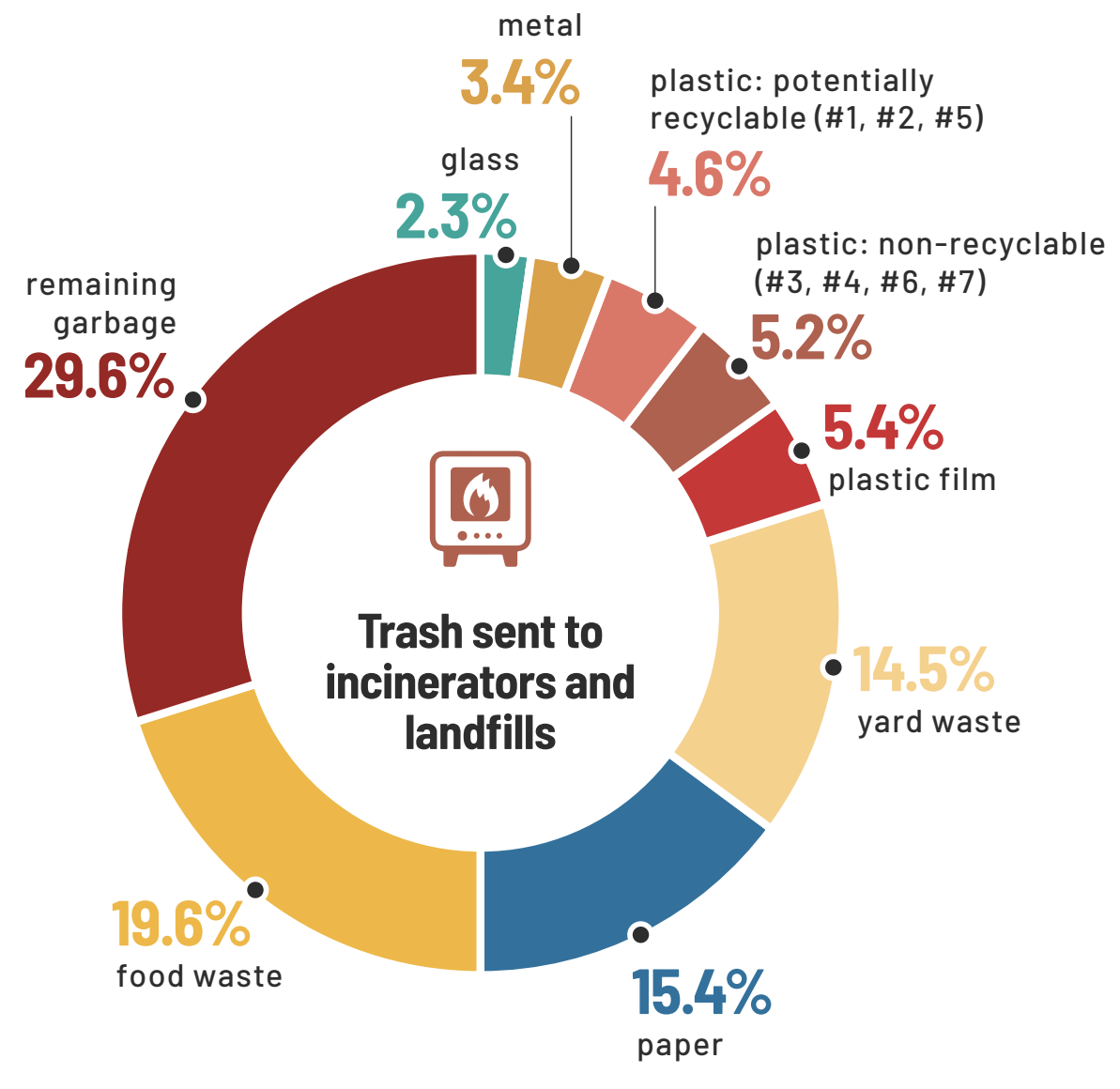

\section{ZERO WASTE STRATEGIES}

Beyond plastic, on average, organics (food waste and yard waste) make up an average of $34.1 \%$ of the waste stream in the cities studied. Traditional recyclables (metal, glass, and paper) make up an additional $21.1 \%$ of the waste stream. These two areas add up to three times the diversion potential of all plastic $(15.2 \%)$, and over 10 times the diversion potential of recyclable plastic. Clearly, the emphasis on increased plastic recycling over other important diversion strategies is disproportionate to the economic and environmental outcomes from reduction and reuse strategies. For a detailed breakdown of what is left in the trash for each city, see the individual data summaries for each city in the Appendix.

Each of the cities in the study has a strong organized community that supports zero waste. The zero waste hierarchy is a guide for how decisions could be made in these communities, including how resources would be spent to achieve zero waste goals. Zero waste policies offer the opportunity for cities to pay for new waste management systems. For example, container deposit laws can be structured to fund collection. These policies motivate the public to return used containers, result in high recycling rates, and give distributors and bottlers clear roles.

FIGURE 9

Zero Waste Hierarchy

Rethink/Redesign

Reduce

Reuse

Recycle/Compost

Material Recovery

Residuals Management

(Biological treatment and

stabilizing landfilling)

Unacceptable

("Waste-to-energy" incineratio and "plastic-to-fuel") 
b. Do not include products that are not recyclable in the program and minimize residual rates through reduced compaction during collection, contract incentives, investments in better MRF operations, and public education.

c. Develop criteria for highest and best use for end markets for recyclable materials (based on the specific values of the community, for example: circularity potential, carbon impact, worker conditions, and local markets). Make sure this criteria is included when writing and evaluating RFPs for service providers.

d. Ensure that contract language protects workers. Employers must ensure drivers and MRF workers are treated as frontline workers, that their health and safety are protected, and that they are paid living wages. Companies must also ensure sufficient staffing levels to provide safe collection in adverse conditions.

2. Increase program access and outreach to residents:

a. Provide carts or bins to all residents.

b. Include multifamily buildings in the program. Require modifications to state or local codes to increase capacity for adequate space, chutes, and access for recycling.

c. Provide multilingual education and outreach efforts to engage all residents.

d. Develop, increase, and promote public space recycling programs.

e. Require recycling at events through the event permitting process for private facilities and in public parks and other public locations.

3. Incentivize participation:

a. Utilize pay-as-you-throw strategies to financially incentivize residents to divert more recyclables.

4. Create demand for recyclables:

a. Work with State and Federal legislatures to establish higher recycled content requirements for manufacturers.

i. The most recent example of this type of legislation was passed last year in California. ${ }^{44} \mathrm{It}$ is the first of its kind in the U.S. The law requires all plastic bottles covered by the state's container redemption program to contain an average of at least $15 \%$ post-consumer resin (PCR) starting in 2022. The recycled-content mandate rises to $25 \%$ in 2025 and $50 \%$ in 2030. Beverage manufacturers that fail to meet the targets will be subject to penalty fees of 20 cents for each pound of PCR by which they fall short. The legislation also has important requirements that producers must report the amounts and types of recycled resin, including what meets the specification for bottle grade (this could be recycled back into bottles).

44 AB-793 Recycling: Plastic beverage containers: Minimum recycled content. California State Legislature (2019-2020)

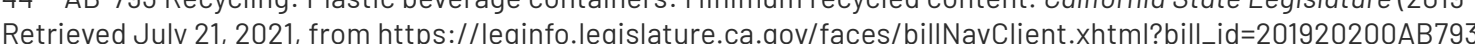

ii. Washington State recently passed a bill that requires minimum post-consumer recycled plastic by weight with $50 \%$ targets to achieve by 2031 for beverage containers, household cleaning products, and personal care products. ${ }^{45}$

b. Create local market development opportunities that drive post-consumer demand of truly recyclable commodities.

c. Require and increase post-consumer content in city and state purchasing guidelines.

5. Require products designed for recyclability to eliminate problematic labels, adhesives, colors, etc There are growing industry commitments to design packaging to be recyclable but this needs to be legislated to ensure compliance and level the playing field. The Association of Plastic Recyclers design standards should be followed and \#3 PVC, \#4 LDPE, \#6 PS, and \#7 other plastic should be eliminated from the system. ${ }^{4}$

\section{FIGURE 11}

\section{Strategies for legitimate recycling}

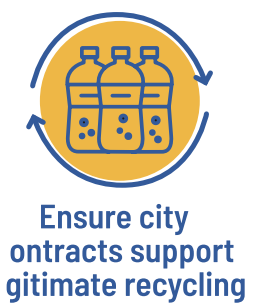

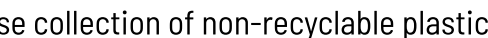

$\checkmark$ Strengthen community outreac

gitimate recycling

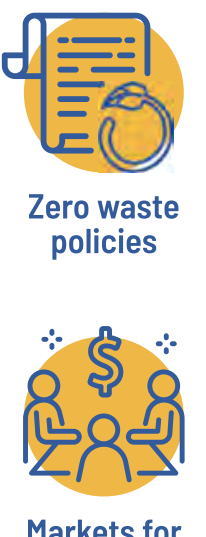

$\checkmark$ Phase out non-recyclable plastic and support redesign

Reject false solutions ("waste-to-energy" and "plastic-to-fuel")

$\checkmark$ Expand bottle bills

\section{Mandete minimum recucled content}

Create economic/local market development opportunities

Doun Moon/GAIA 45 SB 5022 Concerning the management of certain materials to support recycling and waste and litter
reduction. Washington State Legislature (2021-2022). Retrieved July 21, 2021, from https://app.leg.wa.gov/ reduction. Washington State Legislature (2021-2022). Retrie
billsummary?BillNumber=5022\&lnitiative=false\&Year=2021.

46 APR Design ${ }^{\circledR}$ Guide (n.d.). The Association of Plastics Recyclers. Retrieved July 21, 2021, from https://plasticsrecycling.org/

apr-design-guide 


\section{STRATEGY 3: MAKE POLLUTERS PAY}

Federal policy, through the Resource Recovery and Conservation Act, places the burden of regulating waste management squarely on states. Many states have decentralized waste management resulting in a myriad of city and county level waste management programs, the health and monetary costs of which are borne by taxpayers and municipal governments. Furthermore, reduction is the least studied incentivized, implemented, and resourced strategy. Current prevention strategies often focus on what the "consumer" can achieve or lay the primary responsibility of waste management on consumers. The everyday items that we all need are packaged and priced by the manufacturers leaving consumers with few options to select better or no packaging.

According to the Container Recycling Institute, PET bottle recycling increased on average by approximately $40 \%$ in states with this legislation. Bottle redemption programs are also popular with the public and incentivize participation. A recent poll by Eunomia and the Ball Corporation found that $84 \%$ of Americans support a national bottle redemption program. ${ }^{47}$ Both Long Beach and Detroit are in states that have adopted beverage container deposit legislation. Detroit's recycling program is just in its beginning stages so currently the majority of the containers recovered are attributable to the legislation. In Long Beach, the plastic recycling rate reflects the positive impact of the beverage container deposit legislation. While the Minneapolis area has a similar recycling rate, the overall numbers do not include multifamily and commercial recycling.

The investments required to shift towards zero waste systems will cost billions of dollars, but the cause of much of the unnecessary waste, such as single-use plastic, should be the responsibility of the manufacturers of the products.

1. Container deposit laws can be structured to fund collection. These policies motivate the public to return used containers, result in higher recycling rates, and give distributors/bottlers a clear role ${ }^{40}$

2. Extended producer responsibility (EPR) is a policy principle to improve the environmental and social performance of products by extending the responsibility of producers over the entire life cycle of items. EPR policies cover specific categories of materials, and should lead to producers redesigning items or delivery systems to limit the generation and toxicity of waste, and to close the materials feedback loop from cities to producers. Policies should help improve the systems in which they will operate. In this regard, it is important to distinguish between giving producers financial responsibility (which would allow any current recycling systems to continue with added financial support) and giving producers management responsibility (which has a high risk of replacing any public systems and removing or limiting community input into programs, standards, local employment, etc). EPR is not a panacea, and safeguards are necessary. Policies need strong requirements to redesign, reduce, reuse, and recycle collected materials instead of continuing

47 The 50 States of Recycling: A State-by-State Assessment of Containers and Packaging Recycling Rates (2021). Eunomia. https://www.eunomia.co.uk/measuring-packaging-recycling-rates-across-the-us/

48 Real Circularity (nd) Ball. Retrieved July 21, 2021, from https//www ball.com/realcircularity unsustainable waste disposal. To ensure accountability, policies need transparency, public oversight, enforcement, and triggers for additional policies if a system does not achieve targets.

3. States should require packaging manufacturers to pay for regular municipal solid waste composition analysis through fees on the packaging they sell in that state. Another approach could be to tax the gross revenues of the major disposal facilities and have a portion of those funds earmarked for waste composition reports and the remaining go to community-based waste reduction efforts. Minnesota introduced legislation that includes this type of funding mechanism in their 2021 legislative session. ${ }^{49}$

4. Require that the recycling arrows be removed from all plastic packaging and products and enforce new standards in labeling so only materials that are actually recyclable are labeled as such. Oregon provides a model with this legislation..$^{50}$
49 House Bill 1734. Minnesota State Legislature (2021-2022). Retrieved July 21, 2021, from https://legiscan.com/MN/bill/ HF1734/202

Senate Bill 581. Oregon State Legislature (2021). Retrieved July 21, 2021, from https://legiscan.com/OR/text/SB581/ 


\section{APPENDIX I}

\section{TERMINOLOGY}

\#1-7 Resin Identification Code (RIC) - The number that can be on the bottom of some plastic packaging. Because it is surrounded by recycling arrows most people think that it means that it can be recycled but that is not true. Very little of the plastic packaging with the code and arrows could be recycled.

\#1 PET: Polyethylene Terephthalate (for example : soda and water bottles and clamshells)

\#2 HDPE: High Density Polyethylene (for example: milk jugs, shampoo, and laundry detergent bottles) \#3 PVC: Vinyl/Polyvinyl Chloride (for example: some cleaning product bottles, squeeze bottles, and plastic film wrap that clings)

\#4 LDPE: Low Density Polyethylene (for example: some shopping bags, bread bags, frozen food bags, and some films.)

\#5 PP: Polypropylene (for example: margarine and yogurt tubs, their lids, and some straws.)

\#6 PS: Polystyrene (for example: CD cases, disposable cutlery and when it is foamed it can be clamshells and other to go foam containers.)

\#7 OTHER: Any other resins (for example: could be anything, could be a combination of plastics, and it can include bioplastics - which is often confused with compostability

Bottle Deposits and Redemption - When a retailer buys beverages from a distributor, a deposit is paid to the distributor for each container purchased. The consumer pays the deposit to the retailer when buying the beverage, and receives a refund when the empty container is returned to a supermarket or other redemption center. The distributor then reimburses the retailer or redemption center the deposit amount for each container, plus an additional handling fee in most states. Unredeemed deposits are either returned to the state, retained by distributors, or used for program administration.

Chemical Recycling - A term created by the plastic industry that groups various plastic-to-fuel and plastic-to-plastic technologies. These processes reduce the plastic/polymer chain to constituent components, monomers and raw materials through chemical processes such as cracking, gasification or depolymerization. The end result can either be a fuel to be burnt or have the potential to be turned into new plastic for products and packaging. By grouping these technologies together with their vastly different outcomes, it can easily confuse people into thinking that this means it is always recycled into new plastic when this is not the case.

Circularity or Circular Economy - An alternative to a linear approach in which resources are extracted used (often once) and discarded in a way that destroys the potential for becoming an input into the

process again. Circular implies that the source of the material input no longer relies on extraction but is derived from the discard. But the challenge when using or reading this term is that some include false solutions like burning waste and others as acceptable. For example, burning waste destroys the discard and further extraction of natural resources is required to make new materials and products.

End Use of Recyclables - The resulting product that is made from the recycled material.

Extended Producer Responsibility (EPR) - A policy principle to improve the environmental and social performance of products by extending the responsibility of producers over the entire life cycle of items. EPR policies cover specific categories of materials, and should lead to producers redesigning items or delivery systems to limit the generation and toxicity of waste, and to close the materials feedback loop from cities to producers.

End Market - The final step in the chain of recyclable ownership. Generally it is a manufacturer of a product that uses recycled content as an input. In the case of plastics, wash/grind operations are often referred to as end markets. They process the resin and sell to manufacturers to use as recycled feedstock.

Highest and Best Use of Recyclables - Recycled materials can be used in a variety of end uses. Using glass as an example, many believe that recycling bottle glass back into a glass bottle is the highest and best use (often called closed-loop) since it offsets the need for mining new material and dramatically lowers the energy required to make a bottle. There is no agreed to standard of what is the highest and best use of a recycled product.

Incineration - The destruction of materials by burning.

Pay-As-You-Throw - A Pay-As-You-Throw system allows residents to dispose of their source-separated recyclable and organic waste for free, and only charges them for landfill and incineration-bound waste.

Plastic-to-fuel - Any process including but not limited to incineration, pyrolysis, solvolysis or depolymerization are variations of this process in which plastic is ultimately burned.

Plastic Stream - The complete flow of plastic collected for recycling from its source through to recycling or final disposal in landfill or incinerators and other disposal methods. 
Post-Consumer Recycled Content - This differentiates the recycled content in a product or packaging If the content is derived from materials after the consumer has discarded the item (for example, a bottle or newspaper), it is post-consumer. If, for example, it is scrap collected off the floor at a manufacturing facility and put back into the product it is Pre-Consumer Recycled Content. A lot of products or

packaging do not differentiate the two "contents" and might simply claim $100 \%$ recycled content, so the consumer can be confused as to the source and environmental impact.

Material Recovery Facility (MRF) - A facility designed to sort recyclables by type, for example, newspaper, cardboard, plastic, aluminum, and steel cans and further process the material (ex., by cleaning, compressing, and baling) to meet specifications for sale to end markets.

Municipal Solid Waste (MSW) - (Commonly called trash) consists of everyday items such as product packaging, yard trimmings, furniture, clothing, bottles and cans, food, newspapers, appliances, electronics and batteries. Sources of MSW include residential waste and waste from commercial and institutional locations, such as businesses, schools and hospitals. MSW does not include industrial, hazardous, construction and demolition (C\&D) or other kinds of waste. This report focuses on the portion of the MSW that is collected through city programs and redemption programs from residents and businesses.

Recycling Stream - The complete flow of material collected for recycling from its source through to recycling or final disposal in landfill or incinerators and other disposal methods.

Residual - The percentage that the MRF reports of the material that was sent to the MRF that could not be recycled either because it was (i) erroneously put in the recycling bin or cart, or (ii) the inefficiencies of the MRF resulted in it not being captured, or (iii) the processing itself damaged the item so that it was no longer recyclable. Some residual ends up as waste disposed of at the MRF, while other residual is missorted into the wrong commodities and sent to the wrong market, where it is generally disposed of there.

Single-Stream Recycling - A collection and/or processing system in which all recyclables, for example newspaper, cardboard, plastic, aluminum, and steel cans are placed in a single bin or cart for recycling collection. Single-stream recyclables are taken to a MRF for sorting by type of material and further processed to meet specifications for sale to markets.

Waste-to-Energy - The destruction of materials by burning with some generation of electricity or hea (less than $1 \%$ of US energy). In comparison, recycling conserves 3-5 times more energy than waste-toenergy can generate.

Waste Composition - Provides data about what percentage each of the different components represent in the waste stream of a defined area/location. Categories can include very general categories like paper, plastic and metals or very detailed categories (for example, a breakdown of what types of food waste are thrown away - prepared foods, produce, etc.
Waste Stream - The complete flow of waste from its source through to composting, recycling or final disposal in landfill or incinerators and other disposal methods.

Zero Waste - GAIA adopted the Zero Waste International Alliance definition of Zero Waste: "Zero Wast is the conservation of all resources by means of responsible production, consumption, reuse, and recovery of products, packaging, and materials without burning, and with no discharges to land, water, or air that threaten the environment or human health."(ZWIA, 2018) 
APPENDIX \|

\section{METHODOLOGY AND SUMMARY OF DATA}

The following section describes the data and process used in evaluating municipal waste streams within the context of plastic and incineration for the participating cities. For each of the five participating cities, the best available data from city, county, and state sources, as well as existing characterization studies, was researched and compiled for analysis. For any missing data (either data that was publicly unavailable or data we determined to be reasonably inaccurate due to age or lack of detail), regional data was used as a proxy. In some cases, extrapolations were made to provide detail on data that was reported with less specificity. The model was used to establish key benchmarks and synthesize data in charts and graphs to tell the story of the state of waste from the perspective of each community, with an emphasis on the disposable plastic stream. The scope of this work is not intended to replace the need for each community to have a robust zero waste plan. Waste characterization/composition studies are a critical tool for identifying and prioritizing city strategies around diversion and reduction.

A. Scope of Data: The focus of this analysis was on plastic in municipal solid waste (MSW) streams. Construction and demolition, sewage sludge, and other industrial waste streams were not factored into the analysis. The specifics of the types of plastic included in the analysis were limited to the data available in the existing waste studies for the communities. It is estimated that between $18 \%$ and $25 \%$ of the plastic analyzed in the report included non-single use packaging. Many of the studies had a general catch-all category that included durable plastics (like toys, buckets, tubs, garden pots, utensils, etc.) with mixed plastic (\#3-7) container grades. Items that potentially are made from plastic and other materials, such as furniture, electronics, textiles are not included in this plastic analysis.

B. Generation Rate: The total amount, in metric tons, of municipal solid waste (MSW) delivered annually to landfills, incinerators, recycling facilities, or composting facilities was documented in each city studied. Where possible, the data was further broken down by residential or commercial sources of waste. The data is from 2017 to 2020 and typically comes directly from annual city, county or state reporting as detailed in the data sources document for each community.

C. Composition/Characterization: The composition of the waste stream and the composition of the recycling stream were documented by commodity with a focus on streams typically managed through municipal diversion programs (recycling and composting). The characterization studies used for each community for waste and recycling (typically two different studies or sources) are detailed in the data sources document. These studies are from 2013 to 2019 and some of them are specific to the community, while others were statewide or proxy communities that provided the best available match. For the two bottle bill states (Michigan and California), the statewide total weight of redeemed PET, HDPE, glass and aluminum bottles was used to proportionally add a representative amount to recycling totals that is attributable to the city (based on population of city and state). The methodology used to conduct the waste characterization studies varied for each community. The data used was selected so that within each community, the waste and recycling data were comparable to provide a relevant snapshot of current and potential diversion. However, the data is not always comparable between different communities.

Notes on plastic compositions used in study:

1. Type of plastic included in the analysis: Only sort categories listed in the studies that were exclusive to plastic were included and varied by each study as described in the city summaries in Appendix III.

2. \#5 Polypropylene is often included with mixed plastic in many of the waste characterization and recycling composition studies. For the purpose of the analysis in this report, the following sources were used to extrapolate the amount of \#5 PP included with mixed plastic:

a. For mixed plastic in the waste stream, an industry analysis that included composition of resins in the waste stream was used. ("A Data Visualization Tool Identifying Opportunities to Recapture plastic in the U.S. and Canada")

b. For mixed plastic in the recycling stream, estimates from More and Associates, cited in a 2018 industry article were used ( "Mixed Messages")

3. As this study focused on municipal solutions, only economically viable material currently acceptable in curbside municipal programs were included as recyclable. "Recyclable" plastic was defined for the purpose of this study analysis as \#1 PET, \#2 HDPE and \#5 PP. Two standards were used to determine the types of plastic delivered to a MRF that may actually get recycled:

a. The types of material that can be mechanically sorted by a typical MRF or plastic recycling facility (PRF). The predominance of MRFs only have technology capable of sorting bottles and containers. Film and flexible packaging pose processing issues and contaminate the sorting process in most facilities.

b. The availability of domestic U.S. markets (where the recycled plastic is made into new products). MRFs and PRFs sell the sorted material to markets. Commingled \#3\#7 plastic grade has $\$ 0$ or a negative market value (meaning the MRF must pay to get these materials to market). While some film and styrofoam grades have a positive (but significantly lower) market value, they were not included in this analysis as "recyclable" because they are not acceptable in most MRFs as they pose processing issues and contaminate the sorting systems. 
c. For all communities, \#1 PET, \#2 HDPE, and \#5 PP were included as "recyclable," as those grades are both recoverable in a MRF and have reasonable market value in U.S. domestic markets. All other \#3-\#7 plastic were considered non-recyclable in this analysis.

D. Summary of Data Collected for Each City: Tables 1-3 summarize the data collected from public sources used for this study. Long Beach, $\mathrm{CA}$, and Detroit, $\mathrm{Ml}$, are designated with an asterisk $\left({ }^{*}\right)$ to indicate these cities are located in states with statewide redemption programs.

Table 1: Residential and Commercial Annual Generation Rates. The total amount, in metric tons, of municipal solid waste (MSW) delivered annually to landfills, incinerators, recycling facilities, or composting facilities. Source data for each city is described in Part $\mathrm{F}$ below.

TABLE 1

Residential and Commercial Annual Generation Rates

\begin{tabular}{|l|c|c|c|c|c|c|}
\cline { 2 - 7 } \multicolumn{1}{c|}{} & Baltimore, MD & Minneapolis, MN & Newark, NJ & Long Beach, CA* & Detroit, M** \\
\cline { 2 - 7 } & $\begin{array}{c}\text { Total MSW } \\
\text { (primarily } \\
\text { residential) }\end{array}$ & $\begin{array}{c}\text { Total MSW } \\
\text { (residential and } \\
\text { some commercial) }\end{array}$ & $\begin{array}{c}\text { Total MSW } \\
\text { (residential, } \\
\text { commercial and } \\
\text { institutional) }\end{array}$ & $\begin{array}{c}\text { Total MSW } \\
\text { (primarily } \\
\text { residential) }\end{array}$ & $\begin{array}{c}\text { Total MSW } \\
\text { (residential, } \\
\text { commercial and } \\
\text { institutional) }\end{array}$ \\
\hline Population & 593,490 & 420,324 & 277,140 & 475,980 & 674,841 \\
\hline $\begin{array}{l}\text { \% Incinerated in city on } \\
\text { Average }\end{array}$ & $49 \%$ & $100 \%$ & $100 \%$ & $68 \%$ & $0 \%$ \\
\hline $\begin{array}{l}\text { Total Discards (Trash, } \\
\text { Recycling, Compost) }\end{array}$ & 348,400 & 130,720 & 236,388 & 223,101 & 333,454 \\
\hline $\begin{array}{l}\text { MSW DISPOSED (Landfill } \\
\text { and Incineration) }\end{array}$ & 319,450 & 80,396 & 181,883 & 180,129 & 305,385 \\
\hline MSW Incinerated & 156,950 & 80,396 & 181,883 & 123,047 & 0 \\
\hline MSW Landfilled & 162,500 & 0 & 0 & 57,081 & 305,385 \\
\hline Municipal Recycling & 26,650 & 25,362 & 46,870 & 32,587 & 5,433 \\
\hline $\begin{array}{l}\text { State Redemption } \\
\text { Program }\end{array}$ & 0 & 0 & 0 & 10,385 & 11,115 \\
\hline $\begin{array}{l}\text { Municipal Yard Waste and/ } \\
\text { or Food Waste Collection }\end{array}$ & 2,300 & 24,962 & 7,635 & NA & 11,521 \\
\hline
\end{tabular}

Table 2: Endpoint for MSW. The MSW collected for recycling, compost, or disposal as a percent of the sum of all streams. Recycling collection takes place through municipal collection, drop off programs, and the statewide redemption program. Compost only includes municipally collected yard waste. These numbers show the initial destination point, not the percentage of material actually diverted. For recycling, the end point of the collected material in this table is the MRF or the state redemption program where available.

TABLE 2

\section{Endpoint for MSW}

\begin{tabular}{|l|c|c|c|c|c|}
\cline { 2 - 7 } \multicolumn{1}{c|}{} & Baltimore, MD & Minneapolis, MN & Newark, NJ & Long Beach, CA* & Detroit, MI* \\
\cline { 2 - 7 } & $\begin{array}{c}\text { Total MSW } \\
\text { (primarily } \\
\text { residential) }\end{array}$ & $\begin{array}{c}\text { Total MSW } \\
\text { (residential and } \\
\text { some commercial) }\end{array}$ & $\begin{array}{c}\text { Total MSW } \\
\text { (residential, } \\
\text { commercial and } \\
\text { institutional) }\end{array}$ & $\begin{array}{c}\text { Total MSW } \\
\text { (primarily } \\
\text { residential) }\end{array}$ & $\begin{array}{c}\text { Total MSW } \\
\text { (residential, } \\
\text { commercial and } \\
\text { institutional) }\end{array}$ \\
\hline Landfill or Incinerator & $91.7 \%$ & $61.5 \%$ & $76.9 \%$ & $80.7 \%$ & $91.6 \%$ \\
\hline Recycling & $7.6 \%$ & $19.4 \%$ & $19.8 \%$ & $19.3 \%$ & $5.0 \%$ \\
\hline Compost (yard waste) & $0.7 \%$ & $19.1 \%$ & $3.2 \%$ & NA & $3.5 \%$ \\
\hline
\end{tabular}


Table 3: Where Residents and Businesses Discard Plastic. The percentage of all plastic discarded in the city that is currently collected for recycling (but not necessarily recycled, see below) through municipa recycling programs (curbside and drop-off) state redemption programs, or disposed of with trash sent directly to landfills and/or incinerators. Total plastic incinerated or landfilled is based on \% MSW that is incinerated in each city as described in Table 1 .

TABLE 3

Where Residents and Businesses Discard Plastic

\begin{tabular}{|c|c|c|c|c|c|}
\hline & Baltimore, MD & Minneapolis, MN & Newark, NJ & Long Beach, CA* & Detroit, MI* \\
\hline & \multicolumn{5}{|c|}{ Plastic Disposal (metric tons/year) } \\
\hline $\begin{array}{l}\text { Total Plastic Stream } \\
\text { (Discarded and Recycled) }\end{array}$ & 70,300 & 12,968 & 32,470 & 24,375 & 47,712 \\
\hline $\begin{array}{l}\text { Total Plastic Disposed } \\
\text { (Landfill and Incineration) }\end{array}$ & 67,850 & 11,336 & 28,955 & 18,535 & 44,861 \\
\hline Total Plastic Incinerated & 33,336 & 11,336 & 28,955 & 12,661 & 0 \\
\hline \multirow[t]{2}{*}{ Total Plastic Landfilled } & 34,514 & 0 & 0 & 5,874 & 44,861 \\
\hline & \multicolumn{5}{|c|}{ Plastic Recycling (metric tons/year) } \\
\hline $\begin{array}{l}\text { Plastic Recycled Through } \\
\text { State Redemption } \\
\text { Program }\end{array}$ & NA & NA & NA & 2,497 & 2,052 \\
\hline $\begin{array}{l}\text { Plastic Recycled in Single- } \\
\text { stream }\end{array}$ & 2,450 & 1,632 & 3,515 & 3,343 & 799 \\
\hline \multirow{2}{*}{ Total Plastic Recycled } & 2,450 & 1,632 & 3,515 & 5,840 & 2,851 \\
\hline & \multicolumn{5}{|c|}{ Plastic Recycling (metric tons/year) } \\
\hline Landfilled & $49.1 \%$ & $0.0 \%$ & $0.0 \%$ & $24.1 \%$ & $94.0 \%$ \\
\hline Incinerated & $47.4 \%$ & $87.4 \%$ & $89.2 \%$ & $51.9 \%$ & $0.0 \%$ \\
\hline Plastic Sent to MRF & $3.5 \%$ & $12.6 \%$ & $10.8 \%$ & $13.7 \%$ & $1.7 \%$ \\
\hline Redemption Centers & NA & NA & NA & $10.2 \%$ & $4.3 \%$ \\
\hline
\end{tabular}

E. Analysis of City Data: The tables that follow summarize the results of analysis conducted on waste characterization data collected using the publicly available sources cited in Part F below and as summarized in Tables 1-3 above. The calculations applied the definition of recyclable in this report as"\#1 PET, \#2 HDPE, and \#5 PP plastic with viable end markets for the MRF or municipality to purchase the plastic," and as described in detail in Parts A - C. Long Beach, CA, and Detroit, MI are designated with an asterisk $\left({ }^{*}\right)$ to indicate these cities are located in states with statewide redemption programs.

Table 4A \& 4B: Ultimate Fate of Plastic. Tables 4A and 4B show the recyclability of plastic in the disposal and recycling stream in tons/year and as a percentage of the total plastic included in the analysis for this study (including trash and recycling). "Plastic Film in Trash" is included in the "NonRecyclable Plastic in Trash" for the City of Baltimore in the City of Baltimore Master Plan. The Average Recyclable Plastic in Redemption System only includes Long Beach and Detroit.

TABLE 4A

Ultimate Fate of Plastic (tons/year)

\begin{tabular}{|c|c|c|c|c|c|}
\hline & Baltimore, MD & Minneapolis, MN & Newark, NJ & Long Beach, $\mathrm{CA}^{*}$ & Detroit, MI* \\
\hline & \multicolumn{5}{|c|}{ How Much Plastic is Non-Recyclable? } \\
\hline $\begin{array}{l}\text { Non-Recyclable Plastic in } \\
\text { Trash }\end{array}$ & 20,319 & 3,752 & 7,371 & 6,380 & 21,775 \\
\hline $\begin{array}{l}\text { Non-Recyclable Plastic in } \\
\text { Single-stream }\end{array}$ & 962 & 189 & 693 & 1,838 & 196 \\
\hline Plastic Film in Trash & 26,011 & 4,663 & 11,820 & 6,485 & 9,742 \\
\hline \multirow[t]{2}{*}{ Total Non-Recyclable } & 47,292 & 8,604 & 19,884 & 14,703 & 31,713 \\
\hline & \multicolumn{5}{|c|}{ How Much Plastic is Potentially Recyclable? } \\
\hline Recyclable Plastic in Trash & 21,521 & 2,921 & 9,764 & 5,670 & 13,344 \\
\hline $\begin{array}{l}\text { Recyclable Plastic in } \\
\text { Single-stream }\end{array}$ & 1,488 & 1,443 & 2,822 & 1,505 & 603 \\
\hline $\begin{array}{l}\text { Recyclable Plastic in } \\
\text { Redemption System }\end{array}$ & NA & NA & NA & 2,497 & 2,052 \\
\hline $\begin{array}{l}\text { Maximum Potential of } \\
\text { Recyclable Plastic }\end{array}$ & 23,009 & 4,364 & 12,586 & 9,672 & 16,000 \\
\hline Total Plastic Stream & 70,301 & 12,968 & 32,470 & 24,375 & 47,713 \\
\hline
\end{tabular}


Table 4B: Further estimates the total recyclable plastic for each city based on the amount of plastic that is potentially recyclable as defined in this analysis and provides averages across the five cities.

TABLE 4B

Ultimate Fate of Plastic (by percent)

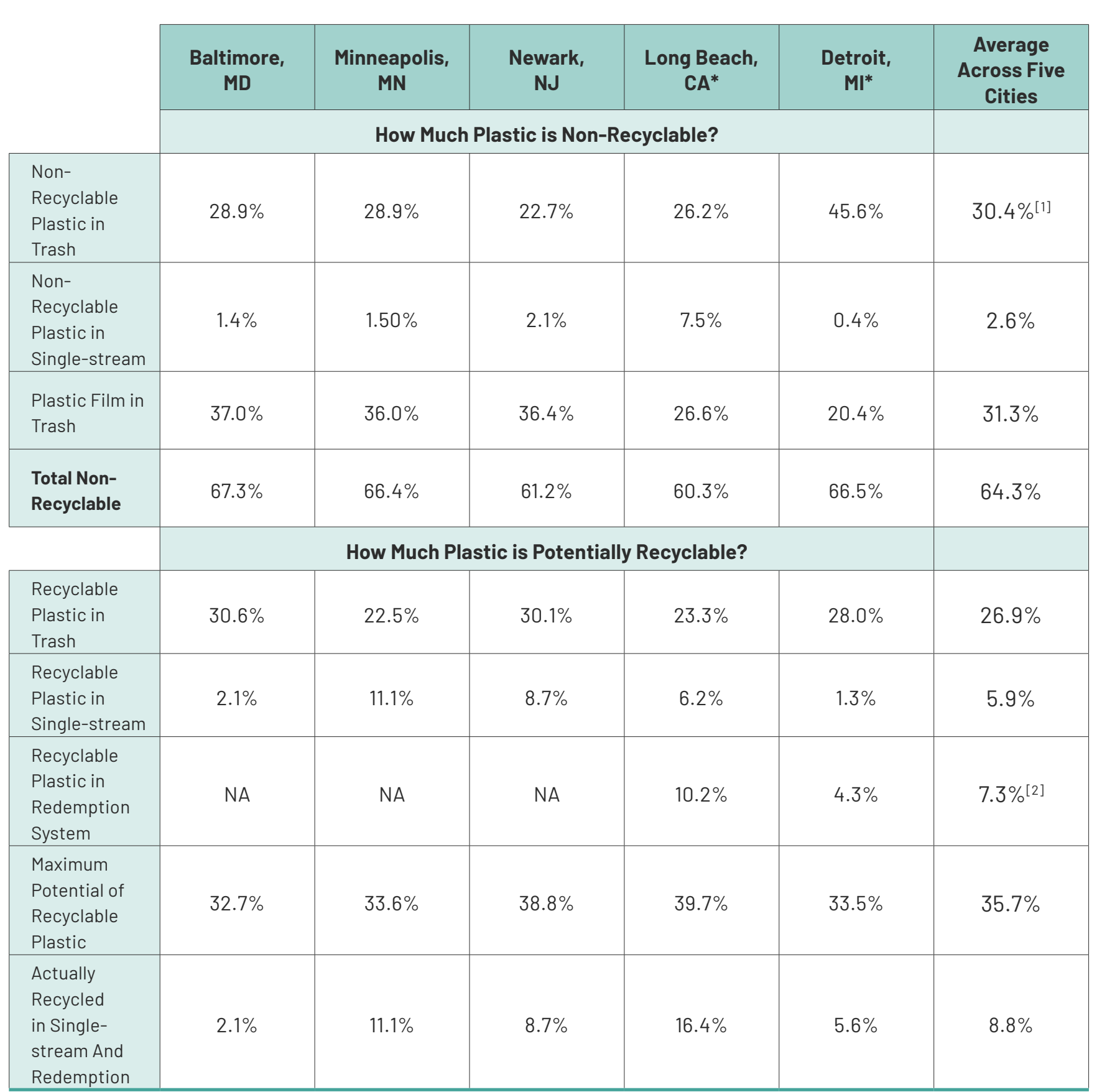

[1] The "Average Across Five Cities" assumes an extrapolation for plastic film in trash and non-recyclable plastic in the trash for the City of Baltimore.

[2] Recyclable Plastic in Redemption System is an average across only cities with statewide redemption programs. The five city average for redemption systems is $2.9 \%$
Table 5: Residential Capture Rates by Commodity. The capture rate shows the percentage of material collected through municipal recycling and deposit as a percentage of the total amount of that material in trash, recycling and deposit systems.

TABLE 5

Residential Capture Rates by Commodity

\begin{tabular}{|c|c|c|c|c|c|}
\hline & Baltimore, MD & Minneapolis, MN & Newark, NJ & Long Beach, $\mathrm{CA}^{*}$ & Detroit, MI* \\
\hline $\begin{array}{l}\text { Recyclable Plastic In } \\
\text { Trash }\end{array}$ & 21,521 & 2,921 & 9,764 & 5,670 & 13,344 \\
\hline $\begin{array}{l}\text { Recyclable Plastic } \\
\text { Recycled and Redemption }\end{array}$ & 1,488 & 1,443 & 2,822 & 4,002 & 2,655 \\
\hline Total Plastic Stream & 23,009 & 4,364 & 12,586 & 9,672 & 15,999 \\
\hline 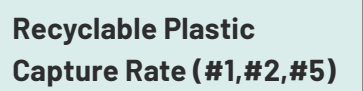 & $6.5 \%$ & $33.1 \%$ & $22.4 \%$ & $41.4 \%$ & $16.6 \%$ \\
\hline Glass in Trash & 9,350 & 1,286 & 4,274 & 3,602 & 8,306 \\
\hline $\begin{array}{l}\text { Glass in Recycling or } \\
\text { Redemption }\end{array}$ & 1,750 & 6,635 & 6,843 & 13,152 & 7,538 \\
\hline Total Glass Stream & 11,100 & 7,921 & 11,117 & 16,754 & 15,844 \\
\hline $\begin{array}{l}\text { Glass } \\
\text { Capture Rate }\end{array}$ & $15.8 \%$ & $83.8 \%$ & $61.6 \%$ & $78.5 \%$ & $47.6 \%$ \\
\hline Aluminum in Trash & 4,000 & 563 & 1,755 & 360 & 1,344 \\
\hline $\begin{array}{l}\text { Aluminum in Recycling or } \\
\text { Redemption }\end{array}$ & 300 & 421 & 366 & 1,786 & 2,323 \\
\hline Total Aluminum Stream & 4,300 & 984 & 2,121 & 2,146 & 3,667 \\
\hline $\begin{array}{l}\text { Aluminum } \\
\text { Capture Rate }^{[1]}\end{array}$ & $7.0 \%$ & $42.8 \%$ & $17.2 \%$ & $83.2 \%$ & $63.4 \%$ \\
\hline Steel in Trash & 7,650 & 482 & 1,810 & 1,441 & 1,344 \\
\hline $\begin{array}{l}\text { Steel in Recycling or } \\
\text { Redemption }\end{array}$ & 450 & 406 & 1,186 & 652 & 103 \\
\hline Total Steel Stream & 8,100 & 888 & 2,996 & 2,093 & 1,447 \\
\hline Steel Capture Rate & $5.6 \%$ & $45.7 \%$ & $39.6 \%$ & $31.1 \%$ & $7.1 \%$ \\
\hline
\end{tabular}

[1] Aluminum is often captured outside of municipal systems. This figure is likely higher. 
Table 6: Average Composition from Single-Stream Residential Collection Programs. This shows the composition of residential recycling based on reporting from the source cited in the communities data summary table.

TABLE 6

\section{Average Composition from Single-Stream Residential Collection Programs}

\begin{tabular}{|c|c|c|c|c|c|}
\hline & Baltimore, MD & Minneapolis, MN & Newark, NJ & Long Beach, $\mathrm{CA}^{*}$ & Detroit, MI* \\
\hline Metal & $2.3 \%$ & $3.3 \%$ & $3.3 \%$ & $3.5 \%$ & $3.0 \%$ \\
\hline Glass & $5.3 \%$ & $26.1 \%$ & $14.6 \%$ & $20.6 \%$ & $14.3 \%$ \\
\hline Paper & $65.1 \%$ & $57.6 \%$ & $60.8 \%$ & $47.7 \%$ & $42.7 \%$ \\
\hline $\begin{array}{l}\text { Plastic (\#1,\#2,\#5): Likely } \\
\text { Recycled }\end{array}$ & $4.5 \%$ & $5.7 \%$ & $6.0 \%$ & $4.6 \%$ & $11.1 \%$ \\
\hline $\begin{array}{l}\text { Plastic (\#3,\#4,\#6,\#7): } \\
\text { Likely Disposed }\end{array}$ & $2.9 \%$ & $0.70 \%$ & $1.5 \%$ & $5.6 \%$ & $3.6 \%$ \\
\hline Residual & $20.0 \%$ & $6.7 \%$ & $13.8 \%$ & $18.0 \%$ & $25.3 \%$ \\
\hline $\begin{array}{l}\text { Notes on Plastic Non- } \\
\text { Packaging Inclusion in } \\
\text { Recycling Composition }\end{array}$ & [1] & [2] & [3] & [4] & [5] \\
\hline
\end{tabular}

[1] The recycling characterization study reported a "mixed plastic" category that included film and other non-recyclable plastic with estimates of \#5 PP removed.

[2] Since the MRF does not ship \#3-\#7 plastic to a PRF, the MRF provided facility wide estimates of \% of non-recyclable bottles in residual.

[3] The recycling composition report included a category of \#3-\#7 mixed plastic which included film and other non-recyclable plastic with estimates of \#5 PP removed.

[4] The recycling composition reporting included a category labeled "mixed plastic" which included film and other non-recyclable plastic with estimates of \#5 PP removed.

[5] The recycling composition study included a more detailed sort of film and non-recyclable plastic grades (\#6 PS cups and clamshells, other plastic).

Table 7: What's Left After Diversion. This shows the composition of MSW disposed in landfills or incinerators based on reporting from the source cited in the communities data summary table.
TABLE 7

What's Left After Diversion

\begin{tabular}{|c|c|c|c|c|c|}
\hline & Baltimore, MD & Minneapolis, MN & Newark, NJ & Long Beach, $\mathrm{CA}^{*}$ & Detroit, $\mathrm{Ml}^{*}$ \\
\hline & \multicolumn{5}{|c|}{ Plastic Disposal (metric tons/year) } \\
\hline Food Waste & $20.5 \%$ & $15.0 \%$ & $24.8 \%$ & $20.5 \%$ & $16.9 \%$ \\
\hline Yard Waste & $11.3 \%$ & $14.1 \%$ & $6.0 \%$ & $19.0 \%$ & $22.0 \%$ \\
\hline Metal & $3.6 \%$ & $3.7 \%$ & $3.5 \%$ & $3.2 \%$ & $3.0 \%$ \\
\hline Glass & $2.9 \%$ & $1.6 \%$ & $2.3 \%$ & $1.9 \%$ & $2.7 \%$ \\
\hline Paper & $13.6 \%$ & $10.8 \%$ & $21.3 \%$ & $10.8 \%$ & $20.1 \%$ \\
\hline $\begin{array}{l}\text { Plastic: Potentially } \\
\text { Recyclable }\end{array}$ & $6.7 \%$ & $3.6 \%$ & $5.4 \%$ & $3.1 \%$ & $4.4 \%$ \\
\hline Plastic: Non-recyclable & $14.5 \%$ & $4.7 \%$ & $4.1 \%$ & $3.7 \%$ & $7.1 \%$ \\
\hline Plastic Film & $\begin{array}{c}\text { Included in } \\
\text { non-recyclable } \\
\text { plastic } \\
(\# 3, \# 4, \# 6, \# 7) \\
\text { above }\end{array}$ & $5.8 \%$ & $6.5 \%$ & $4.1 \%$ & $3.2 \%$ \\
\hline Remaining Garbage & $26.9 \%$ & $40.6 \%$ & $26.0 \%$ & $33.7 \%$ & $20.6 \%$ \\
\hline $\begin{array}{l}\text { Notes on Plastic Non- } \\
\text { Packaging Inclusion in } \\
\text { Waste Composition n }\end{array}$ & [1] & [2] & [3] & [4] & [5] \\
\hline
\end{tabular}

[1] Not well defined, likely some included in what was labeled as "other plastic category" in referenced waste characterization study (roughly $4 \%$ of total waste stream. $18 \%$ of plastic stream in waste).

2] Waste Characterization study included "durable plastic" and the "Non-Recyclable Plastic" categories, which included 10 subcategories: Kitchen; Tableware; Home décor; Home storage; Home improvement; Patio \& Garden; Automotive; Toys; Sports, itness and outdoors; and Other/Unknown. This stream totaled $2.7 \%$ of total waste stream or about $20 \%$ of plastic stream in waste.

3] The Waste Characterization study included an "other plastic" category that included items like hard plastic toys and yogurt cups. About $4 \%$ of total waste stream after PP adjustment or $25 \%$ of plastic stream in waste.

[4] The Waste Characterization study included a category defined as durable plastic and composite plastic. Total of $2.4 \%$ of waste stream after \#5 PP adjustment or $23 \%$ of plastic stream in waste.

[5] The waste characterization study included a sort for plastic labeled with \#3, \#4, \#5 or \#7 plastic, excluding packaging. This accounted for $3.14 \%$ of total waste stream or about $21 \%$ of total plastic stream in waste. 
F. Data Sources by Category:

\begin{tabular}{|c|c|c|c|}
\hline \multicolumn{4}{|c|}{$\begin{array}{l}\text { MSW RECYCLED (Tons) } \\
\text { DATA SET SOURCES AND NOTES }\end{array}$} \\
\hline City & Year & Source & Notes \\
\hline Baltimore, MD & 2017 & $\begin{array}{l}\text { City of Baltimore Master Plan, } \\
\text { Task } 5 \text { Report: } 2017 \text { MDE MRA } \\
\text { report, the } 2017 \text { Baltimore City } \\
\text { MRA Report, the } 2017 \text { BRESCO } \\
\text { tonnage report, the } 2017 \text { NWTS } \\
\text { tonnage report, the } 2017 \text { ORL } \\
\text { tonnage report, and the } 2017 \\
\text { Small Hauler Report. }\end{array}$ & $\begin{array}{l}\text { Residential and Commercial//Institutional } \\
\text { Data were both evaluated separately and } \\
\text { together. Residential waste is collected by DPW, } \\
\text { which includes some waste from Downtown } \\
\text { businesses and City Government buildings. } \\
\text { However, this also includes mixed waste } \\
\text { delivered to ORL by DPW and the Department } \\
\text { of Transportation as well as some mixed waste } \\
\text { loads delivered to ORL by private haulers. }\end{array}$ \\
\hline Long Beach, CA & 2020 & $\begin{array}{l}\text { Provided by the City of Long } \\
\text { Beach on Feb. } 23 \text { rd, } 2021 \text { via } \\
\text { email. }\end{array}$ & $\begin{array}{l}\text { Extrapolated commercial recycling rate using } \\
\text { CalRecycle data and used } 2020 \mathrm{MSW} \text { figure } \\
\text { from City of Long Beach Website. }\end{array}$ \\
\hline Newark, NJ & 2017 & Nu State Municipal Disposal Rates & $\begin{array}{l}\text { MSW recycled includes all paper and beverage } \\
\text { containers, anti-freeze, motor oil, brush, grass, } \\
\text { leaves, consumer electronics, food waste, dry } \\
\text { cell batteries, other glass, other plastic and } \\
\text { textiles when they are generated by a non- } \\
\text { industrial generator. } 10 \% \text { of total metal has been } \\
\text { included as non-industrial. Street sweepings } \\
\text { are no longer counted as recyclable due to their } \\
\text { management as a BUD (NJAC 7:26A-1.3). }\end{array}$ \\
\hline Minneapolis, MN & 2019 & $\begin{array}{l}\text { City of Minneapolis, Division of } \\
\text { Solid Waste and Recycling, } 2020 \\
\text { Factsheet. }\end{array}$ & $\begin{array}{l}\text { Residential MSW Only: Minneapolis Solid Waste } \\
\text { \& Recycling provides service to all residential } \\
\text { buildings containing fewer than four dwelling } \\
\text { units, some townhomes and a small number } \\
\text { of larger buildings, parks, commercial and } \\
\text { municipal properties. All residential customers } \\
\text { are required to have garbage collection, but } \\
\text { are not required to participate in the City's free } \\
\text { recycling services. }\end{array}$ \\
\hline Detroit, MI & 2018 & $\begin{array}{l}\text { Data provided by Natalie Jakub at } \\
\text { Green Living Science. }\end{array}$ & $\begin{array}{l}\text { Data matched figures published in } 2015 \text { Wayne } \\
\text { County Report (as cited in "Report No. CSS17- } \\
09 \text { April 18, } 2017 \text { Opportunities for Sustainable } \\
\text { Materials Management and Zero Waste in } \\
\text { Detroit." Reema Abi-Akar, Gabriel Jones, and Yi } \\
\text { Tang) }\end{array}$ \\
\hline
\end{tabular}

\begin{tabular}{|c|c|c|c|}
\hline \multicolumn{4}{|c|}{$\begin{array}{l}\text { MMSW DISPOSED COMPOSITION } \\
\text { DATA SET SOURCES AND NOTES }\end{array}$} \\
\hline City & Year & Source & Notes \\
\hline Baltimore, MD & 2019 & $\begin{array}{l}\text { City of Baltimore Master Plan, } \\
\text { Task } 5 \text { Report: } 2017 \text { MDE MRA } \\
\text { report, the } 2017 \text { Baltimore City } \\
\text { MRA Report, the } 2017 \text { BRESCO } \\
\text { tonnage report, the } 2017 \text { NWTS } \\
\text { tonnage report, the } 2017 \text { ORL } \\
\text { tonnage report, and the } 2017 \\
\text { Small Hauler Report. }\end{array}$ & $\begin{array}{l}\text { Detailed recent waste sorts, as well as analysis } \\
\text { of actual commodities disposed by Geosyntec. }\end{array}$ \\
\hline Long Beach, CA & 2014 & $\begin{array}{l}\text { CalRecycle Waste Stream } \\
\text { Measurement and Analysis }\end{array}$ & $\begin{array}{l}\text { Extrapolated PP from Mixed Plastic category in } \\
\text { waste stream using "A Data Visualization Tool } \\
\text { Identifying Opportunities to Recapture Plastic } \\
\text { in the US \& Canada" (PP } 13 \% \text { of total plastic } \\
\text { stream). }\end{array}$ \\
\hline Newark, NJ & 2013 & $\begin{array}{l}\text { Report for Mercer County } \\
\text { Improvement Authority } \\
\text { Solid Waste and Recycling } \\
\text { Quantification and } \\
\text { Characterization Study }\end{array}$ & $\begin{array}{l}\text { Extrapolated PP from Mixed Plastic category in } \\
\text { waste stream using "A Data Visualization Tool } \\
\text { Identifying Opportunities to Recapture Plastic } \\
\text { in the US \& Canada" (PP 13\% of total plastic } \\
\text { stream). }\end{array}$ \\
\hline Minneapolis, MN & 2019 & $\begin{array}{l}2016 \text { Minneapolis Residential Solid } \\
\text { Waste Composition Analysis and } \\
\text { Recycling Program Evaluation }\end{array}$ & $\begin{array}{l}\text { Extrapolated PP from Mixed Plastic category in } \\
\text { waste stream using "A Data Visualization Tool } \\
\text { Identifying Opportunities to Recapture Plastic } \\
\text { in the US \& Canada" (PP 13\% of total plastic } \\
\text { stream). }\end{array}$ \\
\hline Detroit, MI & 2016 & $\begin{array}{l}\text { Economic Impact Potential and } \\
\text { Characterization of Municipal } \\
\text { Solid Waste in Michigan }\end{array}$ & $\begin{array}{l}\text { Used Statewide figures because there are no } \\
\text { Detroit-specific characterizations. Extrapolated } \\
\text { PP from Mixed Plastic category in waste stream } \\
\text { using "A Data Visualization Tool Identifying } \\
\text { Opportunities to Recapture Plastic in the US \& } \\
\text { Canada" (PP 13\% of total plastic stream) }\end{array}$ \\
\hline
\end{tabular}




\begin{tabular}{|c|c|c|c|}
\hline \multicolumn{4}{|c|}{$\begin{array}{l}\text { MSW RECYCLED COMPOSITION } \\
\text { DATA SET SOURCES AND NOTES }\end{array}$} \\
\hline City & Year & Source & Notes \\
\hline Baltimore, MD & 2019 & $\begin{array}{l}\text { City of Baltimore Master Plan, } \\
\text { Task } 5 \text { Report: } 2017 \text { MDE MRA } \\
\text { report, the } 2017 \text { Baltimore City } \\
\text { MRA Report, the 2017 BRESCO } \\
\text { tonnage report, the } 2017 \text { NWTS } \\
\text { tonnage report, the } 2017 \text { ORL } \\
\text { tonnage report, and the 2017 } \\
\text { Small Hauler Report }\end{array}$ & $\begin{array}{l}\text { Detailed recent waste sorts, as well as analysis } \\
\text { of actual commodities disposed by Geosyntec. } \\
\text { Extrapolated PP in Mixed Plastic recycling } \\
\text { stream using citation from "Mixed Messaging" in } \\
\text { Recycling Today on June 7, } 2018 .\end{array}$ \\
\hline Long Beach, CA & $\begin{array}{l}2020 \text { (residential) } \\
2014 \text { (commercial) }\end{array}$ & $\begin{array}{l}\text { Waste Management reported } \\
\text { MRF composition for residential. } \\
\text { Commercial was based on } \\
\text { the CalRecycle tool. Included } \\
\text { reported redemption tons for } \\
\text { state, proportioned for Long } \\
\text { Beach Population. Provided by the } \\
\text { City of Long Beach. }\end{array}$ & $\begin{array}{l}\text { Used actual } 2020 \text { data provided by Waste } \\
\text { Management, Inc. through City Reporting. } \\
\text { Extrapolated PP in Mixed Plastic recycling } \\
\text { stream using citation from "Mixed Messaging" } \\
\text { in Recycling Today on June 7, 2018. Added } \\
\text { extrapolated redemption data. }\end{array}$ \\
\hline Newark, NJ & 2020 & $\begin{array}{l}\text { Report on Blended MRF } \\
\text { Commodity Values in the } \\
\text { Northeast, NorthEast Recycling } \\
\text { Council (NERC) together with DEP } \\
\text { Reporting for Newark. }\end{array}$ & $\begin{array}{l}\text { Since NJ State recycling composition was } \\
\text { from 2017, a recent NERC report of average } \\
\text { MRF compositions in the NorthEast was used. } \\
\text { Extrapolated PP in Mixed Plastic recycling } \\
\text { stream using citation from "Mixed Messaging" in } \\
\text { Recycling Today on June 7, } 2018 \text {. }\end{array}$ \\
\hline Minneapolis, MN & 2019 & $\begin{array}{l}2018 \text { Recycling Composition } \\
\text { Data as Listed in } 2020 \text { City of } \\
\text { Minneapolis RFP for Recycling } \\
\text { Services (RFP 2020-38 Issue } \\
\text { Date: September 28, 2020) }\end{array}$ & $\begin{array}{l}\text { Used } 2018 \text { average to avoid impacts of COVID } \\
\text { and align with Minneapolis trash reported } \\
\text { numbers. }\end{array}$ \\
\hline Detroit, MI & 2019 & $\begin{array}{l}2019 \text { Recycling Study By GLS } \\
\text { and the URB Foundation. Added } \\
\text { reported redemption tons for } \\
\text { state, proportioned for Detroit } \\
\text { Population. Provided by Green } \\
\text { Living Science. }\end{array}$ & $\begin{array}{l}\text { Actual waste sort of recycling in Detroit with } \\
\text { addition of redemption data. Extrapolated PP } \\
\text { in Extrapolated PP in Mixed Plastic recycling } \\
\text { stream using citation from "Mixed Messaging" in } \\
\text { Recycling Today on June 7, } 2018 \text {. }\end{array}$ \\
\hline
\end{tabular}

WASTE CHARACTERIZATION SUMMARY

CITY OF BALTIMORE

The following table provides a summary of key program components, for use as context in analyzing Baltimore's data.

\begin{tabular}{|l|l|}
\hline \multicolumn{2}{|c|}{ BALTIMORE DEMOGRAPHICS AND DATA SOURCE SUMMARY } \\
\hline Population & 593,490 \\
\hline \% of Total Waste Incinerated & $49.1 \%$ \\
\hline Municipal Recycling Program & $\begin{array}{l}\text { City provides curbside and drop off recycling. Has not provided free bins or carts } \\
\text { to residents. Free recycling carts planned for distribution in Spring 2021. }\end{array}$ \\
\hline Municipal Composting Program & $\begin{array}{l}\text { No municipal food waste program. No commercial composting facility within } 40 \\
\text { miles of Baltimore. }\end{array}$ \\
\hline Included in Waste Generation Rates & $\begin{array}{l}\text { Municipal Solid Waste (MSW), including estimated waste generated in } \\
\text { residential, commercial, and institutional sectors. }\end{array}$ \\
\hline Data Ouality Summary & $\begin{array}{l}\text { Recent city analysis provides credibility to the accuracy of the data. } \\
\text { Tonnage volumes are from 2017. } \\
\text { Characterization studies are from 2019. }\end{array}$ \\
\hline
\end{tabular}

\section{ABOUT THE DATA SOURCES}

The process for gathering data for Baltimore followed the procedures outlined in the general methodology section. Much of the data needed for the Baltimore analysis was relatively accessible because the City of Baltimore collaborated with consulting group Geosyntec to produce the Recycling and Solid Waste Master Plan. This included recent waste sorts and composition analysis of both the recycling and waste streams, as well as extrapolations of the generation rates, through the sources listed in the chart below. The plastic numbers from this study used in the analysis were approximately $72 \%$ containers and included approximately $18 \%$ non-container durable plastic in the non-recyclable plastic categories, such as small household items like toys, tableware, or home decor. The analysis only included plastic sorted out specifically in plastic grades and did not include all plastic in the waste stream such as those found in electronics, furniture, or textiles. Where the city report combined streams of plastic, the waste sort data was used to extrapolate more detail. As polypropylene (\#5 PP) was not separated from the "mixed plastics" grade, the extrapolation method detailed in the methodology was used. 


\section{HOW MUCH TOTAL MATERIAL IS THROWN OUT AND DIVERTED IN BALTIMORE?}

CHART B1

Residential Annual Generation Rates in tons/year

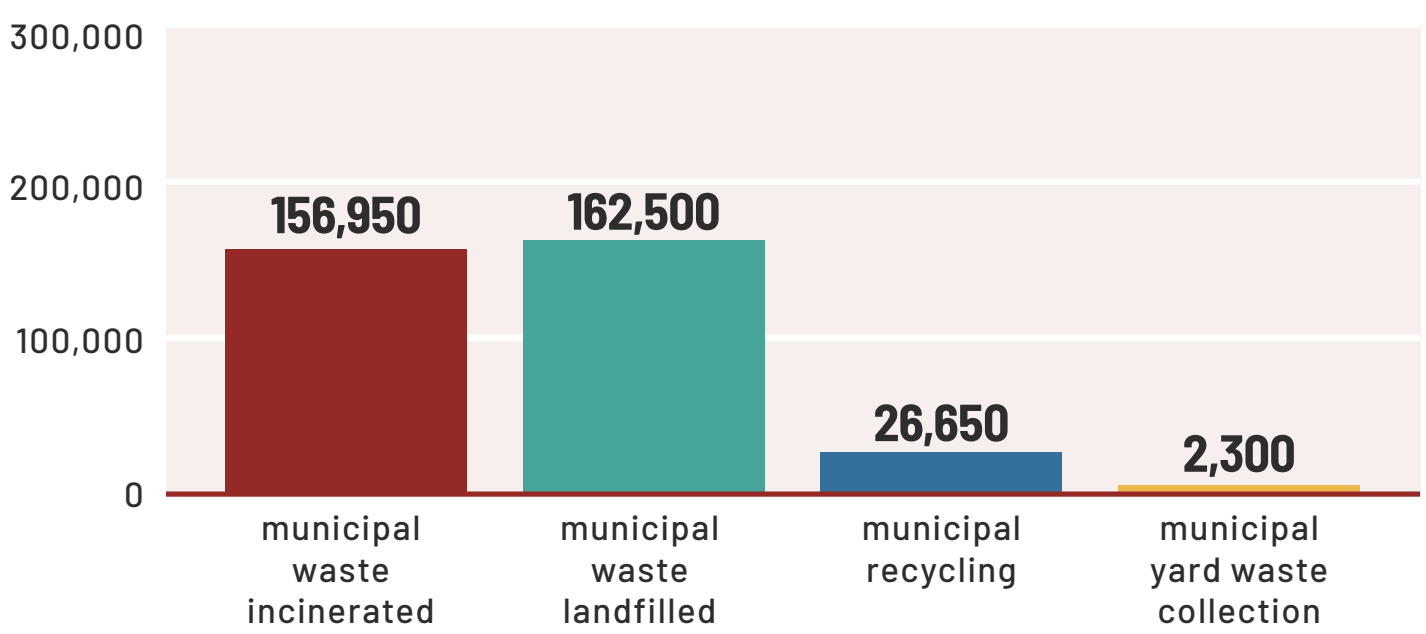

The total amount, in metric tons, of municipal solid waste (MSW) delivered annually to landfills, incinerators, recycling facilities, or composting facilities from households in Baltimore.

CHART B2

Where Waste from Baltimore Goes

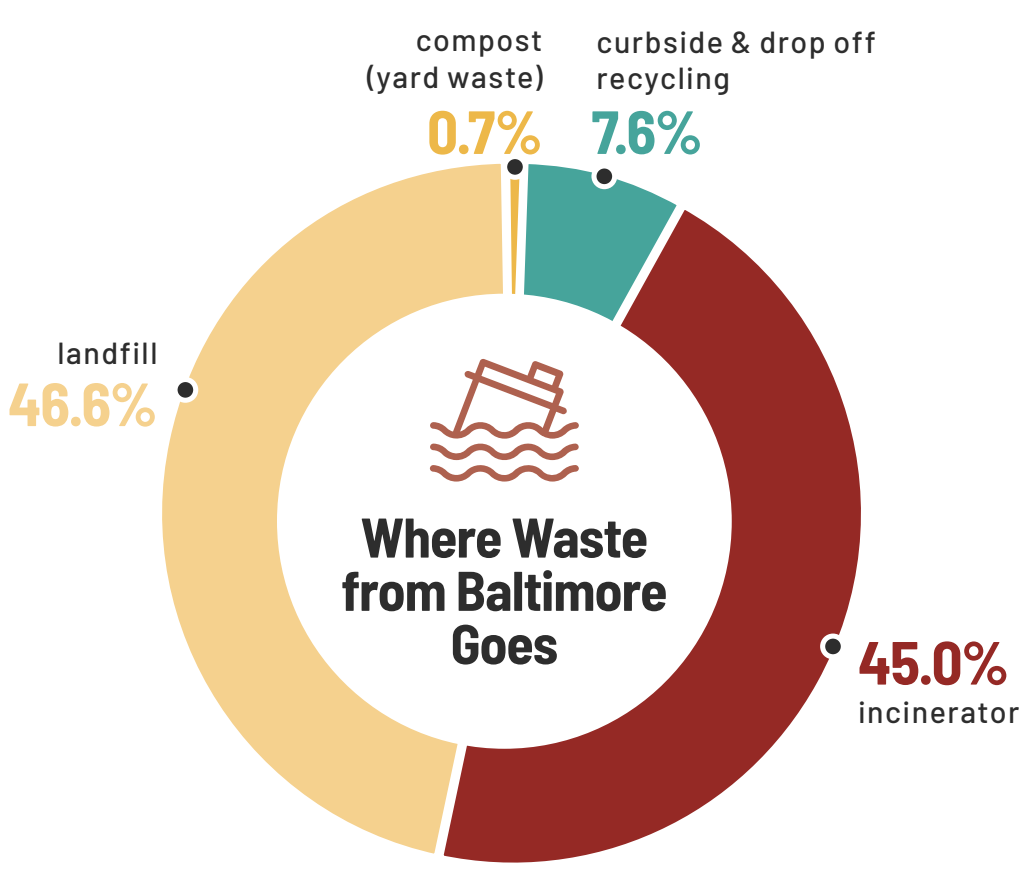

The percentage of MSW collected for recycling, compost, incineration, or disposal. Recycling collection takes place through municipal collection and drop off programs. Compost includes municipally collected yard waste. These numbers show just the initial destination point, not the percentage of material actually diverted (as described).

\section{Key points on generation and MSW sorting :}

- Baltimore sends $91.7 \%$ of its residential waste to a landfill or incinerator. $46.6 \%$ is landfilled and $45 \%$ is incinerated.

- $7.6 \%$ of residential waste is recycled and $0.7 \%$ is composted

- Because there is no statewide bottle bill in Maryland, curbside, and drop off recycling are the only viable options for recycling containers.

\section{WHAT HAPPENS TO PLASTIC DISCARDS IN BALTIMORE?}

Initial Plastic Diversion:

CHART BJ

Where Residents Discard Plastic in Baltimore

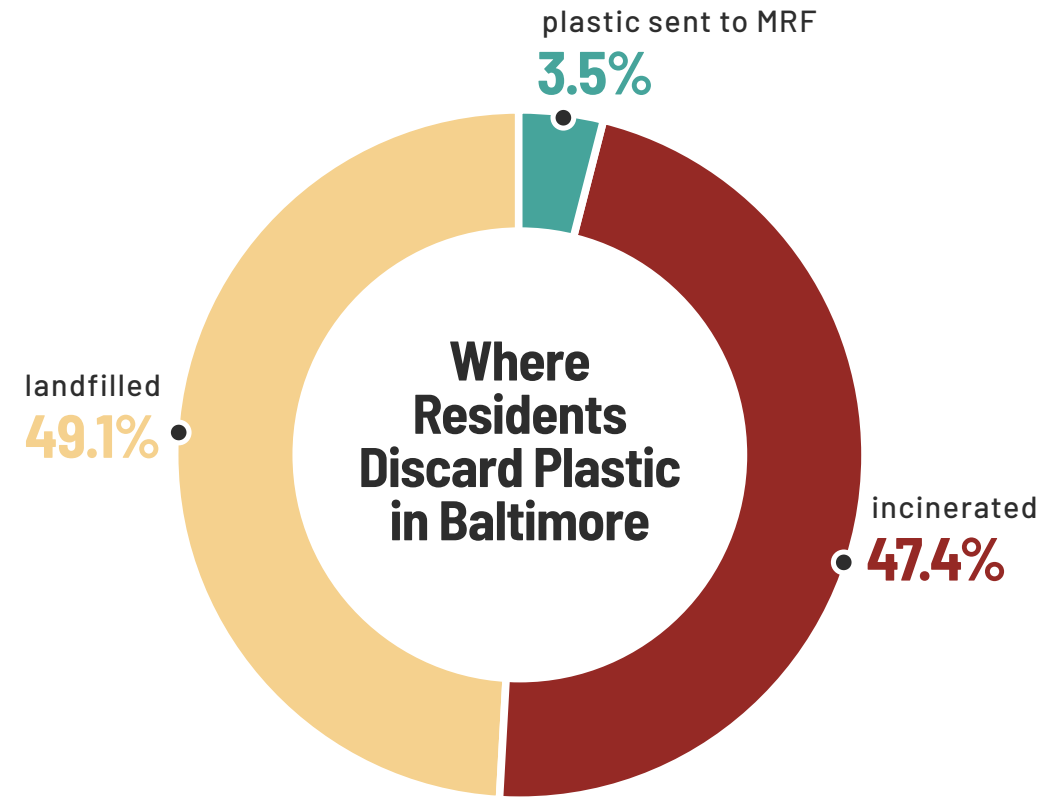

The percentage of all plastic discarded in the city that is currently sent to a materials recovery facility (MRF) for recycling (but not necessarily recycled, see below) through the curbside program, to an incinerator, or landfilled. 
Key Points on Diversion of Plastic:

- Currently $49.1 \%$ of residential plastic goes directly to disposal in landfills; $47.4 \%$ is sent to an incinerator.

- $3.5 \%$ of plastic discarded is currently sent to a recycling center through the city's curbside and drop off recycling program. Maryland has no bottle bill redemption program.

- Diversion rates include some non-recyclable plastic that are incorrectly included in recycling (see next section

\section{PLASTIC THAT "ACTUALLY" GET RECYCLED:}

CHART B4

What Happens to the Plastic in Baltimore's Single-Stream Recycling Program

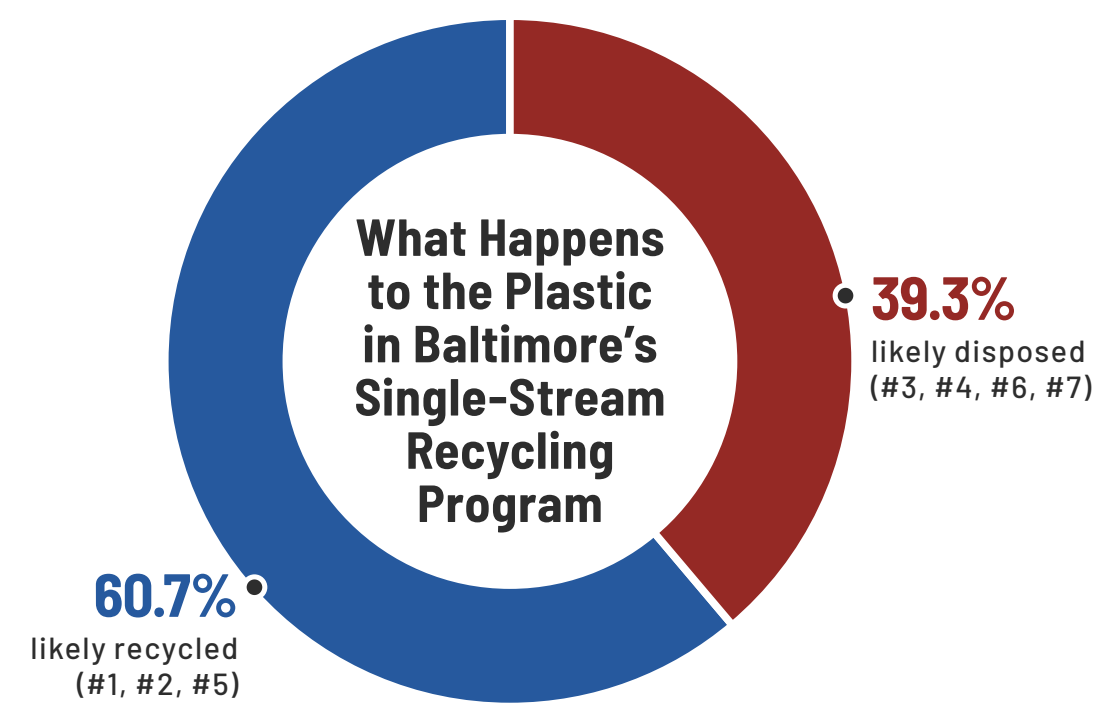

The percentage of plastic that is sorted for recycling and sent to a MRF that is likely recycled or likely disposed of. The study assumes only \#1 PET, \#2 HDPE, and \#5 PP plastic have viable end markets in these cities. It is also assumed that \#3 PVC, \#4 LDPE, \#6 PS, and \#7 other plastic are likely sent to another MRF or secondary processor, or are disposed of (disposal includes incineration, landfilling, burning as fuel at industrial facilities, plastic-to-fuel, etc).

\section{Key Points on Plastic in Baltimore:}

- $39.3 \%$ of plastic collected in Baltimore's municipal recycling program cannot be recycled in the current system.

- While Baltimore currently advertises that it accepts only plastic that is recyclable (plastic jars, bottles, and jugs), residents still send non-recyclable plastic to the recycling program. This shows how difficult it is to educate residents on which types of plastic are recyclable-especially when chasing arrows are used with resin numbers on packaging.

- The MRF likely sends mixed plastic bales to a secondary processor and counts them as recycled from the MRF.

- City reporting on recycling likely includes the non-recyclable material counted as "recycled" because it is often measured by what residents place at the curb or drop off, not by what is actually recycled.

- For every five tons of plastic that is received by a MRF, two tons of this plastic is non-recyclable. This results in increased contamination and increased cost to the city which pays a much higher fee for trash that is sent to recycling. Eliminating non-recyclable plastic would likely reduce processing fees by about $40 \%$.

- If plastic recycling continues without strategies to address non-recyclable plastic, MRFs would be significantly impacted by the increased contamination rates associated with increased recovery.

\section{HOW MUCH ACTUAL PLASTIC RECYCLING IS HAPPENING NOW AND WHAT IS THE POTENTIAL} FOR MORE?

CHART B5

Ultimate Fate of Plastic in Baltimore

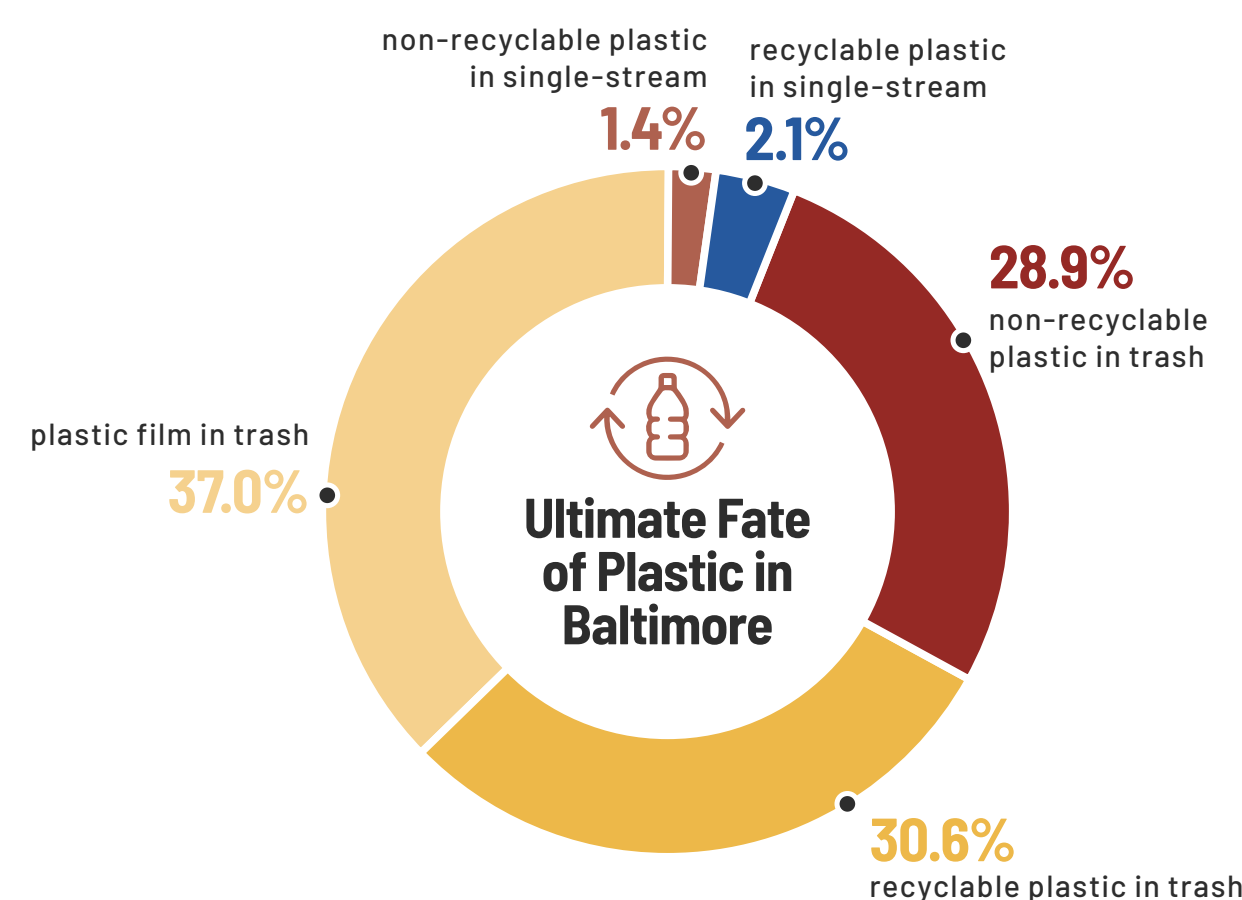

The percentage of recyclable and non-recyclable plastic that ends up in the trash or single-stream system. This chart shows the limited amount of diversion that is possible under the city's current program. 
Key points on Overall State of Plastic:

- $2.1 \%$ of plastic is actually recycled today in Baltimore.

- While $3.5 \%$ of all plastic in Baltimore ends up at a MRF, $1.4 \%$ is non-recyclable.

- $32.7 \%$ of all plastic is potentially recyclable Baltimore; almost $94 \%$ of this recyclable plastic ends up in the trash.

- $30.6 \%$ of all plastic is recyclable and in the trash

- The majority of plastic is non-recyclable and in the waste stream, representing $65.9 \%$ of all plastic

- This includes non-recyclable containers that total $28.9 \%$ of all plastic in Baltimore and plastic film (37\%) that cannot be recycled in single-stream programs and is not collected separately due to significant costs and logistical issues.

- Focusing on reduction will have the biggest impact on reducing plastic in the waste stream, as most plastic is non-recyclable.

\section{HOW LIKELY IS IT THAT WE CAN AT LEAST RECYCLE THE RECYCLABLE PLASTIC?}

CHART B6

Capture Rates by Commodity in Baltimore

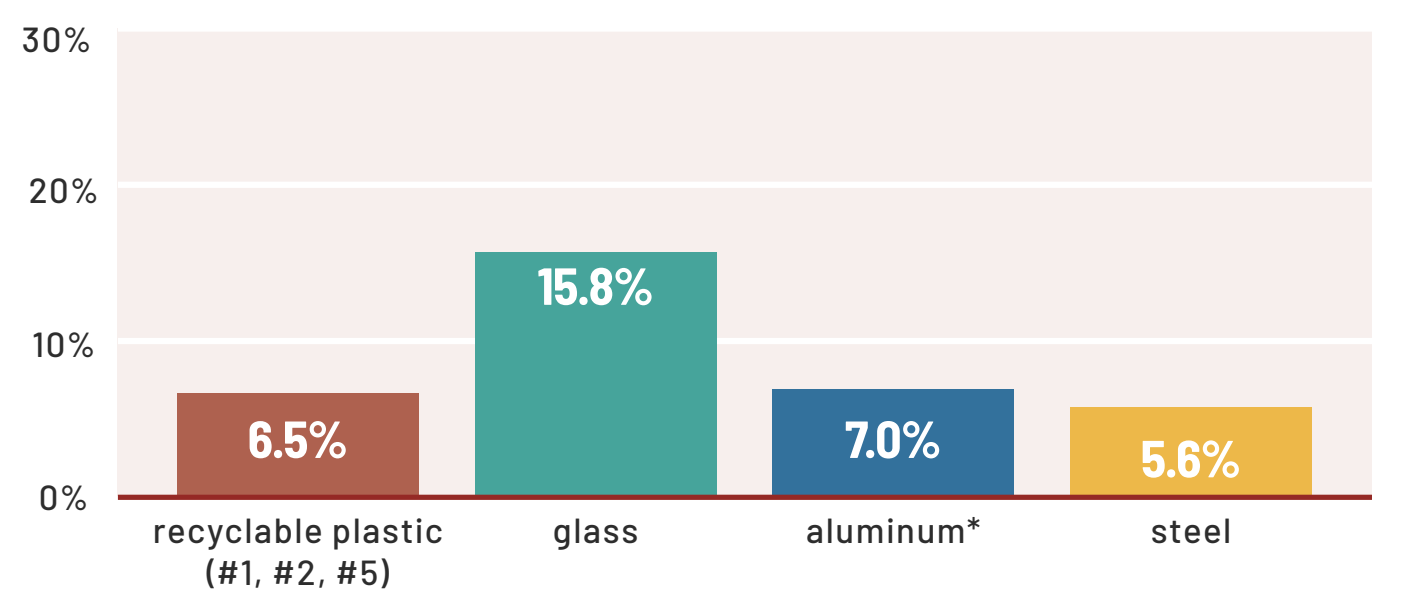

*Curbside only, recovery rate likely higher.

The capture rate of a recyclable commodity is the percentage of that commodity that is disposed of (in the trash or recycling) that is recycled. This chart compares the capture rate for each type of container included in the recycling program.

\section{Key Points on Capture Rate:}

- Less than $7 \%$ of recyclable plastic containers end up in a recycling stream.

- Aluminum in this chart represents only cans recovered through the curbside program as that was the only data available. The actual rate is likely much higher due to sales outside of the residentia collection and processing system, directly to scrap yards.

- Glass is captured at a greater rate than that of recyclable plastic.

\section{WHERE DOES THIS LEAVE SINGLE-STREAM RECYCLING AS A WHOLE?}

CHART B7

Average Composition from Baltimore's Single-Stream Residential Collection Programs

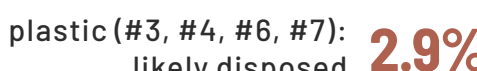

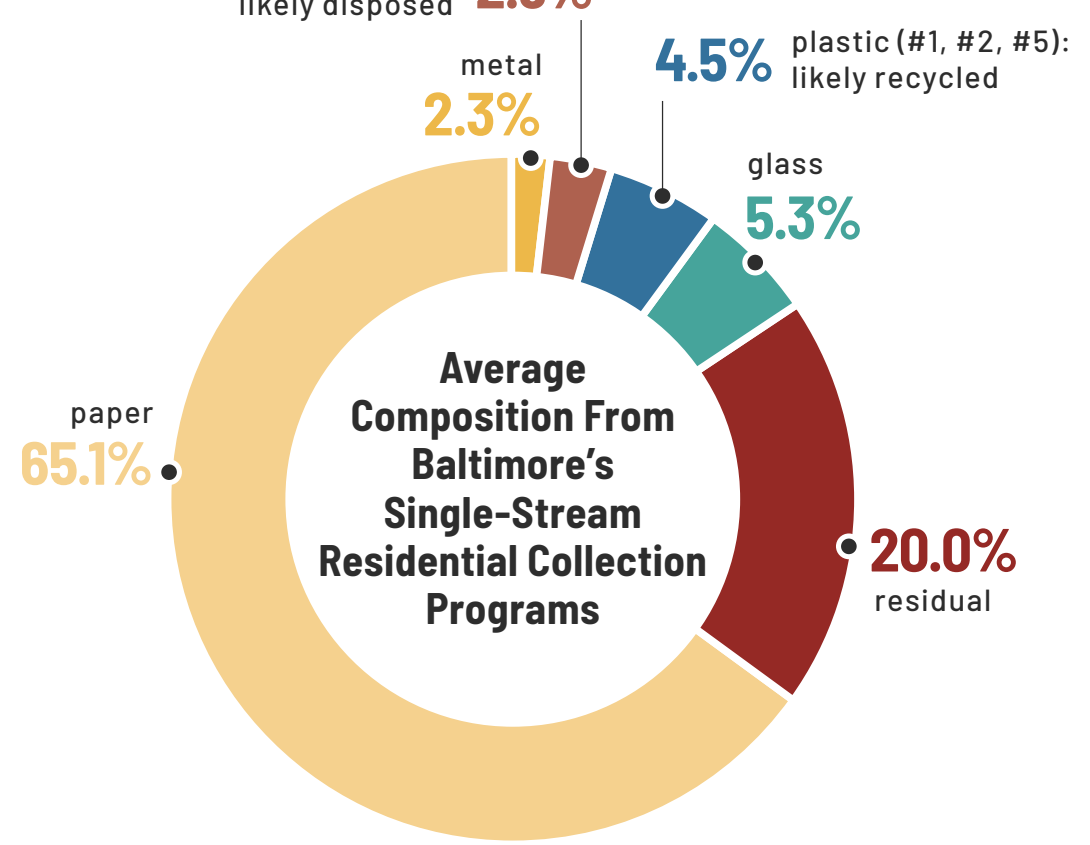

The percentage of materials sorted through the single-stream program that is metal, glass, paper plastic, or residual. This chart shows the MRF's composition of curbside recycling collected in Baltimore.

Key Points of Overall Composition of MRF:

- Over three quarters of recycling in Baltimore's single-stream program is recycled and it's important to continue recycling.

- $72.7 \%$ of the recycling consists of paper, glass, and metals.

- Paper is by far the most recycled commodity at $65.1 \%$ of the recycling stream.

- Glass and metal make up an additional $7.6 \%$ of the recycling stream. 
- While outside the scope of this project, many MRFs use glass for low value uses such as alternative daily cover on landfills, rather than sending the cullet back to glass manufacturers.

- Recyclable plastic makes up $4.5 \%$ of single-stream material.

- About $23 \%$ of all the single-stream materials delivered to the MRF from Baltimore is likely landfilled or sent to another MRF or secondary processor.

- $20 \%$ of material delivered to the MRF is residual: items that were wishcycled (non-recyclable in the first place and mistakenly put in recycling bins and carts); material that was destroyed or

contaminated in the collection and sorting process; or material that cannot be sorted due to the inherent inefficiencies of single-stream MRFs, such as human error or mechanical issues caused by the size, shape, or condition of the material going across the sort line. Some residuals end up as waste disposed of at the MRF, while other residuals are incorrectly sorted into the wrong commodities sent to the wrong market, where they will generally be disposed of.

- $2.9 \%$ is unrecyclable plastic.

\section{WHAT'S LEFT AFTER DIVERSION IN BALTIMORE?}

CHART B8

What's Left After Diversion in Baltimore

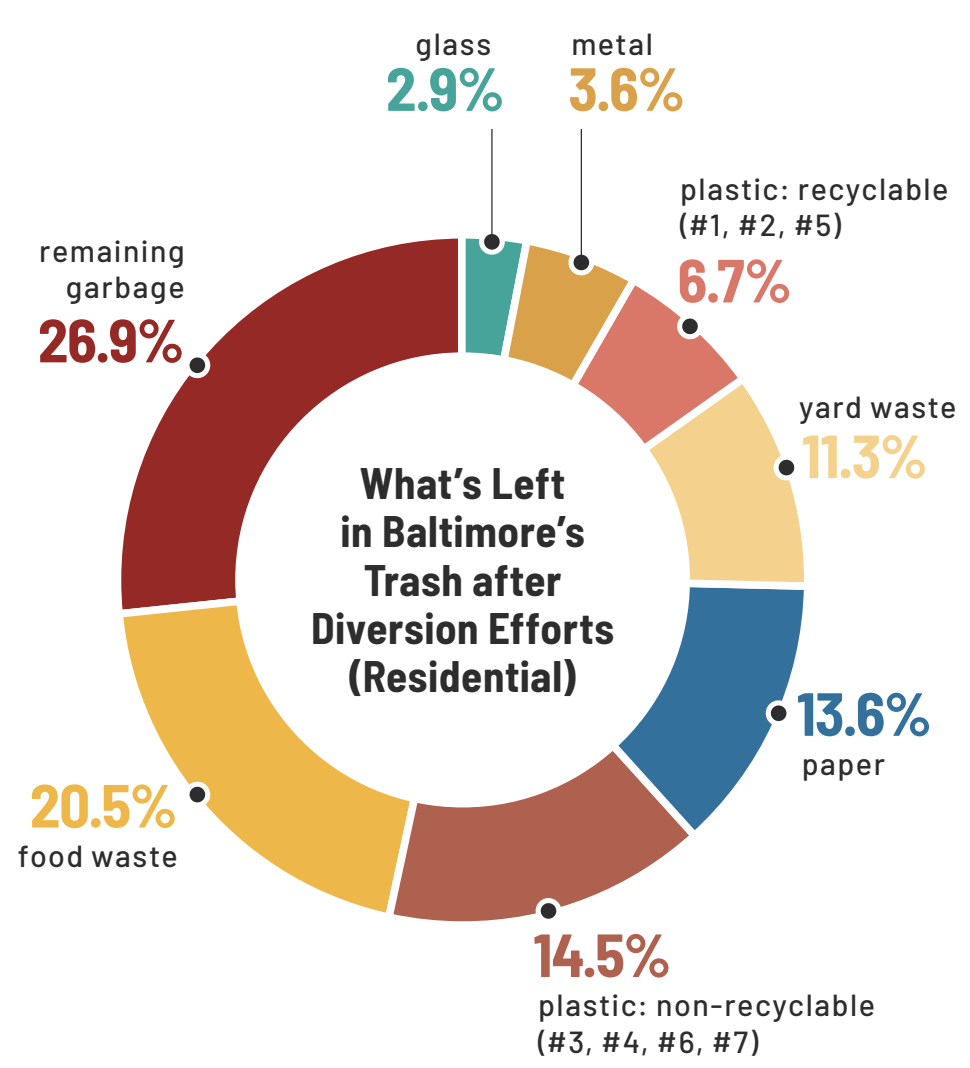

This chart shows the composition of what is left after diversion in Baltimore.
Key Points of What's Left After Diversion in Baltimore

- Food waste $(20.5 \%)$ and yard waste $(11.3 \%)$ make up the $31.8 \%$ of the remaining waste in Baltimore.

- Traditional recyclables of paper (13.6\%), glass (2.9\%), and metal (3.6\%) account for over $20 \%$ of the waste stream

- A small fraction of the waste stream (6.7\%) is potentially recyclable plastic

- Plastic, including non-recyclable (14.5\%) and recyclable packaging (6.7\%), makes up $21.2 \%$ of the waste stream

\section{Data Sources can be found in the Appendix II: Methodology and Data Summary.}


WASTE CHARACTERIZATION SUMMARY

\section{CITY OF MINNEAPOLIS}

The following table provides a summary of key program components, for use as context in analyzing Minneapolis's data.

MINNEAPOLIS DEMOGRAPHICS AND DATA SOURCES SUMMARY

\begin{tabular}{|l|l|}
\hline \multicolumn{2}{|c|}{ MINNEAPOLIS DEMOGRAPHICS AND DATA SOURCES SUMMARY } \\
\hline Population & 420,324 \\
\hline$\%$ of Total Waste Incinerated & $100 \%$ at HERC \\
\hline Municipal Recycling Program & $\begin{array}{l}\text { Weekly cart collection, single-stream. Mission driven recycling partner, Eureka } \\
\text { Recycling. }\end{array}$ \\
\hline Municipal Composting Program & Opt in residential cart program. \\
\hline Included in Waste Generation Rates & $\begin{array}{l}\text { Just city serviced accounts - does not include the majority of commercial } \\
\text { accounts in the city that require their own service. }\end{array}$ \\
\hline Data Quality Summary & $\begin{array}{l}\text { Recent 2019 data for generation rates provided by the City. } \\
\text { Recycling composition provided in recent City RFP. } \\
\text { Minneapolis waste composition from 2015 Hennepin County Study. }\end{array}$ \\
\hline
\end{tabular}

\section{ABOUT THE DATA SOURCES:}

The process for gathering data for Minneapolis followed the procedures outlined in the general methodology section. The City of Minneapolis publishes a fact sheet each year, outlining the amount of MSW disposed, recycled, and composted, among other things. The fact sheet for 2020 was used for the total tons of material disposed, recycled, and composted. A 2015 Hennepin County Study provided a detailed composition of Minneapolis' residential waste stream. The plastic numbers from this study used in the analysis were approximately $80 \%$ containers and included approximately $20 \%$ non-container durable plastic in the non-recyclable plastic categories, such as small household items like toys,

tableware, or home decor. The analysis only included plastic sorted out specifically in plastic grades and did not include all plastic in the waste stream such as those found in electronics, furniture, or textiles. A 2018 composition of the recycling for Minneapolis was used as listed in 2020 City of Minneapolis RFP for Recycling Services (RFP 2020-38 Issue Date: September 28, 2020). As polypropylene (\#5 PP) was not separated from the "mixed plastic" grade in the trash or recycling composition study, the extrapolation method detailed in the methodology was used.

\section{HOW MUCH TOTAL MATERIAL IS THROWN OUT AND DIVERTED IN MINNEAPOLIS?}

CHART MI

Residential and Commercial Annual Generation Rates in tons/year

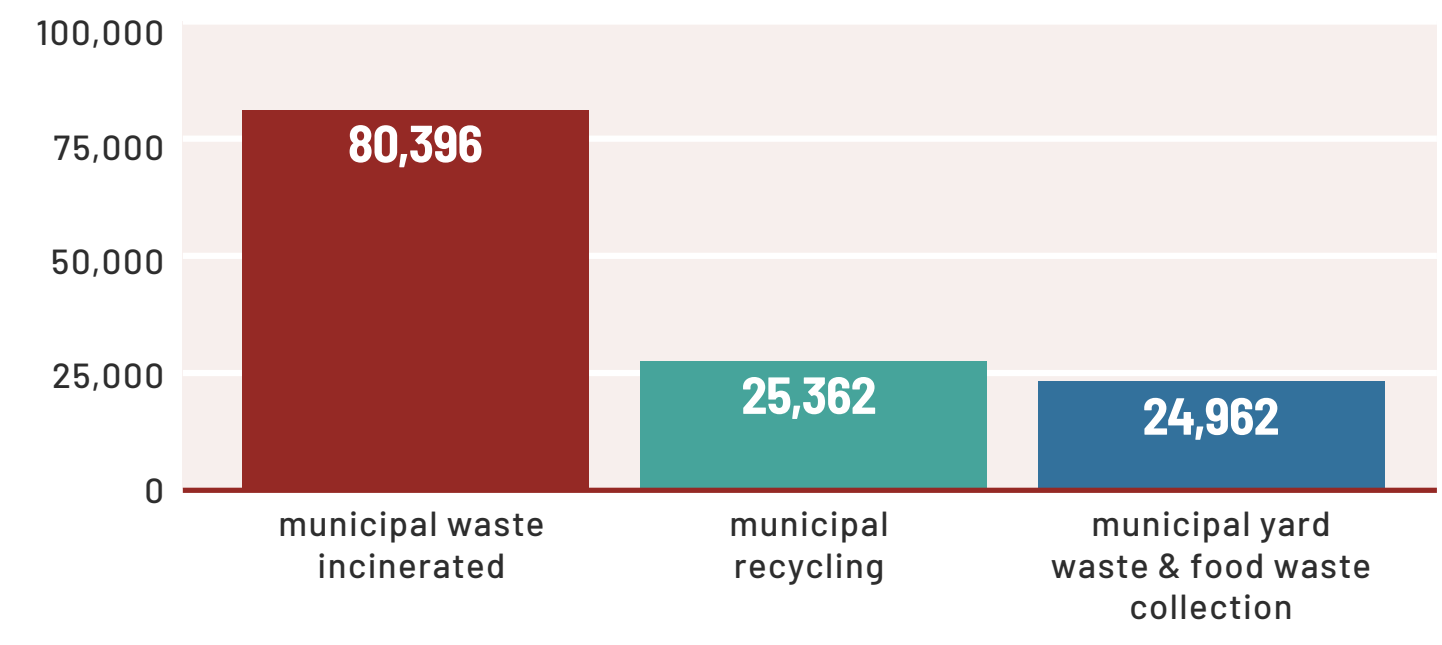

The total amount, in metric tons, of municipal solid waste (MSW) delivered annually to landfills incinerators, recycling facilities, or composting facilities from households and businesses in Minneapolis.

CHART M2

Where Waste from Minneapolis Goes

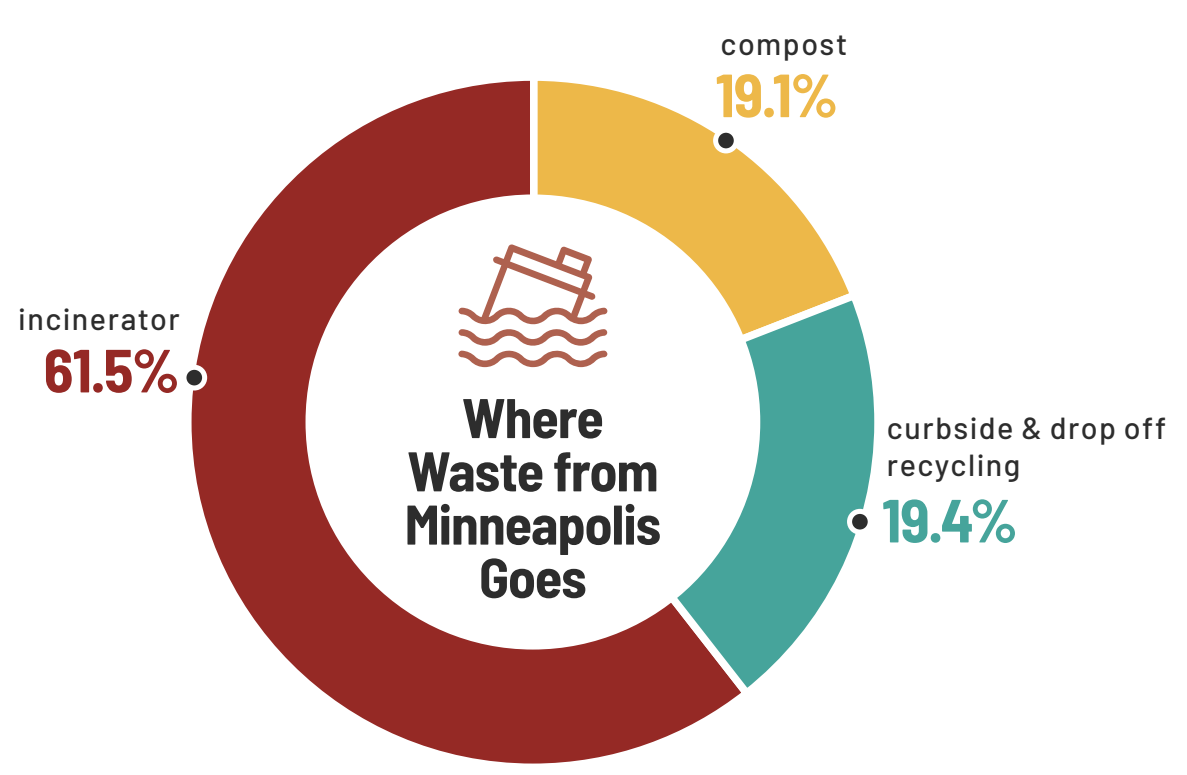


The percentage of MSW collected for recycling, compost, or incineration. Recycling collection takes place through municipal collection and drop off programs. Compost includes municipally collected food waste and yard waste. These numbers show just the initial destination point, not the percentage of material actually diverted (as described).

Key Points on Generation and MSW Sorting:

- Minneapolis sends all waste bound for disposal (61.5\%) to the HERC incinerator located in downtown Minneapolis.

- $19.4 \%$ of MSW is diverted through the city's municipal recycling program.

- $19.1 \%$ of MSW is collected for composting. Minneapolis provides cart based yard waste and food waste collection options to single-family household residents.

\section{WHAT HAPPENS TO PLASTIC DISCARDS IN MINNEAPOLIS?}

Initial Plastic Diversion:

CHART M3

Where Residents and Businesses Discard Plastic in Minneapolis

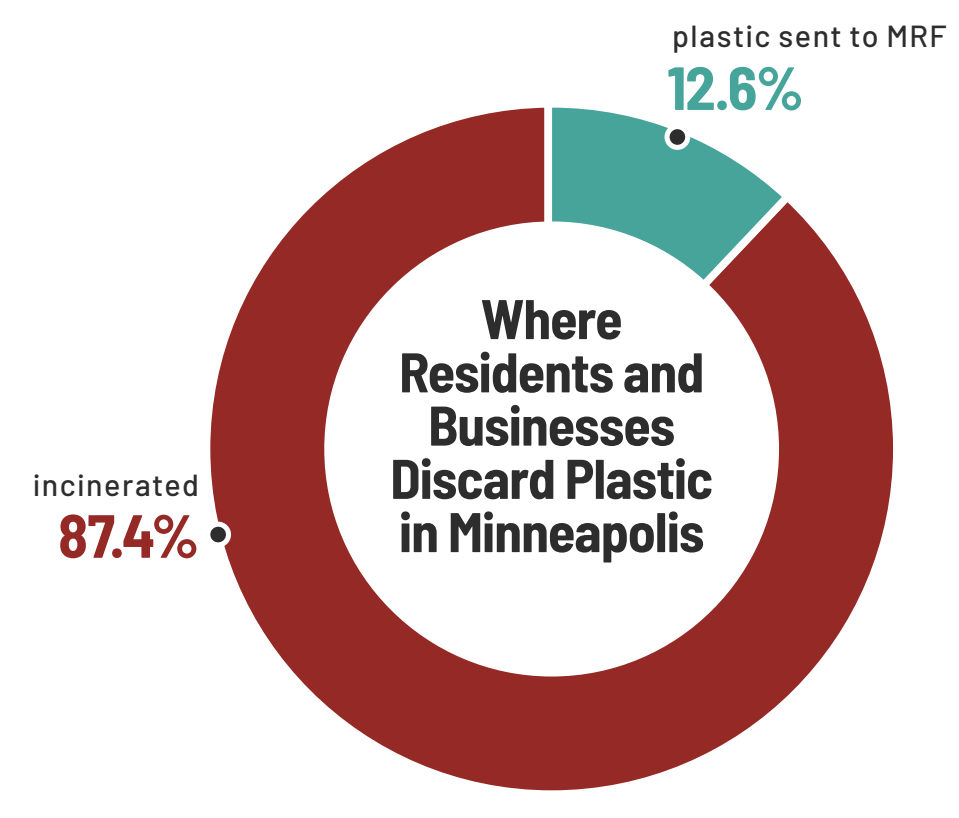

The percentage of all plastic discarded in the city that is currently sent to a materials recovery facility (MRF) for recycling (but not necessarily recycled, see below) through the curbside recycling program or to an incinerator.
Key Points on Diversion of Plastic:

- Currently $87.4 \%$ of plastic is incinerated

- $12.6 \%$ of plastic is sent to a MRF for recycling through the city's curbside and drop off recycling program. Minnesota has no bottle bill redemption program.

- Diversion rates include some non-recyclable plastic that are incorrectly included in recycling (se next section).

\section{PLASTIC THAT "ACTUALLY" GET RECYCLED:}

CHART ML

What Happens to the Plastic in Minneapolis' Single-Stream Recycling Program

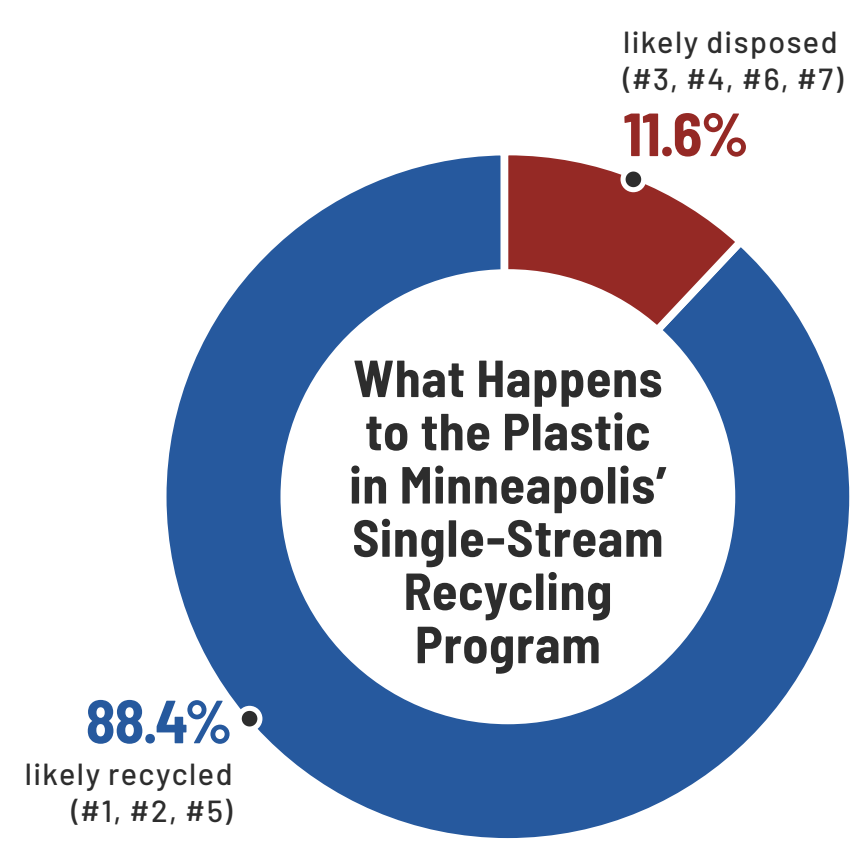

The percentage of plastic that is sorted for recycling and sent to a MRF that is likely recycled or likely disposed of. The study assumes only \#1 PET, \#2 HDPE, and \#5 PP plastic have viable end markets in these cities.

Key Points on Plastic in Minneapolis:

- $11.6 \%$ of plastic collected in Minneapolis' municipal curbside recycling program cannot be recycled in the current system.

- While Minneapolis currently advertises that it accepts only plastic that is recyclable, for years, the city accepted all plastic types (including non-recyclable). This shows how difficult it is to educate residents on which types of plastic are recyclable-especially when chasing arrows are used with resin numbers on packaging. 
- Because Minneapolis works with a mission-driven recycler, this has unique impacts on its recycling program.

- Eureka Recycling, the city's contracted recycling processor for residential recycling, includes this non-recyclable plastic in the residual rate.

- While the city may still include non-recyclable material in its total recycling numbers, the city is given a transparent reporting of what is actually recycled at the MRF.

- For every ten tons of plastic that is received by a MRF, about one ton of this plastic is nonrecyclable. This results in increased contamination and increased cost to the city which pays a much higher fee for trash that is sent to recycling. Eliminating non-recyclable plastic would likely reduce processing fees related to plastics by $11.6 \%$.

- If plastic recycling continues without strategies to address non-recyclable plastic, MRFs would be significantly impacted by the increased contamination rates associated with increased recovery.

\section{HOW MUCH ACTUAL PLASTIC RECYCLING IS HAPPENING NOW AND WHAT IS THE POTENTIAL} FOR MORE?

The "Ultimate Fate of Plastic in Minneapolis" chart summarizes the overall picture of where all plastic ultimately ends up in Minneapolis. This chart shows the limited amount of diversion that is possible under the city's current program.

CHART M5

Ultimate Fate of Plastic in Minneapolis

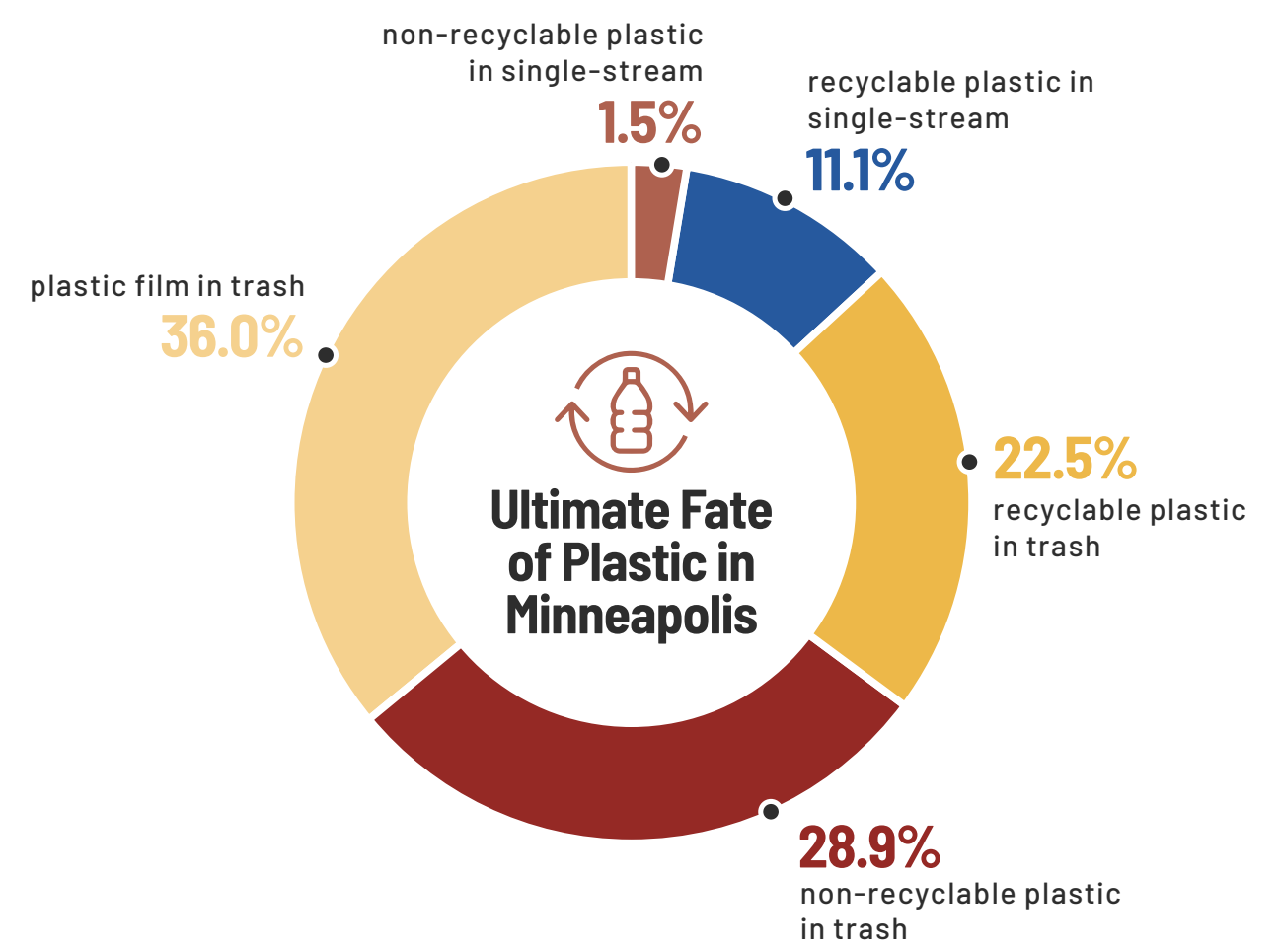

The percentage of recyclable and non-recyclable plastic that ends up in the trash or single-stream system. This chart shows the limited amount of diversion that is possible under the city's current program.

Key points on Overall State of Plastic:

- $11.1 \%$ of all plastic is actually recycled today in Minneapolis.

- While $12.6 \%$ of all plastic in Minneapolis ends up at a MRF, $1.5 \%$ is non-recyclable.

- $33.6 \%$ of all plastic is recyclable in Minneapolis; two-thirds of this recyclable plastic ends up in the trash.

- $22.5 \%$ of all plastic is recyclable and in the trash.

- The majority of plastic is non-recyclable and in the waste stream, representing $64.9 \%$ of all plastic.

- This includes non-recyclable containers that total $28.9 \%$ of all plastic in Minneapolis and plastic film (36\%) that cannot be recycled in single-stream programs and is not collected separately due to significant costs and logistical issues.

- Focusing on reduction will have the biggest impact on reducing plastic in the waste stream, as most plastic is non-recyclable.

\section{HOW LIKELY IS IT THAT WE CAN AT LEAST RECYCLE THE RECYCLABLE PLASTIC?}

CHART ME

Capture Rates by Commodity in Minneapolis

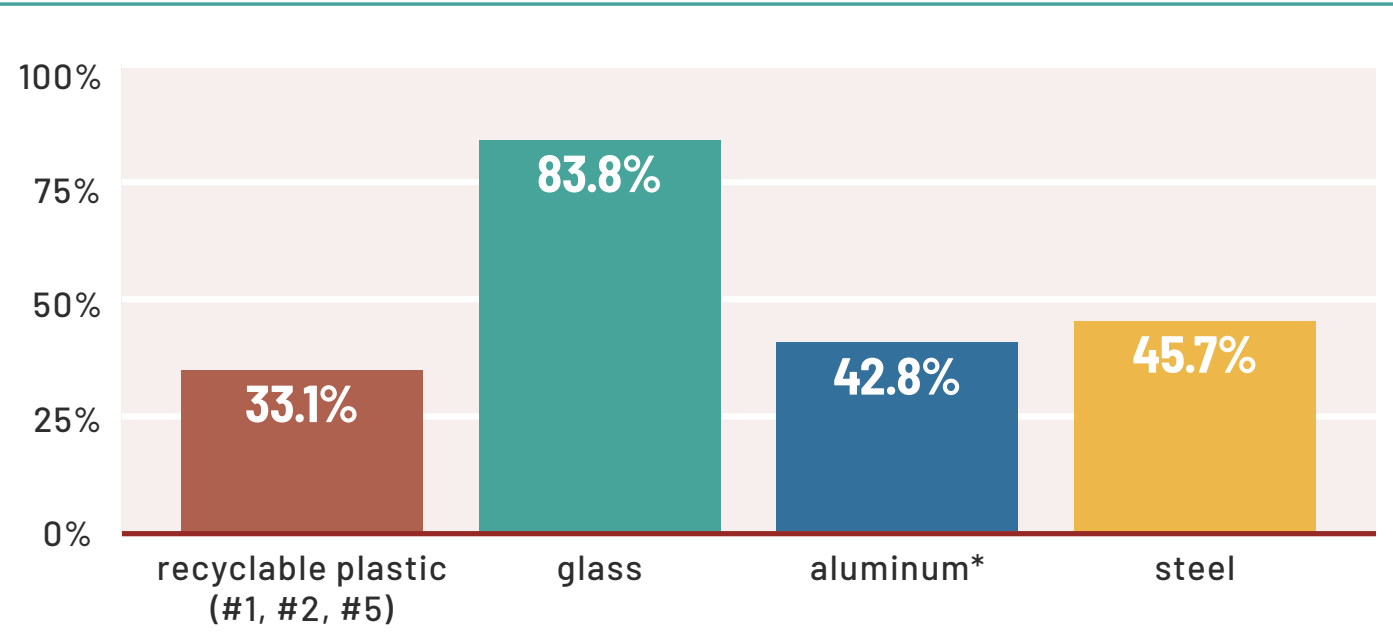

*Curbside ony, recovery rate likely higher.

The capture rate of a recyclable commodity is the percentage of that commodity that is disposed of (in the trash or recycling) that is recycled. This chart compares the capture rate for each type of container included in the recycling program. 


\section{Key Points on Capture Rate:}

- $33 \%$ of recyclable plastic containers end up in a recycling stream.

- Aluminum in this chart represents only cans recovered through the curbside program as that was the only data available. The actual rate is likely much higher due to sales outside of the residential collection and processing system, directly to scrap yards.

- Other commodities, like glass, steel, and aluminum, are captured at greater rates than that of recyclable plastic.

\section{WHERE DOES THIS LEAVE SINGLE-STREAM RECYCLING AS A WHOLE?}

\section{CHART M7}

Average Composition from Minneapolis' Single-Stream Residential Collection Programs

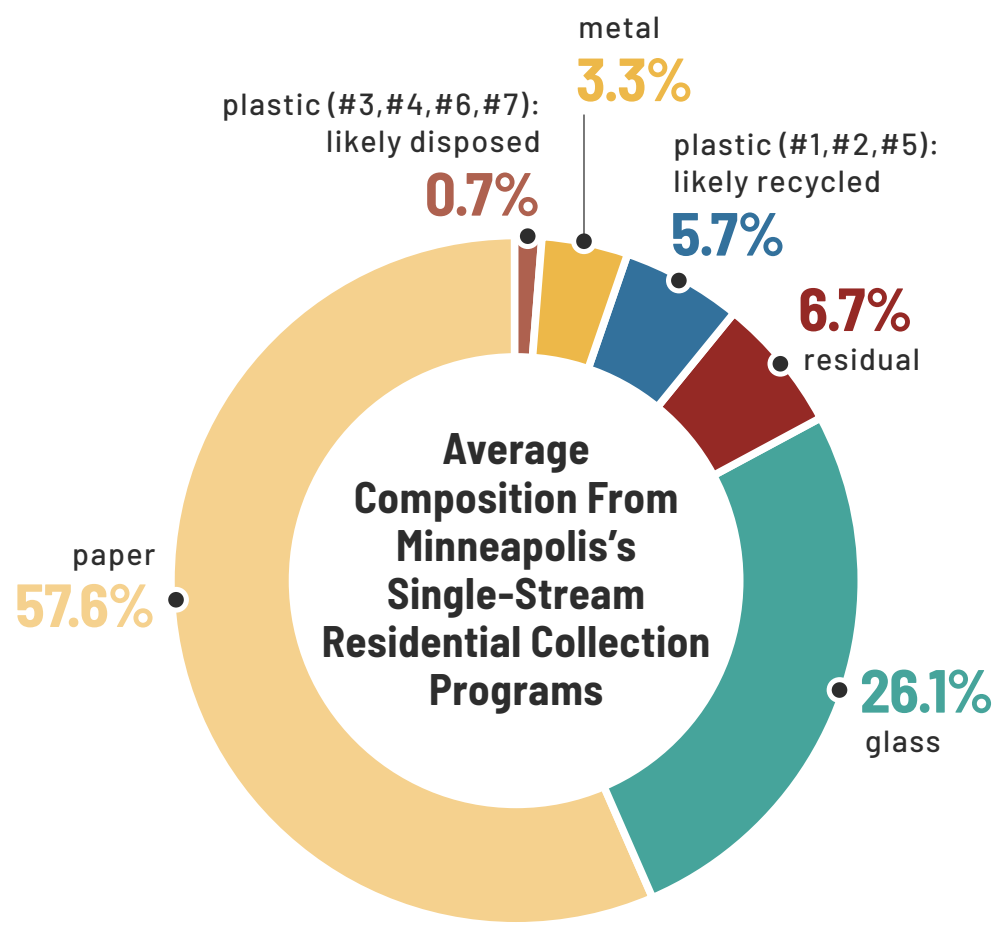

The percentage of materials sorted through the single-stream program that is metal, glass, paper. plastic, or residual. This chart shows the MRF's composition of curbside recycling collected in

Minneapolis.

\section{Key Points of Overall Composition of MRF}

- Over $90 \%$ of recycling in Minneapolis's single-stream program is recycled and it's important to continue recycling.

- $87 \%$ of the recycling consists of paper, glass, and metals.

- Paper is by far the most recycled commodity at $57.6 \%$ of the recycling stream.

- Glass and metals make up an additional $29.4 \%$ of the recycling stream. Eureka Recycling sends all glass to a beneficiation facility that results in a majority of it being used to make new bottles.

- Recyclable plastic makes up $5.7 \%$ of single-stream material.

- $7.4 \%$ of all the single-stream materials delivered to the MRF from Minneapolis is likely disposed of, burned for energy, or sent to another MRF or secondary processor.

- $6.7 \%$ of material delivered to the MRF is residual: items that were wishcycled (non-recyclable in the first place and mistakenly put in recycling bins and carts); material that was destroyed or contaminated in the collection and sorting process; or material that cannot be sorted due to the inherent inefficiencies of single-stream MRFs, such as human error or mechanical issues caused by the size, shape, or condition of the material going across the sort line. Some residuals end up as waste disposed of at the MRF, while other residuals are incorrectly sorted into the wrong commodities sent to the wrong market, where they will generally be disposed of.

- $0.7 \%$ is non-recyclable plastic.

- Eureka's residual rate is extremely low for a single-stream facility, indicative of its unique mission-driven approach.

- This level of transparency on MRF residual rate shows the impact that non-recyclable plastic has on contamination. 


\section{WHAT'S LEFT AFTER DIVERSION IN MINNEAPOLIS?}

CHART M8

What's Left After Diversion in Minneapolis

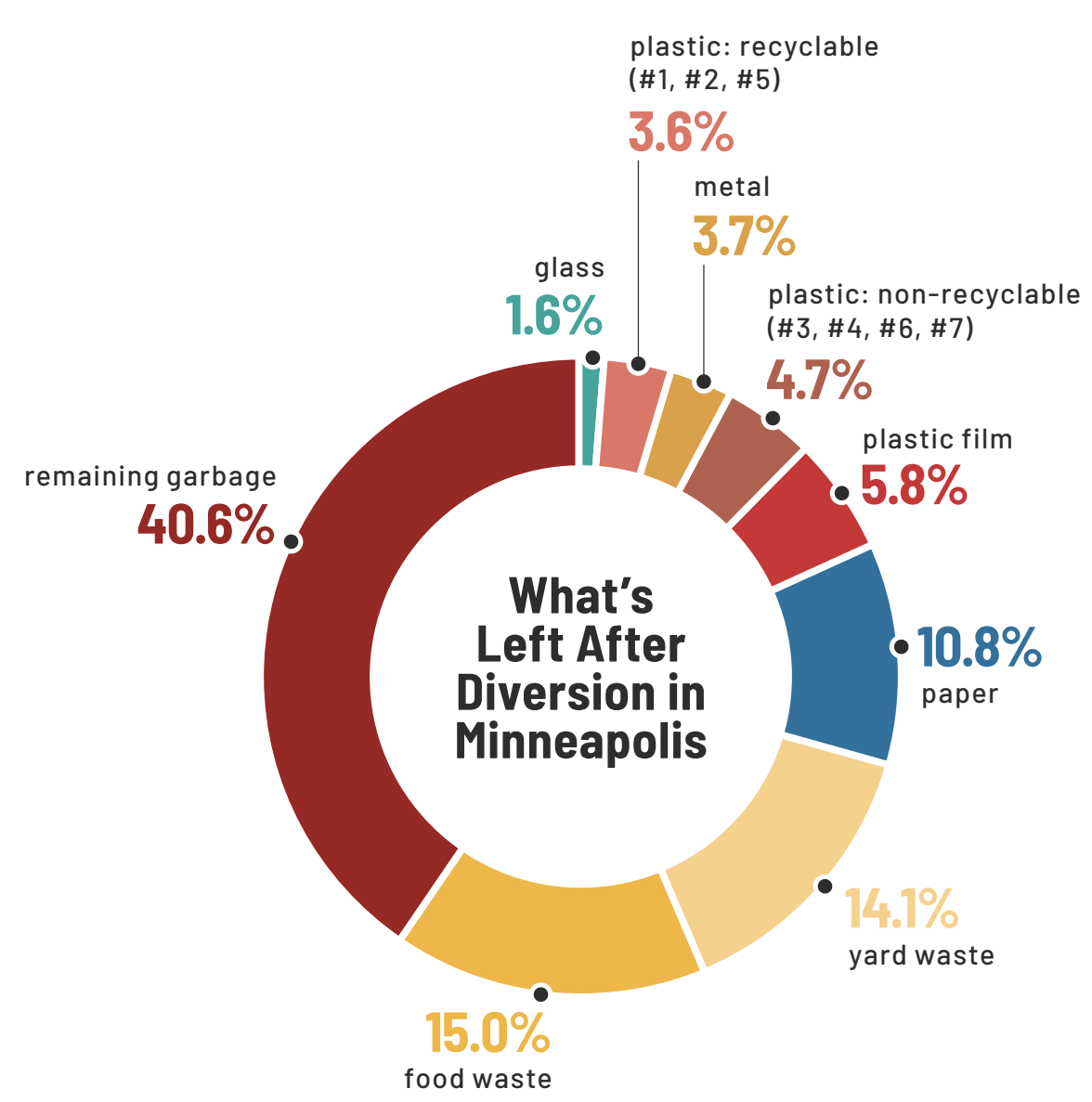

This chart shows the composition of what is left after diversion in Minneapolis.

\section{Key Points of What is Left After Diversion in Minneapolis:}

- Food waste (15\%) and yard waste $(14.1 \%)$ make up the largest divertable fraction of what's left in the trash, totalling over $29 \%$ of the remaining waste in Minneapolis.

- Traditional recyclables of paper ( $10.8 \%$ ), glass ( $1.6 \%$ ), and metal (3.7\%) also account for over $16 \%$ of the waste stream

- A small fraction of the waste stream (3.6\%) is potentially recyclable plastic.

- Plastic, including film (5.8\%), non-recyclable (4.7\%), and recyclable packaging (3.6\%), makes up $14.1 \%$ of the waste stream

- Plastic film makes up about half of non-recyclable plastic.

Data Sources can be found in the Appendix II: Methodology and Data Summary.
WASTE CHARACTERIZATION SUMMARY

CITY OF NEWARK

The following table provides a summary of key program components, for use as context in analyzing Newark's data.

NEWARK DEMOGRAPHICS AND DATA SOURCE SUMMARY

\begin{tabular}{|l|l|}
\hline Population & 227,140 \\
\hline \% of Total Waste Incinerated & $100 \%$ \\
\hline Municipal Recycling Program & Curbside Recycling Program \\
\hline Municipal Composting Program & None \\
\hline Included in Waste Generation Rates & Municipal Solid Waste (MSW) includes residential, commercial and institutional. \\
\hline Data Quality Summary & $\begin{array}{l}\text { State 2017 generation rates for recycling and trash. } \\
\text { No city specific composition data on recycling or trash. } \\
\text { Used another county as a proxy for trash and average northeast MRF report for } \\
\text { recycling. }\end{array}$ \\
\hline
\end{tabular}

\section{ABOUT THE DATA SOURCES}

The process for gathering data for Newark followed the procedures outlined in the general methodology section. The total tons of MSW recycled and disposed specific to Newark were gathered from NJ State Department of Environmental Protection's published figures titled "2017 Generation, Disposal and Recycling Rates in New Jersey (Tons)." As no published waste characterization study was available specific to Newark, a 2013 study of Mercer County had to be used as a proxy. The plastic numbers from this study used in the analysis were approximately $75 \%$ containers and included approximately $25 \%$ non-container durable plastic in the non-recyclable plastic categories, such as small household items like toys, tableware, or home decor. The analysis only included plastic sorted out specifically in plastic grades and did not include all plastic in the waste stream such as those found in electronics, furniture, or textiles. A 2017 DEP report specific to Newark was used as an estimate for composting, but offered only vague composition details on recycling composition. As a proxy, a recent report on recycling composition based on facility averages for 14 MRFs in the 11 State NE Region was used for Newark's recycling composition. As polypropylene (\#5 PP) was not separated from the "mixed plastic" grade in the trash or recycling composition study, the extrapolation method detailed in the methodology was used. 


\section{HOW MUCH TOTAL MATERIAL IS THROWN OUT AND DIVERTED IN NEWARK?}

CHART N1

Residential and Commercial Annual Generation Rates in tons/year

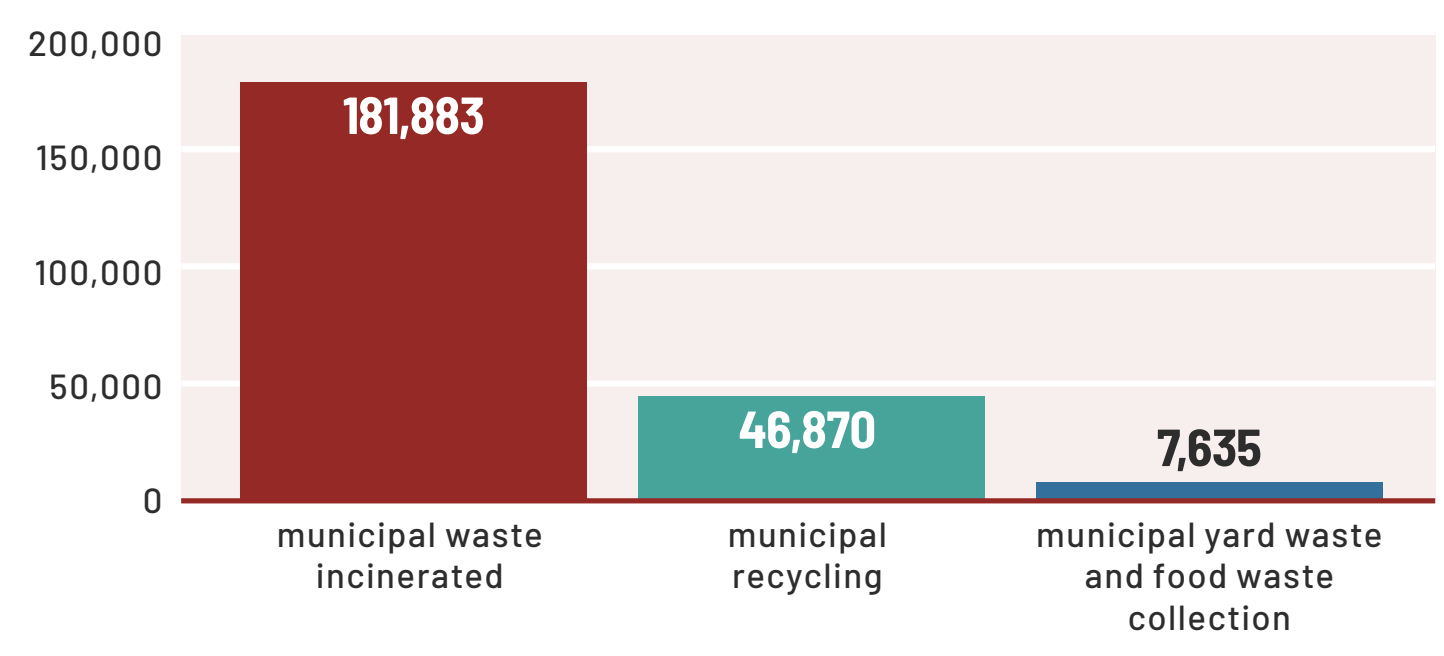

The total amount, in metric tons, of municipal solid waste (MSW) delivered annually to incinerators, recycling facilities, or composting facilities from households and businesses in Newark.

CHART N2

Where Waste From Newark Goes

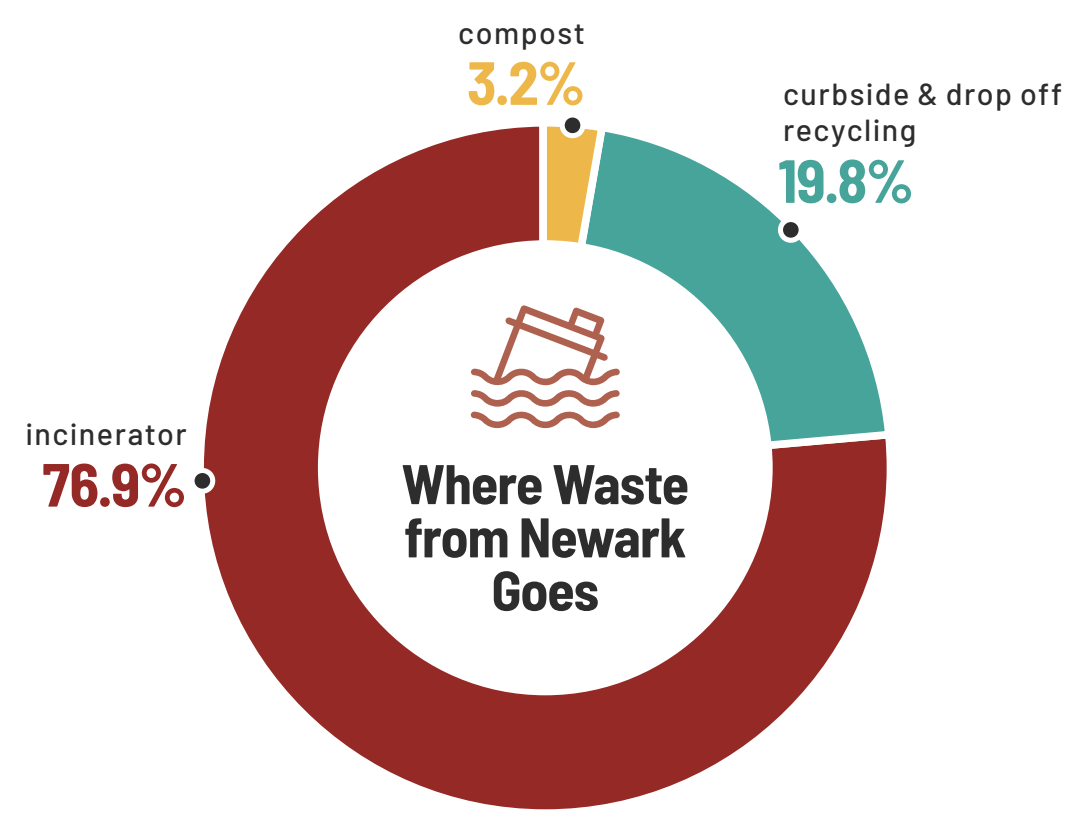

The percentage of MSW collected for recycling, compost, or incineration. Recycling collection takes place through municipal collection programs. Compost includes municipally collected yard waste

and food waste. These numbers show just the initial destination point, not the percentage of materia actually diverted (as described).

Key Points on Generation and MSW Sorting

- Newark sends all waste bound for disposal (76.9\%) to incineration.

- A total of $19.8 \%$ of MSW is diverted for recycling.

- Compost diversion accounts for $3.2 \%$ of MSW. Based on state reporting, about half of compost diversion is yard waste and the other half is food waste.

- Diversion rates include some non-recyclable plastic that are incorrectly included in recycling (see next section).

\section{WHAT HAPPENS TO PLASTIC DISCARDS IN NEWARK?}

Initial Plastic Diversion:

CHART N3

Where Residents and Businesses Discard Plastic in Newark

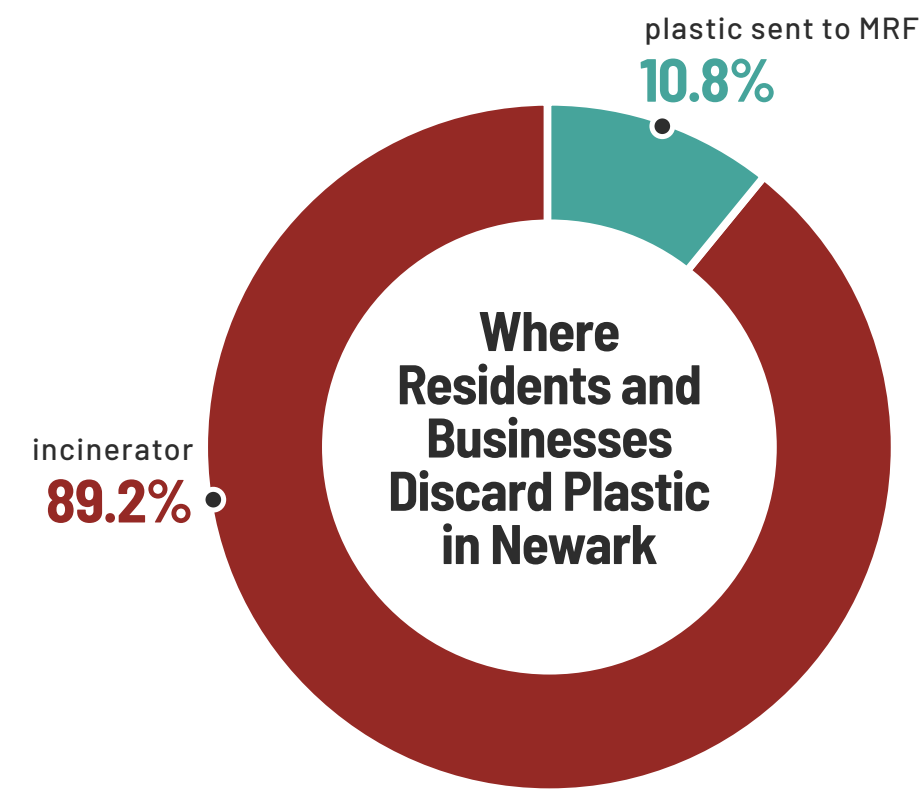

The percentage of all plastic discarded in the city that is currently sent to a materials recovery facility (MRF) for recycling (but not necessarily recycled, see below) through the curbside recycling program or to an incinerator 
Key Points on Diversion of Plastic:

- Currently, $89.2 \%$ of plastic is incinerated.

- $10.8 \%$ of plastic is sent to a MRF for recycling through the city's curbside recycling program. New Jersey has no bottle bill redemption program.

- Diversion rates include some non-recyclable plastic that are incorrectly included in recycling (see next section).

\section{PLASTIC THAT "ACTUALLY" GET RECYCLED}

CHART N 4

What Happens to the Plastic in Newark's Single-Stream Recycling Program

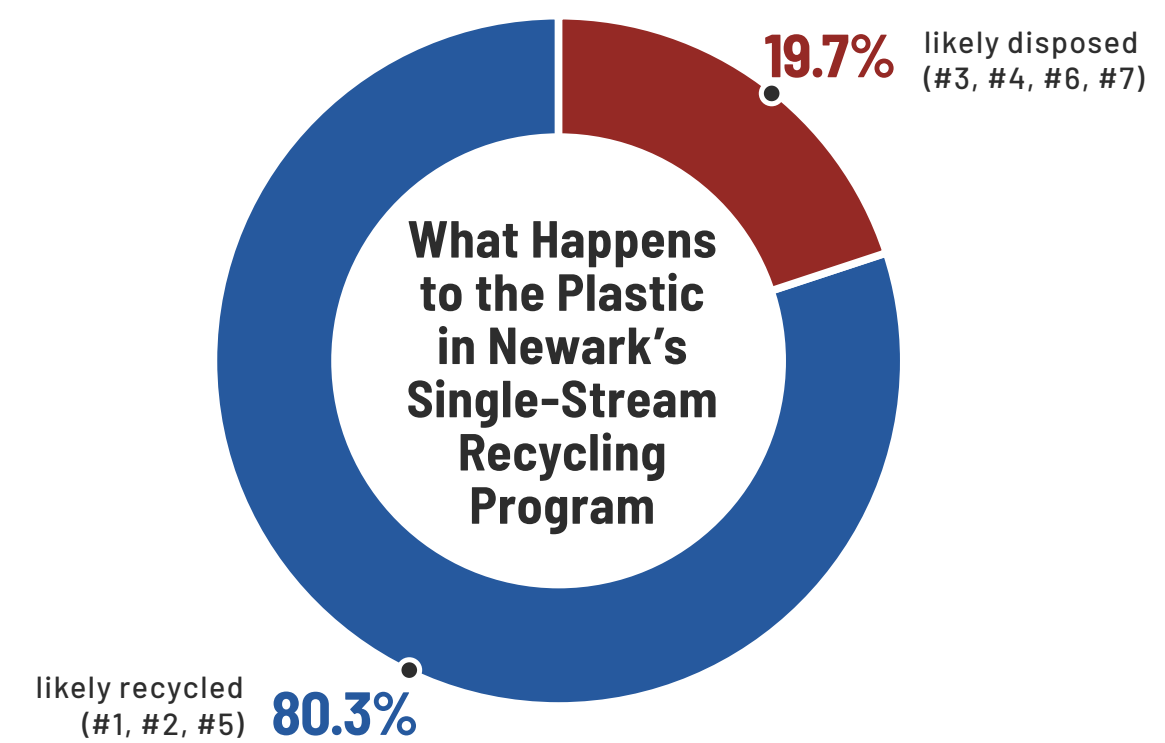

The percentage of plastic that is sorted for recycling and sent to a MRF that is likely recycled or disposed of The study assumes only \#1 PET, \#2 HDPE, and \#5 PP plastic have viable end markets in these cities. It is also assumed that \#3 PVC, \#4 LDPE, \#6 PS, and \#7 other plastic are likely sent to another MRF or secondary processor, or are disposed of (disposal includes incineration, landfilling, burning as fuel at industrial facilities, plastic-to-fuel, etc).

\section{Key Points on Plastic in Newark:}

- $19.7 \%$ of plastic collected in Newark's municipal curbside recycling program cannot be recycled in the current system.

- The MRF likely sends mixed plastic bales to a secondary processor and counts them as recycled from the MRF.

- City reporting on recycling likely includes the non-recyclable material counted as "recycled" since it is often measured by what residents put at the curb, not by what is actually recycled.
- For every five tons of plastic that is received by a MRF, one ton of this plastic is non-recyclable. This results in increased contamination and increased cost to the city which pays a much higher fee for trash that is sent to recycling. Eliminating non-recyclable plastic would likely reduce processing fees associated with plastic recycling by $20 \%$.

- If plastic recycling continues without strategies to address non-recyclable plastic, MRFs would be significantly impacted by the increased contamination rates associated with increased recovery.

\section{HOW MUCH ACTUAL PLASTIC RECYCLING IS HAPPENING NOW AND WHAT IS THE POTENTIAL}

FOR MORE?

\section{CHART N5}

Ultimate Fate of Plastic in Newark

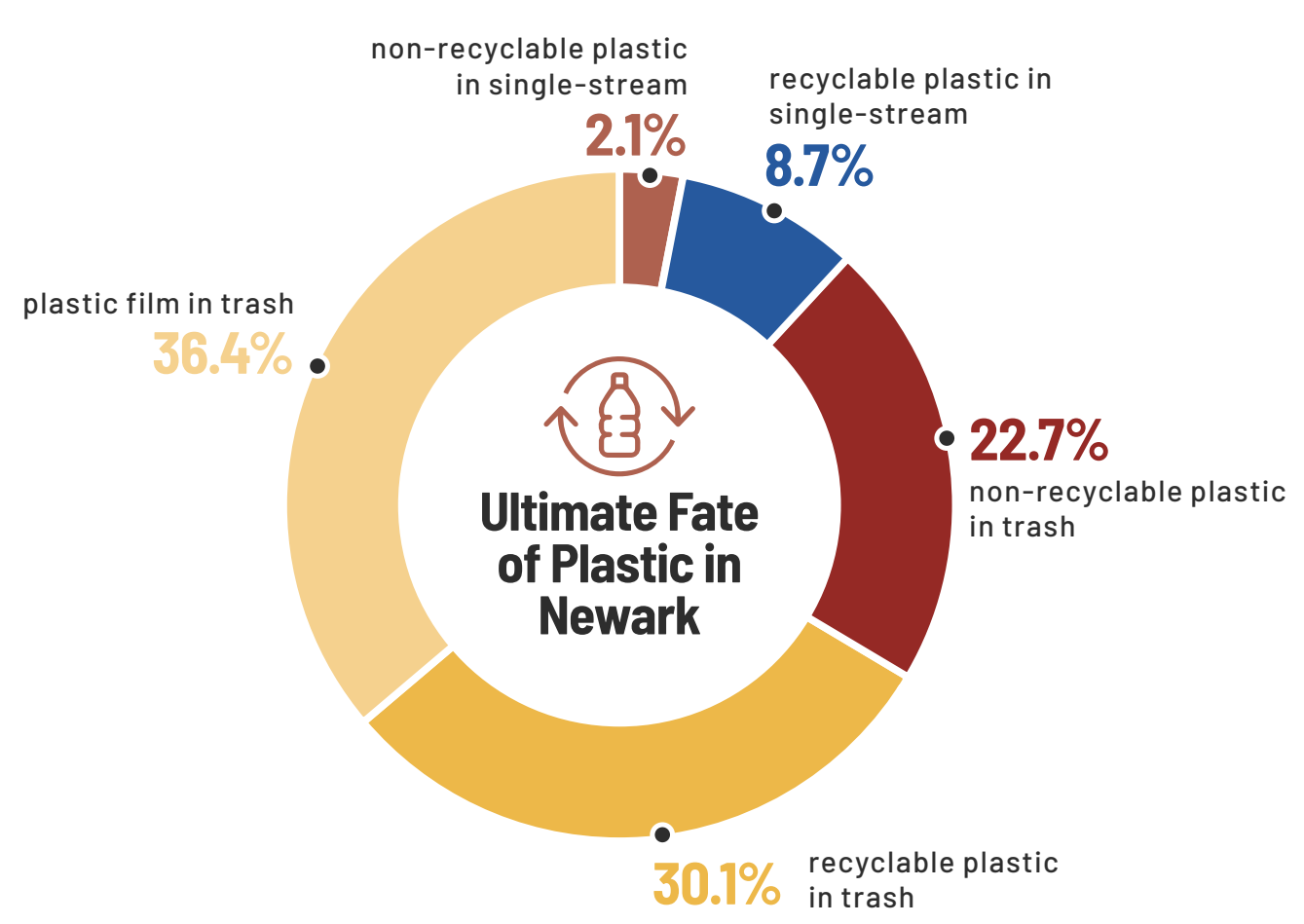

The percentage of recyclable and non-recyclable plastic that ends up in the trash or single-stream system. This chart shows the limited amount of diversion that is possible under the city's current program.

Key Points on Overall State of Plastic:

- $8.7 \%$ of all plastic is actually recycled today in Newark.

- $61.2 \%$ of plastic (non-recyclable plastic in the trash, plastic film in trash, and non-recyclable plastic at a MRF) cannot be recycled in Newark's current system.

- $38.8 \%$ of all plastic is potentially recyclable today. 
- $77.6 \%$ of all recyclable plastic is in the trash, not the recycling.

- The majority of plastic is non-recyclable and in the waste stream, representing $59.1 \%$ of all plastic.

- This includes non-recyclable containers that total $22.7 \%$ of all plastic in Newark and plastic film $(36.4 \%)$ that cannot be recycled in single-stream programs and is not collected separately due to significant costs and logistical issues.

- Focusing on reduction will have the biggest impact on reducing plastic in the waste stream, as most plastic is non-recyclable.

\section{HOW LIKELY IS IT THAT WE CAN AT LEAST RECYCLE THE RECYCLABLE PLASTIC?}

CHART N6

Capture Rates by Commodity in Newark

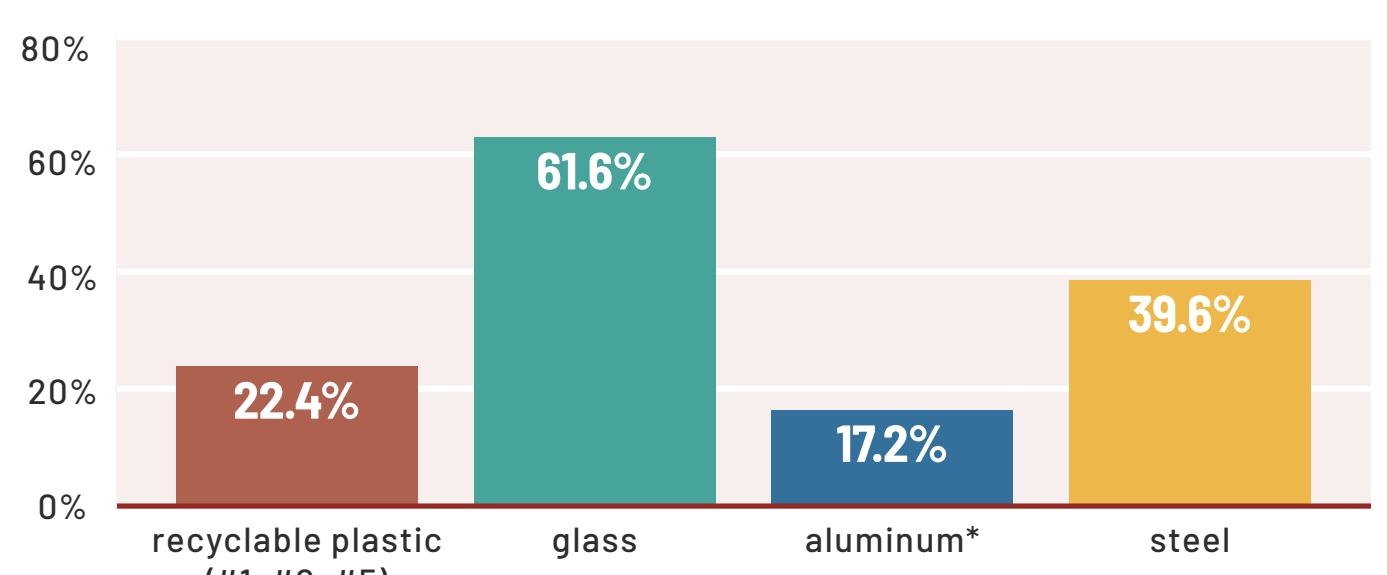

$(\# 1, \# 2, \# 5)$

aluminum

steel

*Curbside only, recovery rate likely higher.

The capture rate of a recyclable commodity is the percentage of that commodity that is disposed of (in the trash or recycling) that is recycled. This chart compares the capture rate for each type of container included in the recycling program.

Key Points on Capture Rate:

- $22.4 \%$ of recyclable plastic containers end up in a recycling stream and $77.6 \%$ of all recyclable plastic is in the trash, not recycling.

- Other commodities, like glass and steel, are captured at higher rates than that of recyclable plastic

- All commodities in Newark are captured at a low rate. With the exception of glass, more than half of all containers end up in the trash in Newark.

- Focusing on plastic recycling will have much less of an impact without a successful recycling program for all commodities, particularly given the low capture rate of plastic compared to other containers.

\section{WHERE DOES THIS LEAVE SINGLE-STREAM RECYCLING AS A WHOLE?}

CHART N7

Average Composition from Newark's Single-Stream Residential Collection Programs

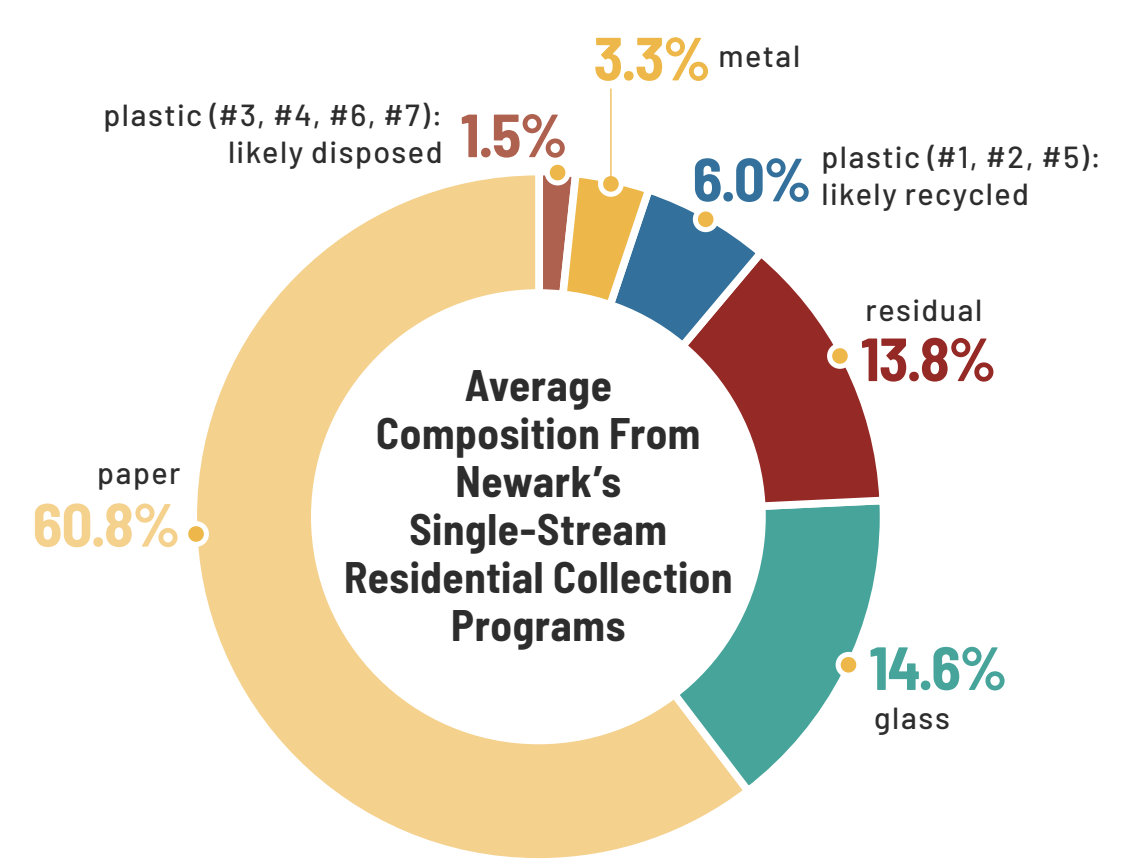

The percentage of materials sorted through the single-stream program that is metal, glass, paper plastic, or residual. This chart shows the MRF's composition of curbside recycling collected in Newark.

Key Points of Overall Composition of MRF:

- About $85 \%$ of recycling in Newark's single-stream program is recycled and it's important to continue recycling.

- Over three quarters of the recycling consists of paper, glass, and metals

- Paper is by far the most recycled commodity at $60.8 \%$ of the recycling stream.

- Glass and metals make up an additional $18 \%$ of the recycling stream.

- While outside the scope of this project, many MRFs use glass for low value uses such as alternative daily cover on landfills, rather than sending the cullet back to glass manufacturers.

- Recyclable plastic makes up $6 \%$ of single-stream material.

- $15.3 \%$ of all the single-stream materials delivered to the MRF from Newark is likely disposed of burned for energy, or sent to another MRF or secondary processor.

- $13.8 \%$ of material delivered to the MRF is residual: items that were wishcycled (non-recyclable in the first place and mistakenly put in recycling bins and carts); material that was destroyed or contaminated in the collection and sorting process; or material that cannot be sorted due to the inherent inefficiencies of single-stream MRFs, such as human error or mechanical issues caused by the size, shape, or condition of the material going across the sort line. Some residuals end 
up as waste disposed of at the MRF, while other residuals are incorrectly sorted into the wrong commodities sent to the wrong market, where they will generally be disposed of.

- $1.5 \%$ is non-recyclable plastic.

- These numbers reflect the glass, metal, and plastic collected in curbside recycling bins and carts.

\section{WHAT'S LEFT AFTER DIVERSION IN NEWARK?}

CHART N8

What's Left After Diversion in Newark

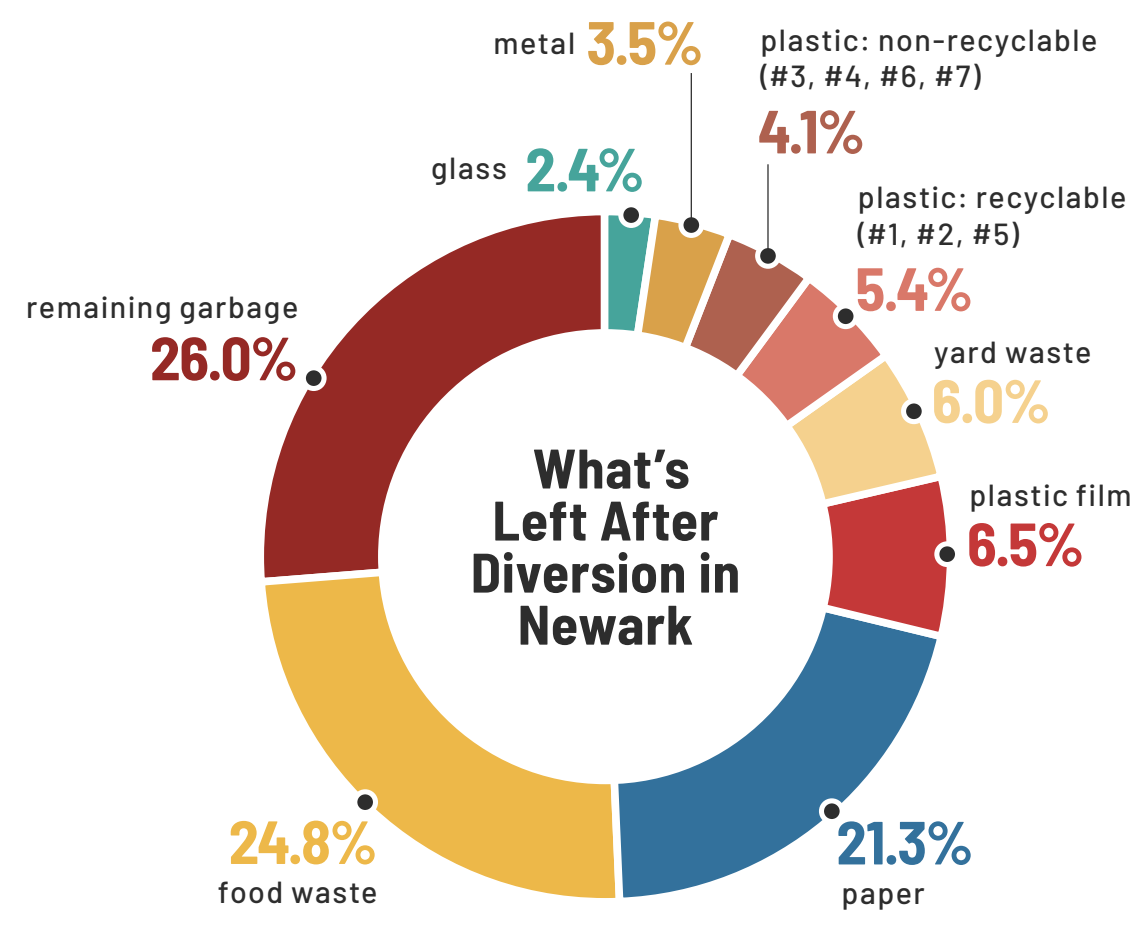

This chart shows the composition of what is left after diversion in Newark.

Key Points of What's Left After Diversion in Newark:

- Food waste (24.8\%) and yard waste (6\%) make up the largest fraction of what's left in the trash, totaling $30.8 \%$ of the remaining waste in Newark.

- Traditional recyclables of paper (21.3\%), glass (2.4\%), and metal (3.5\%) also account for over $27 \%$ of the waste stream

- A small fraction of the waste stream (5.4\%) is potentially recyclable plastic.

- Plastic, including film (6.5\%), non-recyclable (4.1\%), and recyclable packaging (5.4\%), makes up $16 \%$ of the waste stream

- Plastic film makes up almost two-thirds of non-recyclable plastic.

Data Sources can be found in the Appendix II: Methodology and Data Summary.
WASTE CHARACTERIZATION SUMMARY

CITY OF LONG BEACH

The following table provides a summary of key program components, for use as context in analyzing Long Beach's data.

LONG BEACH DEMOGRAPHICS AND DATA SOURCE SUMMARY

\begin{tabular}{|c|c|}
\hline Population & 475,980 \\
\hline$\%$ of Total Waste Incinerated & $68 \%$ of all waste goes to the SERFF incinerator and the rest to a landfill. \\
\hline Municipal Recycling Program & $\begin{array}{l}\text { Weekly single-stream collection, recently dropped all plastic and now only } \\
\text { collects \#1PET, \#2 HDPE, and \#5 PP. }\end{array}$ \\
\hline Municipal Composting Program & There is no citywide collection of yard waste or food waste. \\
\hline Included in Waste Generation Rates & $\begin{array}{l}\text { Long Beach numbers include both residential and commercial components of } \\
\text { MSW within the city. }\end{array}$ \\
\hline Data Quality Summary & $\begin{array}{l}\text { Composition and generation of recycling is specific to Long Beach and from } \\
2019 \text {. } \\
\text { Composition of waste is from statewide data tools using } 2014 \text { data. } \\
\text { Generation of waste is from county reported } 2019 \text { numbers. }\end{array}$ \\
\hline
\end{tabular}

\section{ABOUT THE DATA SOURCES}

The process for gathering data for Long Beach followed the procedures outlined in the general methodology section. Total tons recycled and disposed of were reported by the city. The CalRecycle Waste Stream Measurement and Analysis tool was used to extrapolate commercial and residential volumes, as well as provide the composition of the waste stream. The percentage incinerated was reported as part of an $L A$ County report. The plastic numbers from this study used in the analysis were approximately $77 \%$ containers and included approximately $23 \%$ non-container durable plastic in the nonrecyclable plastic categories, such as composite plastic and small household items like toys, tableware or home decor. The analysis only included plastic sorted out specifically in plastic grades and did not include all plastic in the waste stream such as those found in electronics, furniture, or textiles. Recycling composition was provided by the recycling vendor, Waste Management, upon request of the city as part of the requirements of the recycling contract. As polypropylene (\#5 PP) was not separated from the "mixed plastic" grade in the trash or recycling composition study, the extrapolation method detailed in the methodology was used. 


\section{HOW MUCH TOTAL MATERIAL IS THROWN OUT AND DIVERTED IN LONG BEACH?}

CHART LBI

Residential Annual Generation Rates in tons/year

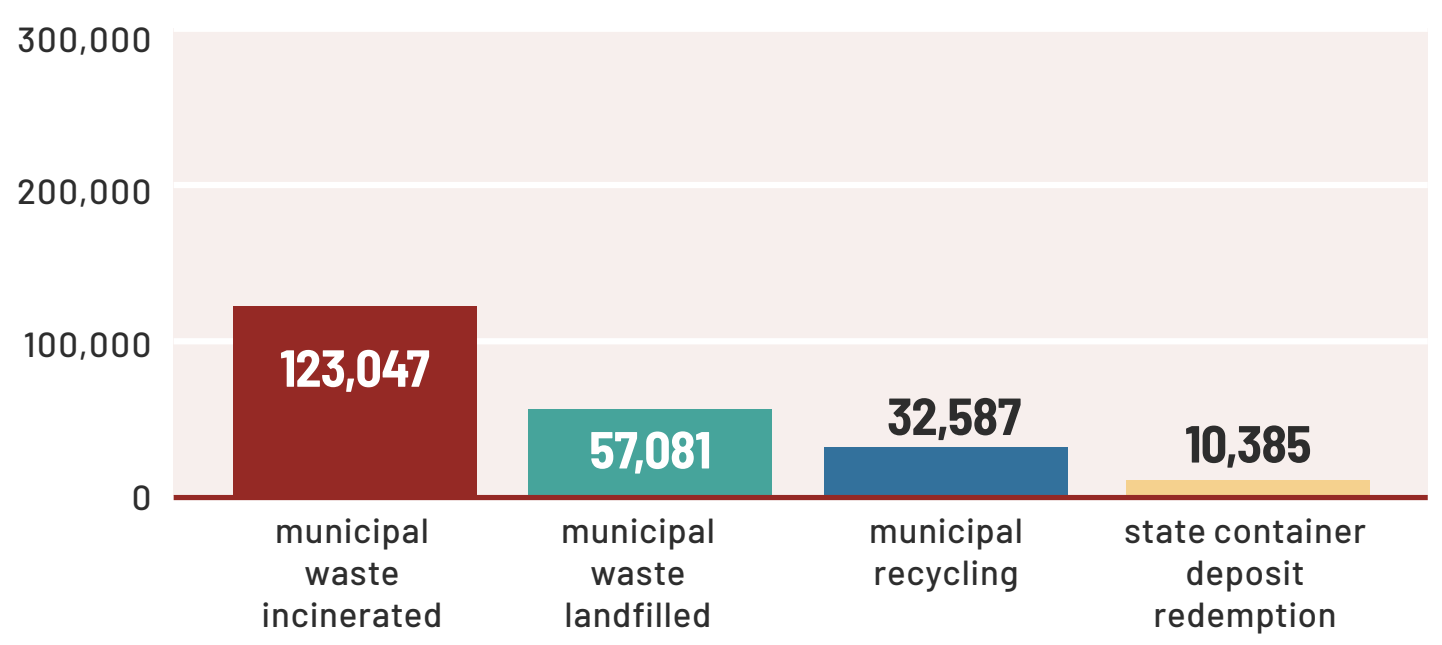

The total amount, in metric tons, of municipal solid waste (MSW) delivered annually to landfills, incinerators, recycling facilities, or composting facilities from households and businesses in Long Beach. The compost collection is based on the statewide characterization tool for commercial composting.

\section{CHART LB2}

Where Waste from Long Beach Goes

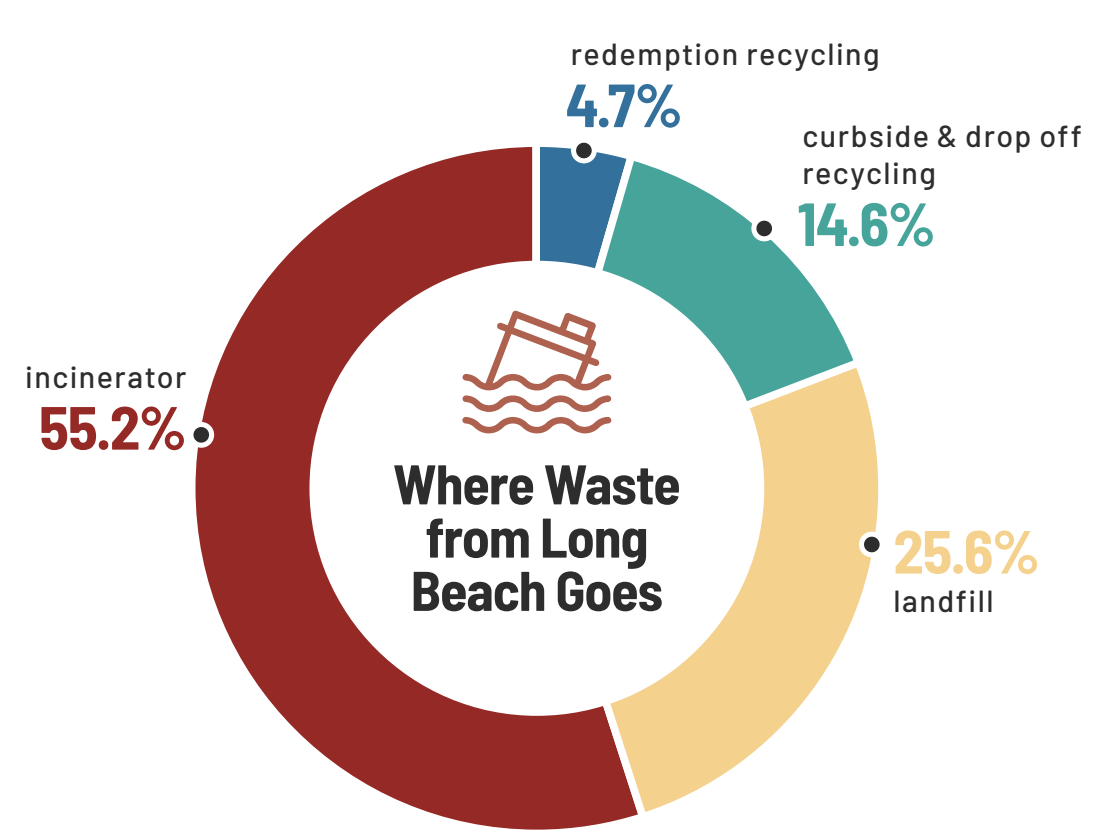

The percentage of MSW collected for recycling, compost, incineration, or disposal. Recycling collection takes place through municipal collection, drop off programs, and the statewide redemption program.

There are no reported composting numbers on the residential side in Long Beach. These numbers show the initial destination point, not the percentage of material actually diverted (as described).

Key Points on Generation and MSW Sorting:

- Long Beach sends almost $81 \%$ of its waste directly to disposal: $55.2 \%$ of its waste is incinerated and $25.6 \%$ is sent to landfills.

- Over two-thirds of disposal discards get sent to an incinerator.

- $19.3 \%$ of MSW is diverted for recycling.

- $14.6 \%$ is collected through municipal curbside and drop off recycling programs.

- $4.7 \%$ is collected through the bottle deposit redemption program

- Slightly more than half of all waste in Long Beach comes from the commercial sector, while the majority of recycling comes from the residential sector. There was no available data for residential compost.

\section{WHAT HAPPENS TO PLASTIC DISCARDS IN LONG BEACH?}

\section{Initial Plastic Diversion}

CHART LB3

Where Residents and Businesses Discard Plastic in Long Beach

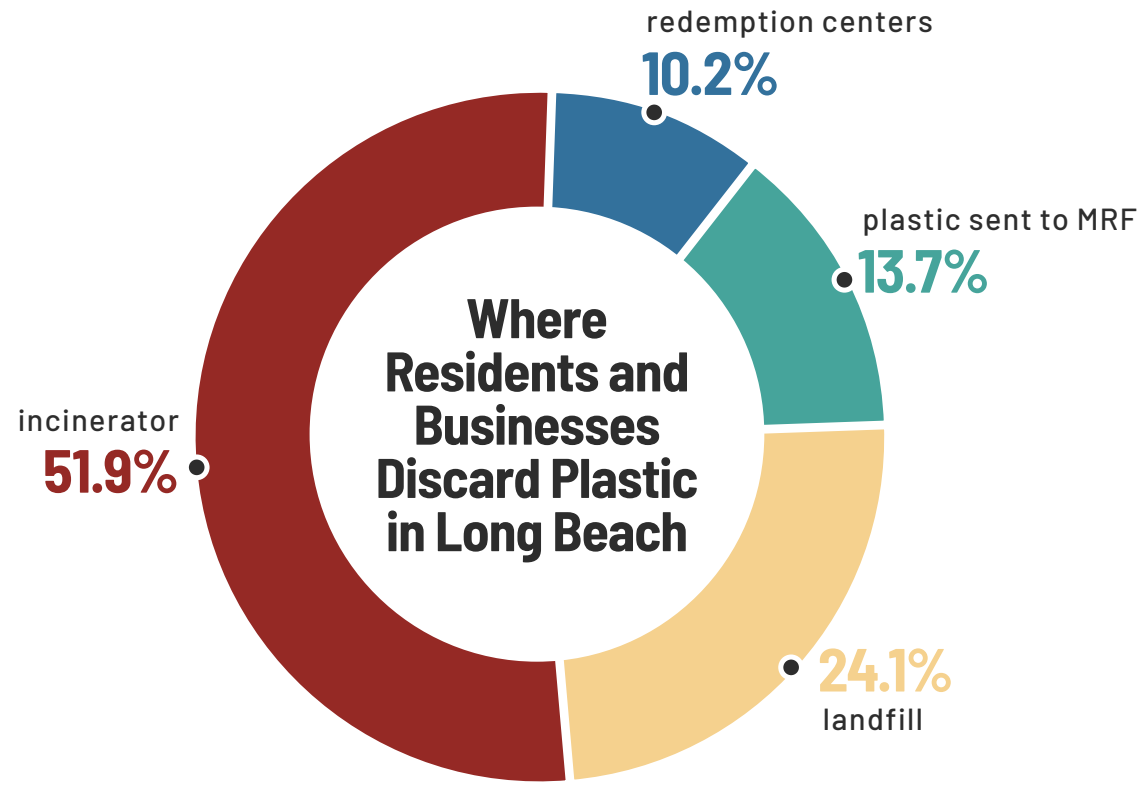


The percentage of all plastic discarded in the city is currently sent to a materials recovery facility (MRF) for recycling (but not necessarily recycled, see below) through the curbside program, to a redemption center, to an incinerator, or landfilled.

\section{Key Points on Diversion of Plastic:}

- Currently $76 \%$ of plastic goes directly to disposal with two-thirds going to incineration and the remainder to landfills.

- $13.7 \%$ of all plastic in Long Beach is collected for residential recycling through the city curbside recycling program or through the State redemption system. This does not ensure that it is actually recycled (see next section).

$10.2 \%$ is captured through the state redemption program.

- While the curbside recycling program captures more overall plastic than the state bottle deposit program, it is important to factor in the net plastic actually recycled, as discussed in the following program, it

- Diversion rates include some non-recyclable plastic that are incorrectly included in recycling (see next section).

\section{PLASTIC THAT "ACTUALLY" GETS RECYCLED}

CHART LB4

What Happens to the Plastic in Long Beach's Single-Stream Recycling Program

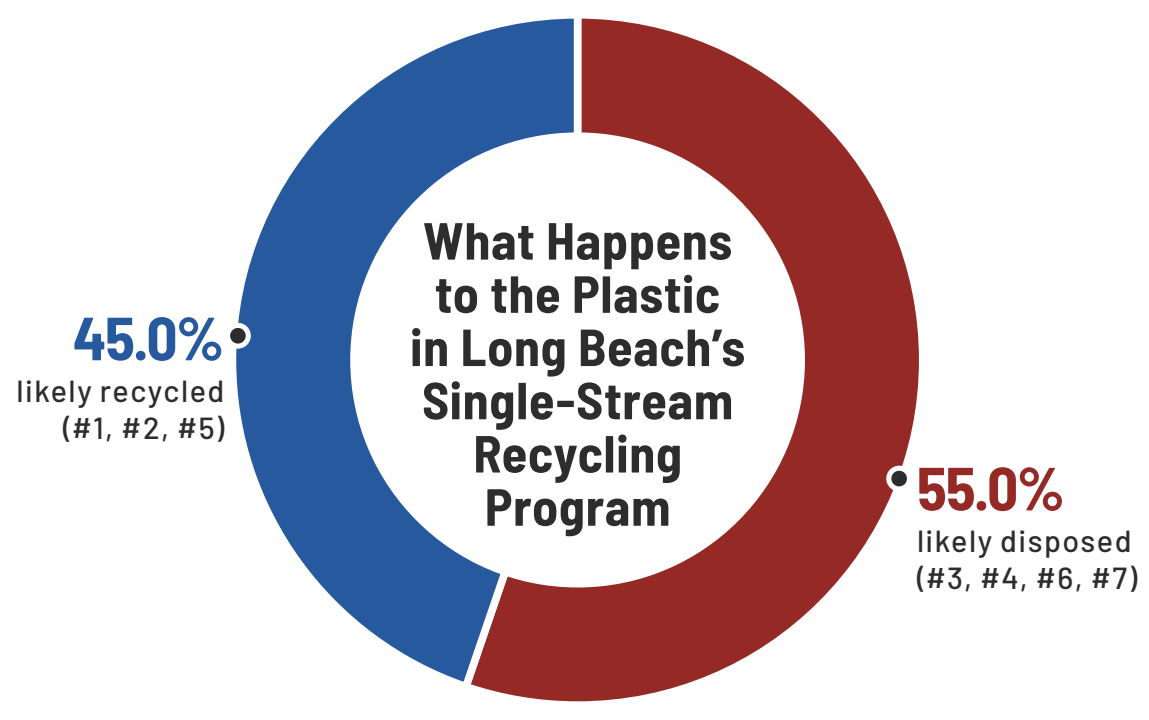

The percentage of plastic that is sorted for recycling and sent to a MRF that is likely recycled or likely disposed of. The study assumes only \#1 PET, \#2 HDPE, and \#5 PP plastic have viable end markets in these cities. It is also assumed that \#3 PVC, \#4LDPE, \#6 PS, and \#7 other plastic are likely sent to another MRF or secondary processor, or are disposed of (disposal includes incineration, landfilling, burning as fuel at industrial facilities, plastic-to-fuel, etc)

\section{Key Points on Plastic in Long Beach:}

- It is assumed that $100 \%$ of the state deposit program only accepts recyclable bottles as defined in this report (\#1 PET, \#2 HDPE, and \#5 PP) and that all bottles collected through it are actually

As discussed in the following section, even though the gross amount of plastic collected through the deposit program is lower than plastic collected curbside, the net plastic recycled from the deposit program nets out to over 1.5 times the amount that is collected and actually recyclable in the curbside program.

- Just because plastic makes it to a recycling bin does not mean it is actually recycled.

- The majority of plastic collected in Long Beach's municipal curbside recycling program (55\%) cannot be recycled in the current system.

- Despite dropping non-recyclable plastic from the recycling program, the contamination is still present, demonstrating the difficulty in educating residents on which plastic to include in recycling.

- The MRF where recycling from Long Beach goes worked with the city to transition away from collecting 3-7 plastic, as there was no market for them.

- City reporting on recycling likely includes the non-recyclable material counted as "recycled" because it is often measured by what residents place at the curb, not by what is actually recycled.

- For every two tons of plastic that is received by a MRF, one ton of this plastic is non-recyclable plastic. This results in increased contamination and increased cost to the city which pays a much higher fee for trash that is sent to recycling. Eliminating non-recyclable plastic would likely cut processing fees associated with plastic recycling in half.

- If plastic recycling continues without strategies to address non-recyclable plastic, MRFs would be significantly impacted by the increased contamination rates associated with increased recovery. 


\section{HOW MUCH ACTUAL PLASTIC RECYCLING IS HAPPENING NOW AND WHAT IS POTENTIAL FOR MORE?}

CHART LBD

Ultimate Fate of Plastic in Long Beach

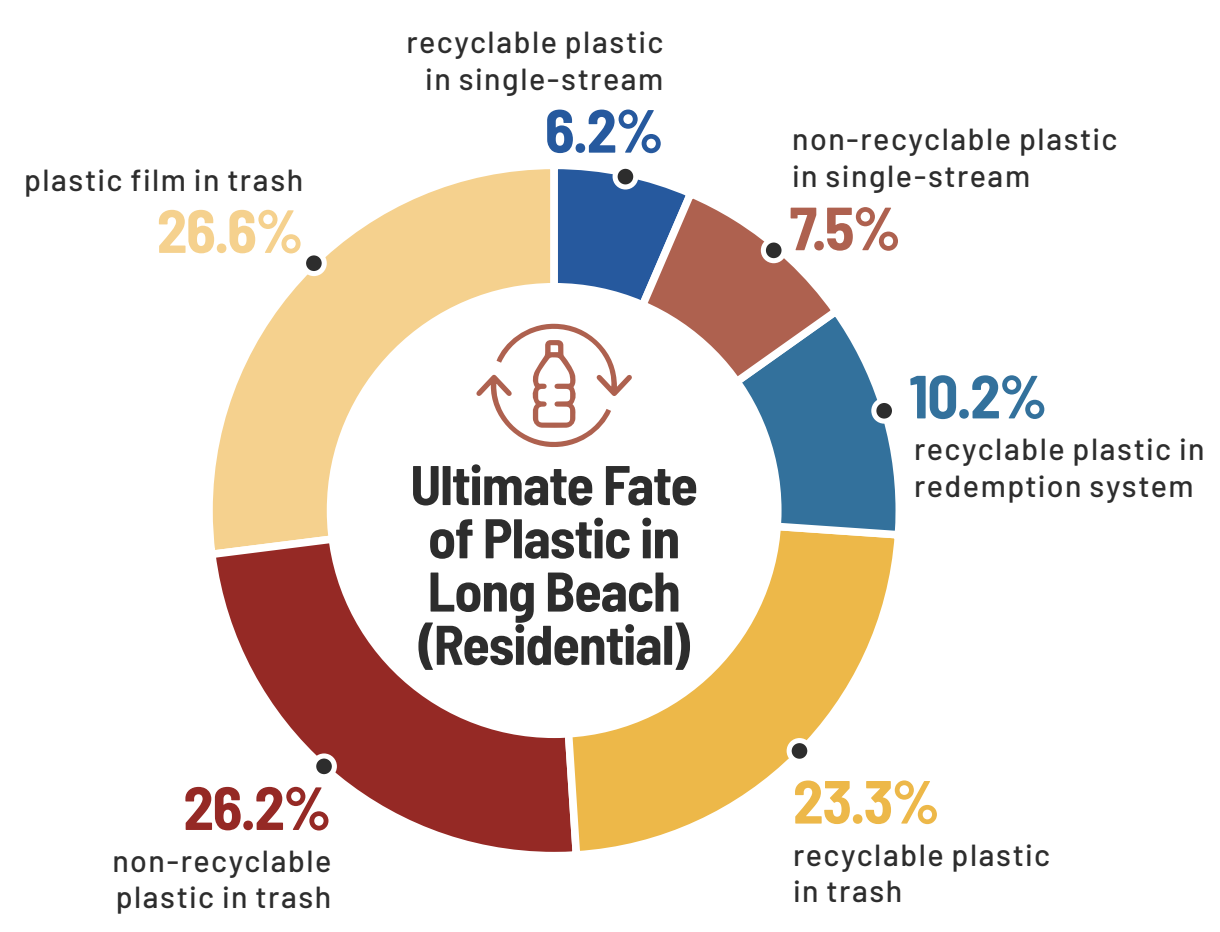

The percentage of recyclable and non-recyclable plastic that ends up in the trash, single-stream, or redemption system. While Long Beach collects data on both residential and commercial plastic, this chart only includes residential data. This chart shows the limited amount of diversion that is possible under the city's current program.

\section{Key Points on Overall State of Plastic:}

- $16.4 \%$ of all plastic is actually recycled today in Long Beach.

- $6.2 \%$ of plastic is collected through the curbside recycling program.

- The deposit redemption program (10.2\%) is a more impactful method of recycling plastic compared to curbside recycling.

- However, $83.6 \%$ of plastic is still trashed in Long Beach.

- $60.3 \%$ of plastic cannot be recycled in Long Beach's current system.

- $39.7 \%$ of all plastic is potentially recyclable today.

- The majority of plastic is non-recyclable and in the waste stream, representing $52.8 \%$ of all plastic.

- This includes non-recyclable containers $(26.2 \%)$ and plastic film (26.6\%) that cannot be recycled in single-stream programs and is not collected separately due to significant costs and logistical issues.
- Focusing on reduction will have the biggest impact on reducing plastic in the waste stream, as most plastic is non-recyclable.

\section{HOW LIKELY IS IT THAT WE CAN AT LEAST RECYCLE THE RECYCLABLE PLASTIC?}

CHART LB6

Capture Rates by Commodity in Long Beach

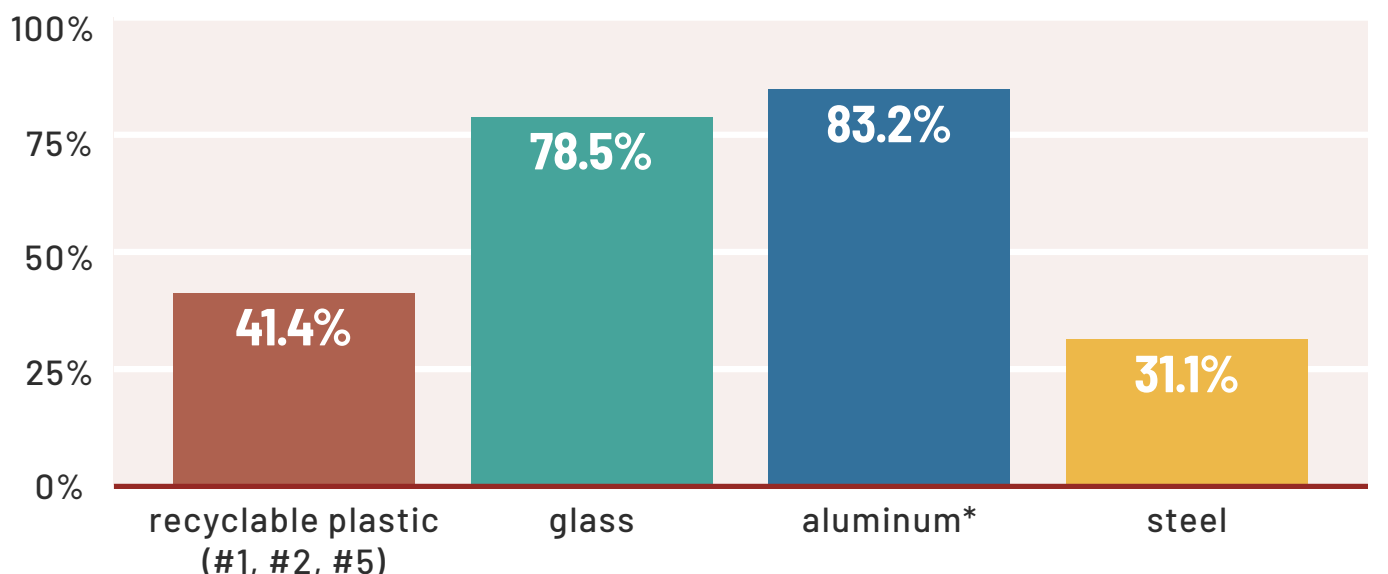

${ }^{*}$ Curbside only, recovery rate likely higher.

The capture rate of a recyclable commodity is the percentage of that commodity that is disposed of (in the trash or recycling) that is recycled. This chart compares the capture rate for each type of container included in the recycling program.

\section{Key Points on Capture Rate:}

- $41.4 \%$ of recyclable plastic containers end up in a recycling stream and $58.6 \%$ of all recyclable plastic is in the trash, not the recycling. As described above, most of these are captured through the deposit redemption system.

- The bottle bill has increased the recyclable plastic capture rate, however it is still less than that of glass and aluminum.

- Deposit legislation greatly improves glass and aluminum recovery.

- Focusing on plastic recycling will have much less of an impact without a successful recycling program for all commodities, particularly given the low capture rate of plastic compared to other containers. 


\section{WHERE DOES THIS LEAVE SINGLE-STREAM RECYCLING AS A WHOLE?}

CHART LB7

Average Composition from Long Beach's Single-Stream Residential Collection Programs

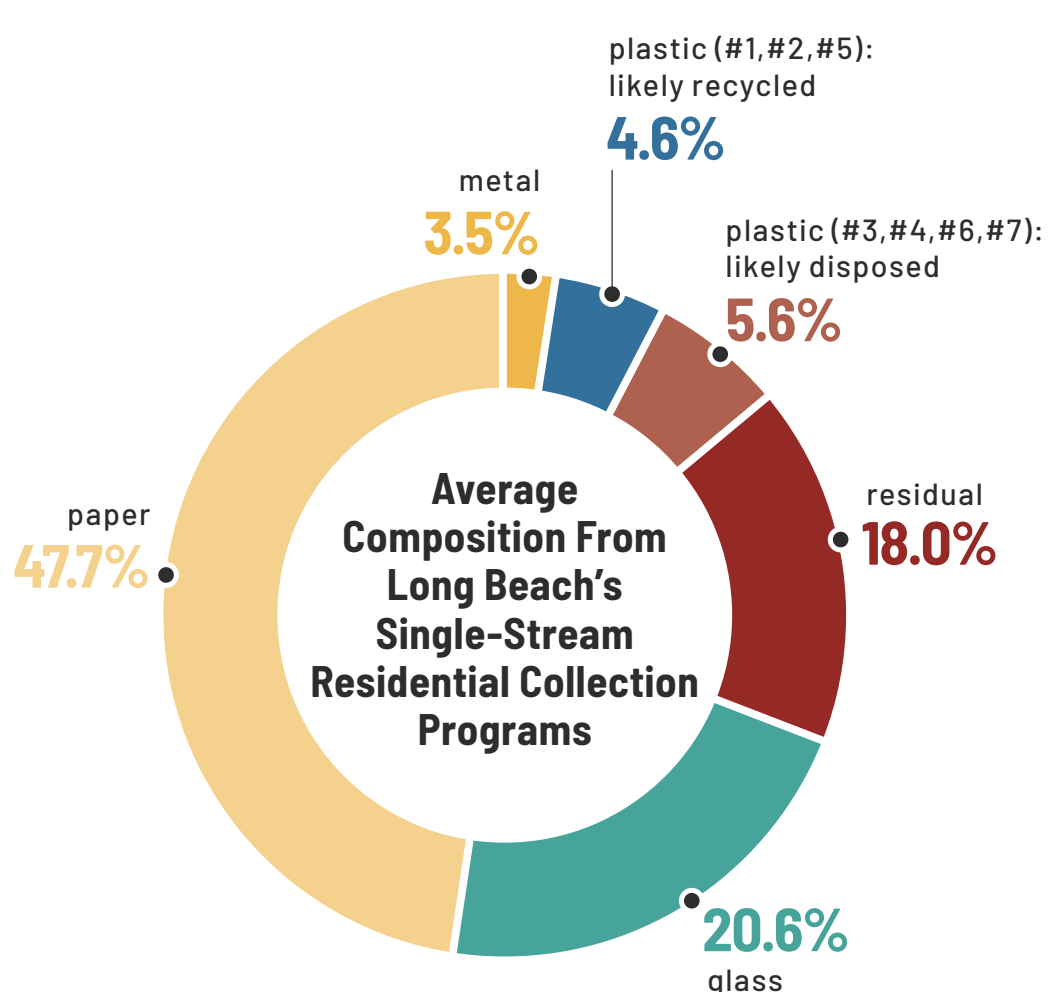

The percentage of materials sorted through the single-stream program that is metal, glass, paper, plastic, or residual. This chart shows the MRF's composition of curbside recycling collected in Long Beach.

Key Points of Overall Composition of MRF

- Over $76 \%$ of recycling in Long Beach's single-stream program is recycled and it's important to continue recycling.

- $71.8 \%$ of the recycling consists of paper, glass, and metals that all have stable domestic end markets

- Paper is by far the most recycled commodity at $47.7 \%$ of the recycling stream.

- Glass and metal make up an additional $24.1 \%$ of the recycling stream.

- While outside the scope of this project, many MRFs use glass for low value uses such as alternative daily cover on landfills, rather than sending the cullet back to glass manufacturers.

- Recyclable plastic makes up less than $5 \%$ of single-stream material.

- $23.6 \%$ of all the single-stream materials delivered to the MRF from Long Beach is likely ultimately disposed of, burned for energy, or sent to another MRF or secondary processor.
- $18 \%$ of material delivered to the MRF is residual: items that were wishcycled (non-recyclable in the first place and mistakenly put in recycling bins and carts); material that was destroyed or contaminated in the collection and sorting process; or material that cannot be sorted due to the inherent inefficiencies of single-stream MRFs, such as human error or mechanical issues caused by the size, shape, or condition of the material going across the sort line. Some residuals end up as waste disposed of at the MRF, while other residuals are incorrectly sorted into the wrong commodities sent to the wrong market, where they will generally be disposed of.

- $5.6 \%$ is non-recyclable plastic.

- These numbers reflect the glass, metal, and plastic collected in curbside recycling bins and carts. They do not include the glass, metal, and plastic collected through the state redemption program or brought directly to a metal recycling facility.

\section{WHAT'S LEFT AFTER DIVERSION IN LONG BEACH?}

CHART LB8

What's Left After Diversion in Long Beach

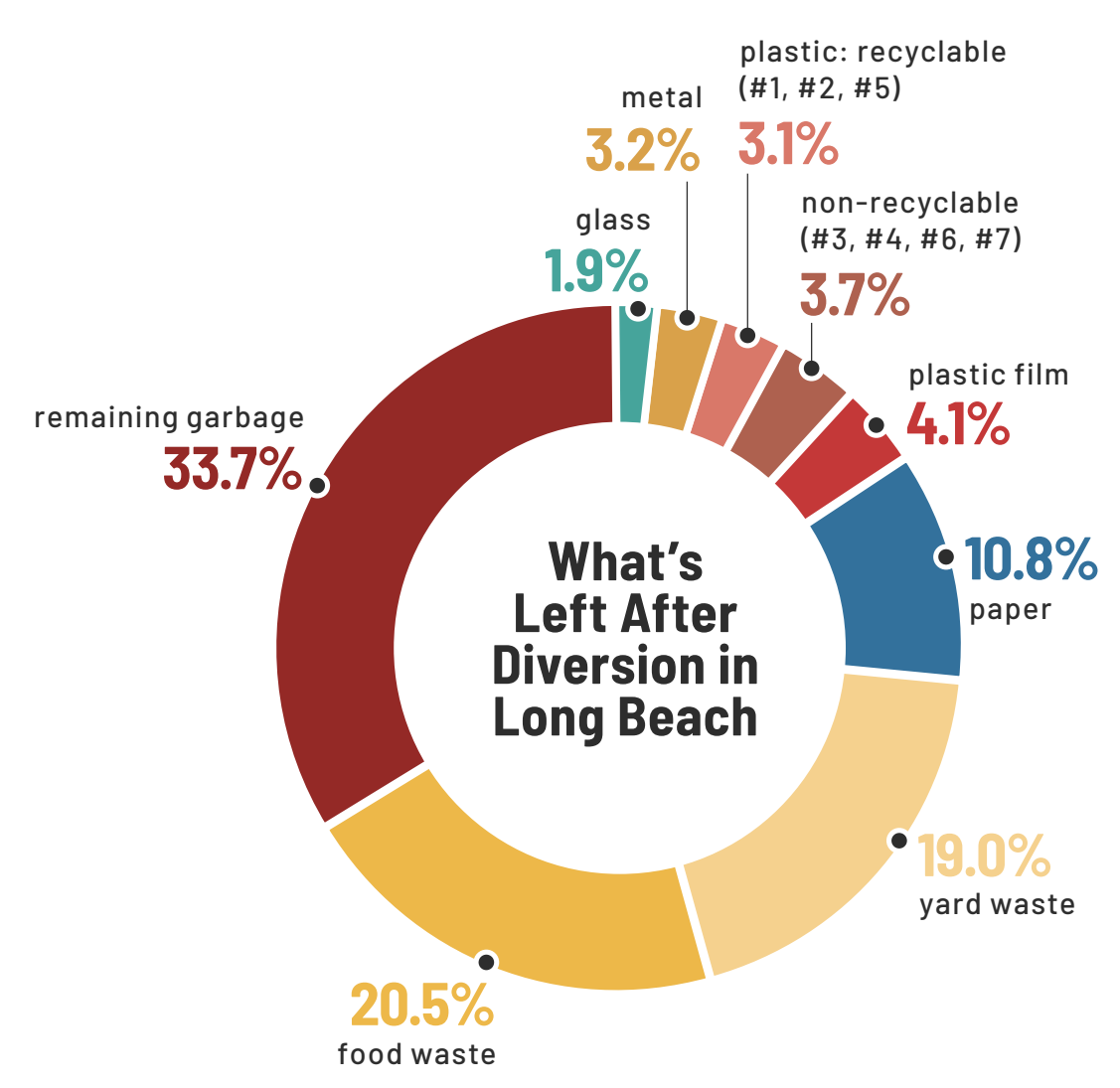

This chart shows the composition of what is left after diversion in Long Beach. 


\section{Key Points of What's Left After Diversion in Long Beach:}

- Food waste $(20.5 \%)$ and yard waste $(19.0 \%)$ make up the largest fraction of what's left in the trash, totalling over $39 \%$ of the remaining waste in Long Beach.

- Traditional recyclables of paper (10.8\%), glass (1.9\%), and metal (3.2\%) account for about $16 \%$ of the waste stream

- A small fraction of the waste stream $(3.1 \%)$ is potentially recyclable plastic

- Plastic, including film (4.1\%), non-recyclable (3.7\%), and recyclable packaging $(3.1 \%)$, makes up almost $11 \%$ of the waste stream

- Plastic film makes up more than half of non-recyclable plastic.

Data Sources can be found in the Appendix II: Methodology and Data Summary.
WASTE CHARACTERIZATION SUMMARY

CITY OF DETROIT

The following table provides a summary of key program components, for use as context in analyzing Detroit's data.

\begin{tabular}{|l|l|}
\hline \multicolumn{2}{|c|}{ DETROIT DEMOGRAPHICS AND DATA SOURCE SUMMARY } \\
\hline Population & 647,841 \\
\hline$\%$ of Total Waste Incinerated & $0 \%$ (since incinerator shut down in 2019) \\
\hline Municipal Recycling Program & $\begin{array}{l}\text { Since 2015, the city has provided "optional" recycling pickup. Collection service is } \\
\text { every ther week with a 36\% participation rate. } \\
\text { available to residenty, bins and carts are now }\end{array}$ \\
\hline Municipal Compost upon request from the City.
\end{tabular}

\section{ABOUT THE DATA SOURCES:}

The process for gathering data for Detroit followed the procedures outlined in the general methodology section. Recent work by Green Living Science (GLS) and the Urb Foundation provided a detailed composition of Detroit's single-stream recycling program. GLS was also able to provide total tons of MSW recycled, landfilled, incinerated, and composted in Detroit in 2018. These numbers did not diffe significantly from the available 2015 Wayne County Reporting. No published waste characterization study specific to Detroit was available. A Michigan statewide residential composition study from 2016 was used in its place. The plastic collection numbers from Economic Impact Potential and Characterization of Municipal Solid Waste in Michigan used in the analysis were approximately $79 \%$ containers and included approximately $21 \%$ non-container durable plastic, such as small household items like toys, tableware or home decor. The analysis only included plastic sorted out specifically in plastic grades and did not include all plastic in the waste stream such as those found in electronics, furniture or textiles. As polypropylene (\#5 PP) was not separated from the "mixed plastic" grade in the trash composition study, the extrapolation method detailed in the methodology was used. 


\section{HOW MUCH TOTAL MATERIAL IS THROWN OUT AND DIVERTED IN DETROIT?}

CHART D1

Residential and Commercial Annual Generation Rates in tons/year

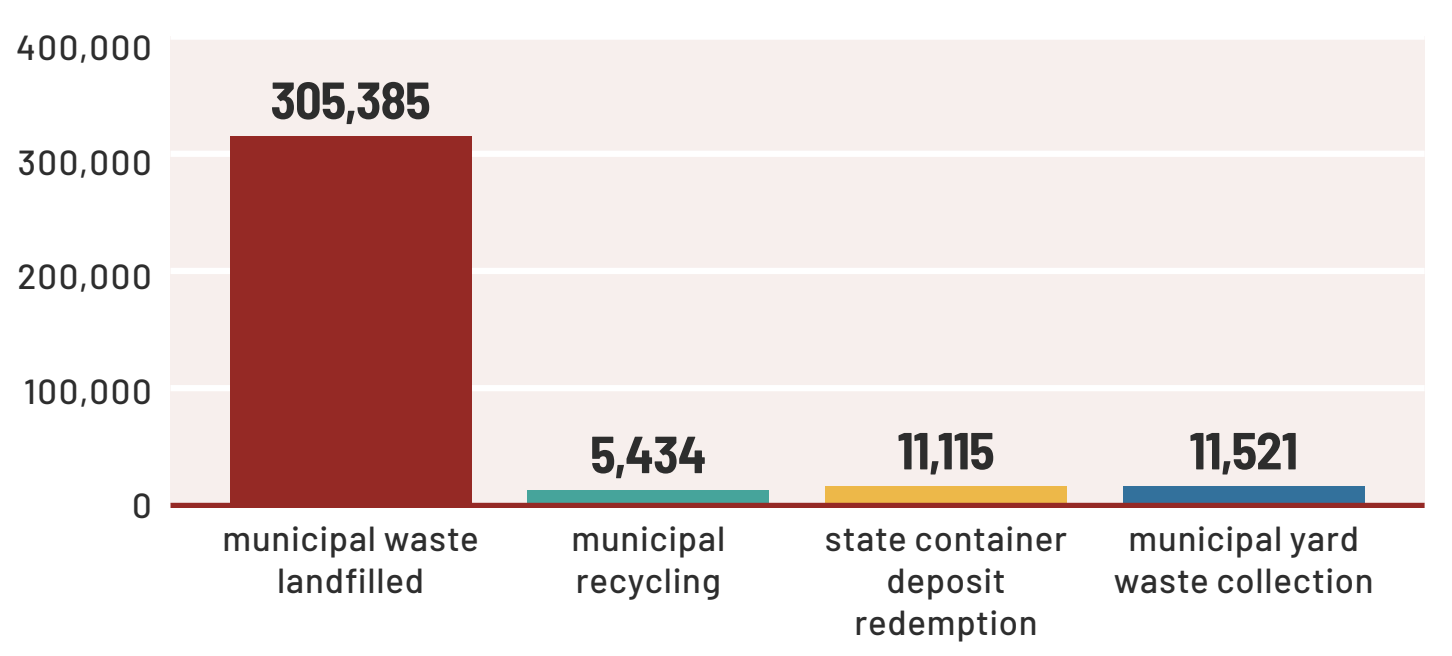

The total amount, in metric tons, of municipal solid waste (MSW) delivered annually to landfills, incinerators, recycling facilities, or composting facilities from households and businesses in Detroit.

CHART D2

Where Waste from Detroit Goes

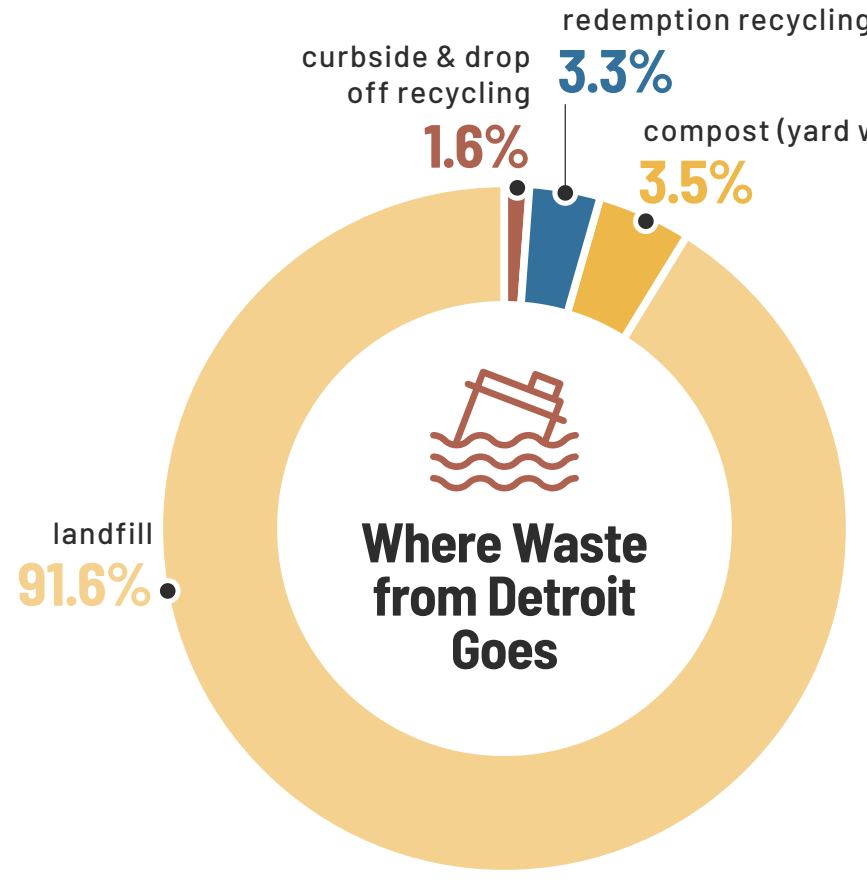

The percentage of MSW collected for recycling, compost, or disposal. Recycling collection takes place through municipal collection, drop off programs, and the statewide redemption program. Compost only includes municipally collected yard waste. These numbers show a breakdown of material reaching the initial destination point, not the percentage of material actually diverted (as described).

\section{Key Points on Generation and MSW Sorting :}

- Detroit sends all waste bound for disposal (91.6\%) to landfills because the incinerator shut down in 2019.

- A total of $5.0 \%$ of MSW is diverted for recycling.

- $1.6 \%$ is collected through municipal curbside and drop off recycling programs.

- $3.3 \%$ is collected through the state bottle redemption program, which is more than twice the percentage that is diverted through the municipal recycling program.

- Compost diversion accounts for $3.5 \%$ of MSW, the majority of which is yard waste. Detroit provides seasonal yard waste pickup. There is currently no citywide food waste collection program.

\section{WHAT HAPPENS TO PLASTIC DISCARDS IN DETROIT?} Initial Plastic Diversion:

CHART D3

Where Residents and Businesses Discard Plastic in Detroit

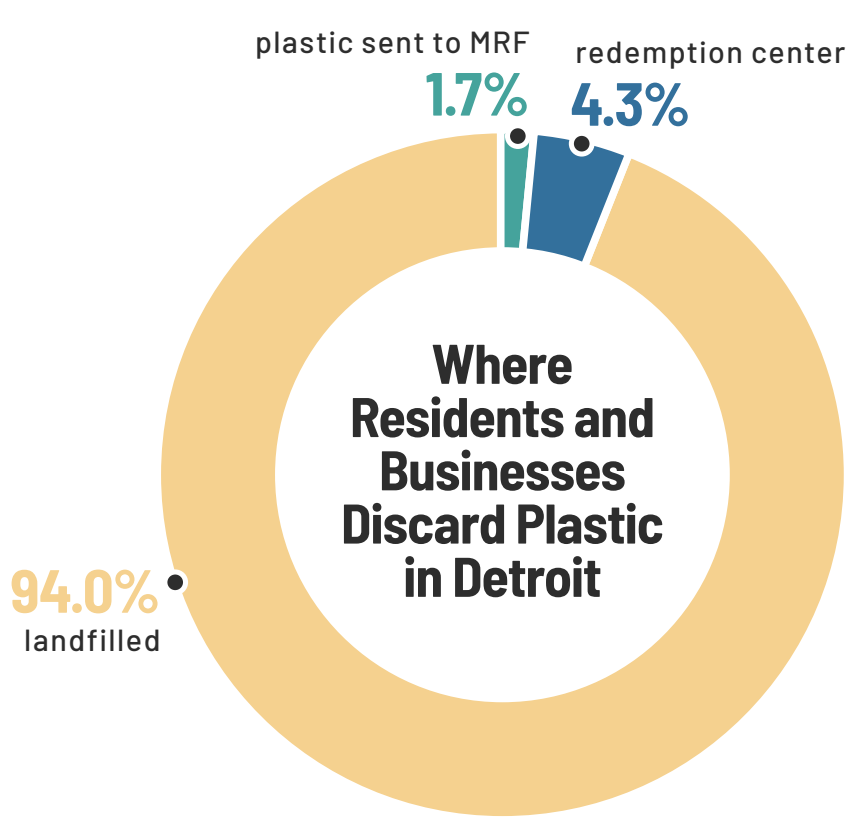

The percentage of all plastic discarded in the city that is currently sent to a materials recovery facility (MRF) for recycling (but not necessarily recycled, see below) through the curbside recycling program, to a redemption center, or landfilled. 
Key Points on Diversion of Plastic:

- Currently $94.0 \%$ of plastic goes directly to disposal in landfills.

- The vast majority of plastic is captured through the state bottle deposit program (4.3\%) compared to the curbside recycling program (1.7\%).

- Diversion rates include some non-recyclable plastic that are incorrectly included in recycling (see next section).

\section{PLASTIC THAT "ACTUALLY" GETS RECYCLED}

CHART D 4

What Happens to the Plastic in Detroit's Single-Stream Recycling Program

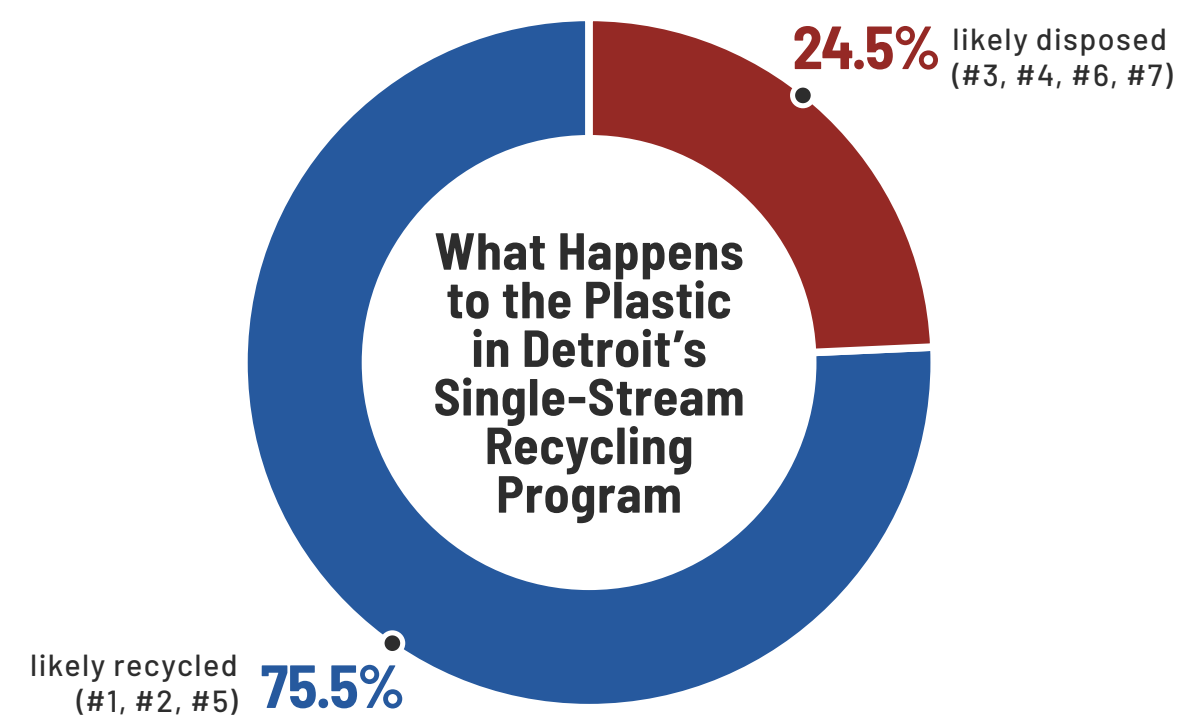

The percentage of plastic that is sorted for recycling and sent to a MRF that is likely recycled or likely disposed of. The study assumes only \#1 PET, \#2 HDPE, and \#5 PP plastic have viable end markets in these cities. It is also assumed that \#3 PVC, \#4 LDPE, \#6 PS, and \#7 other plastic are likely sent to another MRF or secondary processor, or are disposed of (disposal includes incineration, landfilling, burning as fuel at industrial facilities, plastic-to-fuel, etc).

Key Points on Plastic in Detroit:

- It is assumed that $100 \%$ of the state deposit program only accepts recyclable bottles as defined in this report (\#1 PET, \#2 HDPE, and \#5 PP) and that all bottles collected through it are actually recycled.

- $24.5 \%$ of plastic collected in Detroit's municipal curbside recycling program cannot be recycled in the current system.
Because the city advertises inclusion of all plastic (including non-recyclable), excluding only plastic bags, this is not surprising.

- The MRF likely sends mixed plastic bales to a secondary processor and counts them as recycled from the MRF.

- City reporting on recycling likely includes the non-recyclable material counted as "recycled" because it is often measured by what residents place at the curb, not by what is actuly recycled.

- For every four tons of plastic that is received by a MRF, one ton of this plastic is non-recyclable. This results in increased contamination and increased cost to the city which pays a much higher fee for trash that is sent to recycling. Eliminating non-recyclable plastic would likely reduce processing fees associated with plastic recycling by $25 \%$.

- If plastic recycling continues without strategies to address non-recyclable plastic, MRFs would be significantly impacted by the increased contamination rates associated with increased recovery.

\section{HOW MUCH ACTUAL PLASTIC RECYCLING IS HAPPENING NOW AND WHAT IS THE POTENTIAL FOR} MORE?

CHART D

Ultimate Fate of Plastic in Detroit

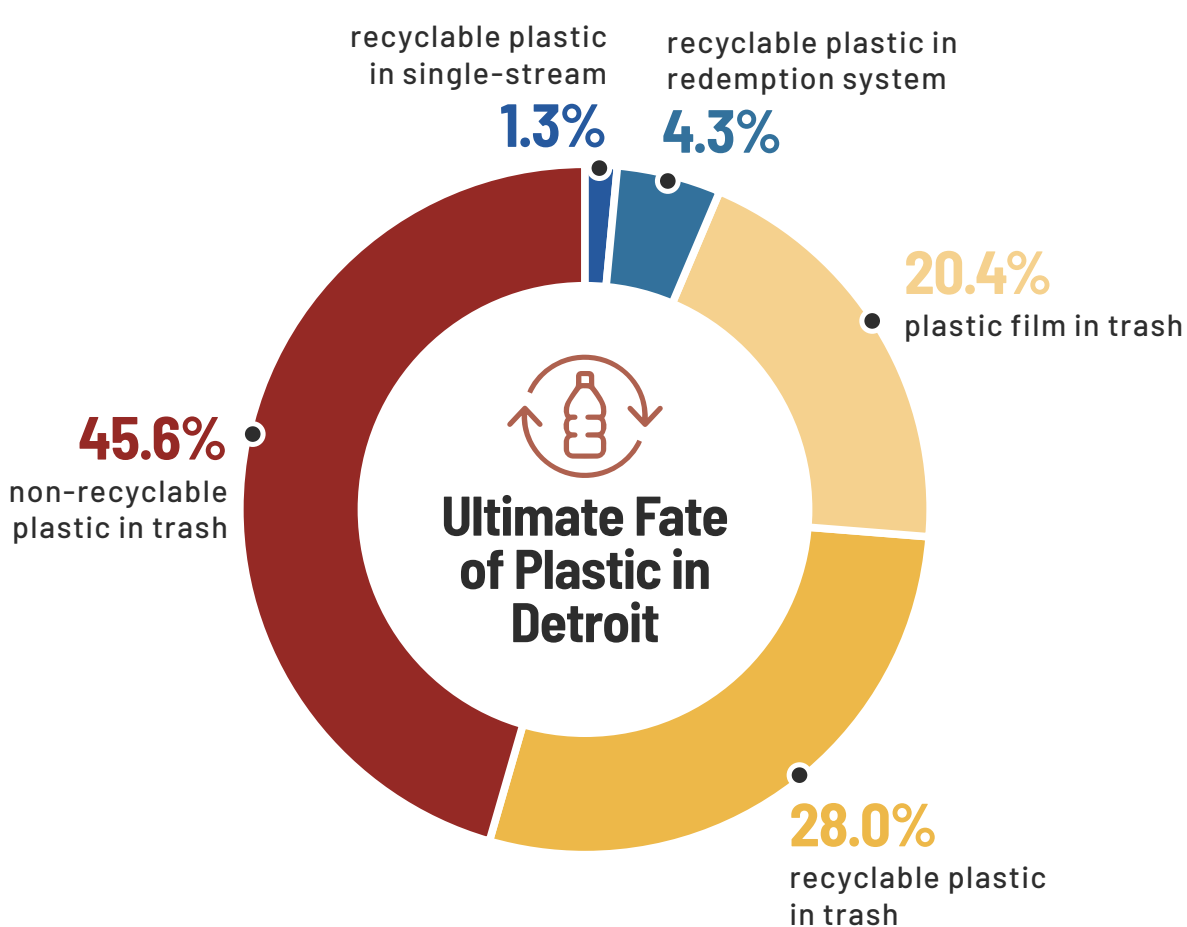

The percentage of recyclable and non-recyclable plastic that ends up in the trash, single-stream, or redemption system. This chart shows the limited amount of diversion that is possible under the city's current program. 
Key Points on Overall State of Plastic:

- $5.6 \%$ of all plastic is actually recycled today in Detroit, either through the redemption system or the single-stream curbside recycling program.

- $1.3 \%$ of plastic is recycled through the curbside recycling program.

- The deposit redemption program (4.3\%) is a much more cost-effective and impactful method of recycling plastic compared to curbside recycling-however, it still results in almost $95.0 \%$ of plastic being trashed in Detroit.

- The majority of plastic is non-recyclable and in the waste stream, representing $66 \%$ of all plastic.

- This includes non-recyclable containers (45.6\%) and plastic film (20.4\%) that cannot be recycled in single-stream programs and is not collected separately due to significant costs and logistical issues.

- Focusing on reduction will have the biggest impact on reducing plastic in the waste stream, as most plastic is non-recyclable.

\section{HOW LIKELY IS IT THAT WE CAN AT LEAST RECYCLE THE RECYCLABLE PLASTIC?}

CHART D 6

Capture Rates by Commodity in Detroit

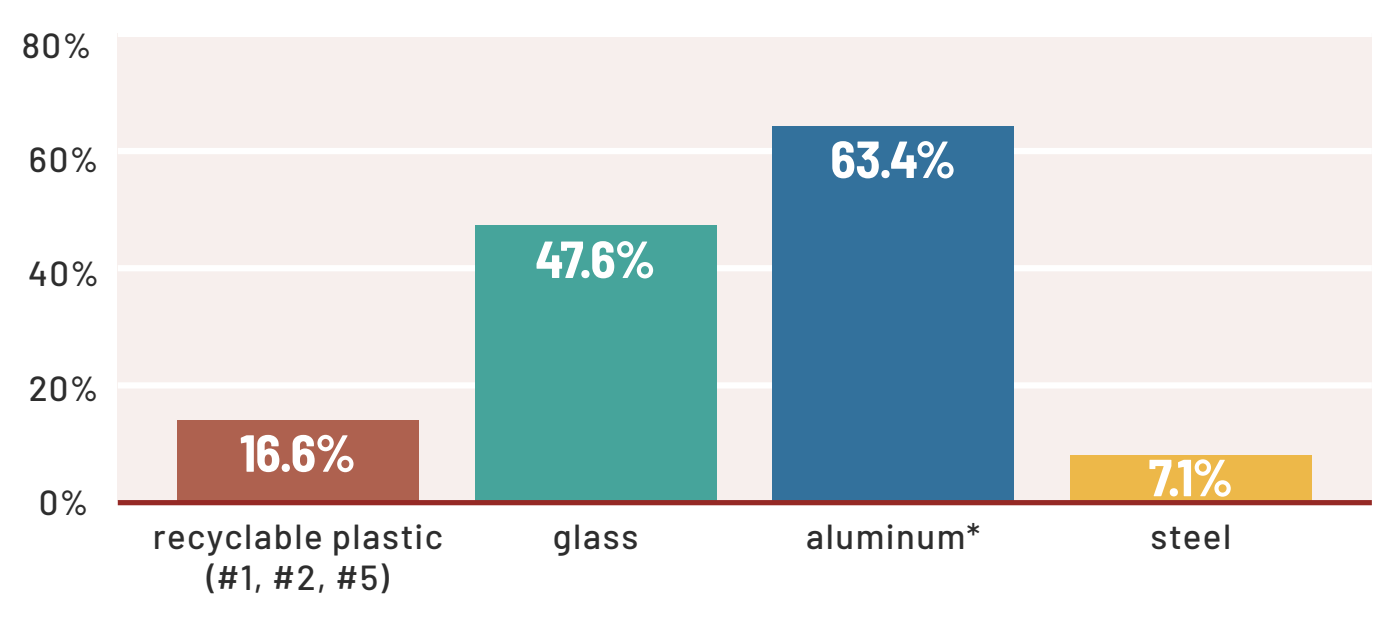

${ }^{*}$ Curbside only, recovery rate likely higher.

The capture rate of a recyclable commodity is the percentage of that commodity that is disposed of (in the trash or recycling) that is recycled. This chart compares the capture rate for each type of container included in the recycling program.

\section{Key Points on Capture Rate:}

- $16.6 \%$ of recyclable plastic containers end up in a recycling stream and $83.4 \%$ of all recyclable plastic ends up in the trash, not the recycling. As described above, most of these are captured through the deposit redemption system.

- This includes non-recyclable containers ( $45.6 \%$ ) and plastic film (20.4\%), both of which cannot be recycled in single-stream programs. Glass and aluminum are captured at rates $3-4$ times greater than that of recyclable plastic.

- Focusing on plastic recycling will have much less of an impact without a successful recycling program for all commodities, particularly given the low capture rate of plastic compared to other containers.

\section{WHERE DOES THIS LEAVE SINGLE-STREAM RECYCLING AS A WHOLE?}

CHART D7

Average Composition from Detroit's Single-Stream Residential Collection Programs

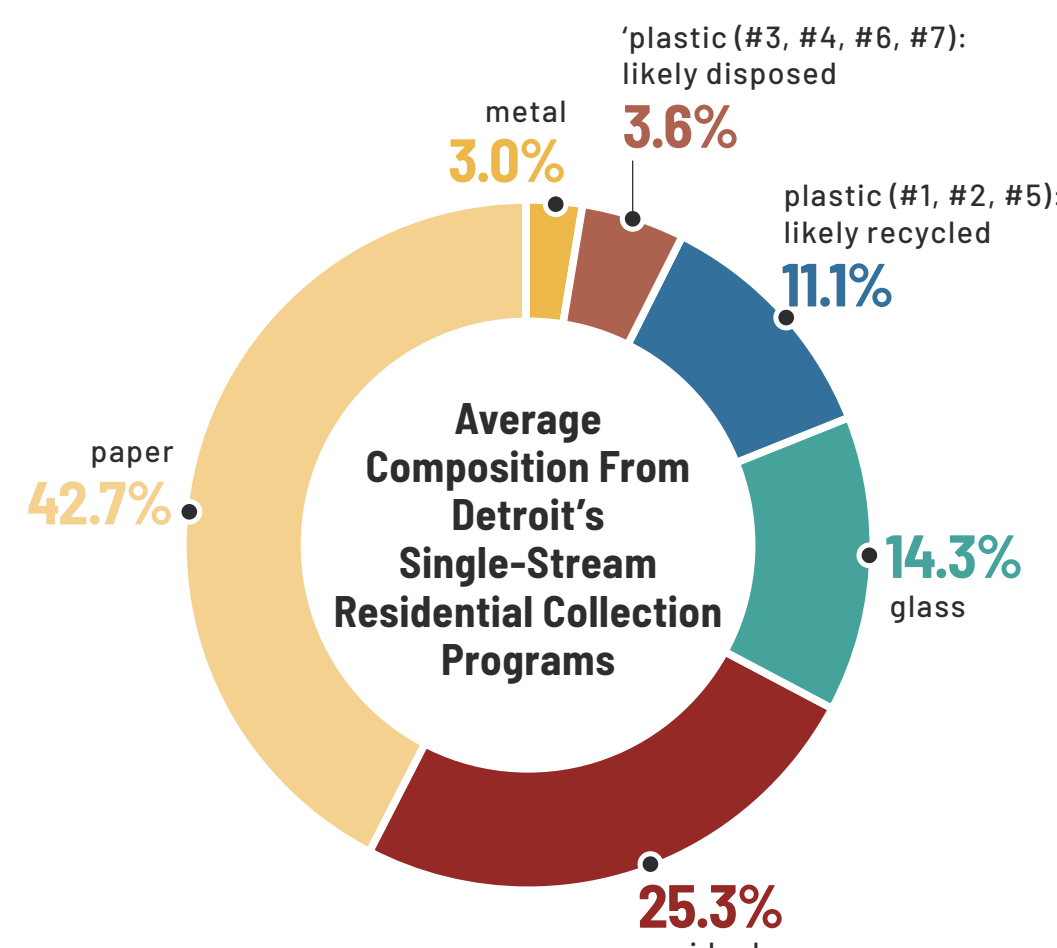

The percentage of materials sorted through the single-stream program that is metal, glass, paper plastic, or residual. This chart shows the MRF's composition of curbside recycling collected in Detroit. 
Key Points of Overall Composition of MRF:

- Over $70 \%$ of recycling in Detroit's single-stream program is recycled and it is important to continue recycling.

- Over $60 \%$ the recycling consists of paper, glass, and metal.

- Paper is by far the most recycled commodity at $42.7 \%$ of the recycling stream.

- Glass and metal make up an additional $17.3 \%$ of the recycling stream.

- While outside the scope of this project, many MRFs use glass for low value uses such as alternative daily cover on landfills, rather than sending the cullet back to glass manufacturers.

- Recyclable plastic makes up $11.1 \%$ of single-stream material.

- $28.9 \%$ of all the single-stream materials delivered to the MRF from Detroit is likely landfilled or sent to another MRF or secondary processor.

- $25.3 \%$ of material delivered to the MRF is residual: items that were wishcycled (non-recyclable in the first place and mistakenly put in recycling bins and carts); material that was destroyed or contaminated in the collection and sorting process; or material that cannot be sorted due to the inherent inefficiencies of single-stream MRFs, such as human error or mechanical issues caused by the size, shape, or condition of the material going across the sort line. Some residuals end up as waste disposed of at the MRF, while other residuals are incorrectly sorted into the wrong commodities sent to the wrong market, where they will generally be disposed of

- $3.6 \%$ is non-recyclable plastic.

- These numbers reflect the glass, metal, and plastic collected in curbside recycling bins and carts. They do not include the glass, metal, and plastic collected through the state redemption program or brought directly to a metal recycling facility.

\section{WHAT'S LEFT AFTER DIVERSION IN DETROIT}

CHART D8

What's Left After Diversion in Detroit

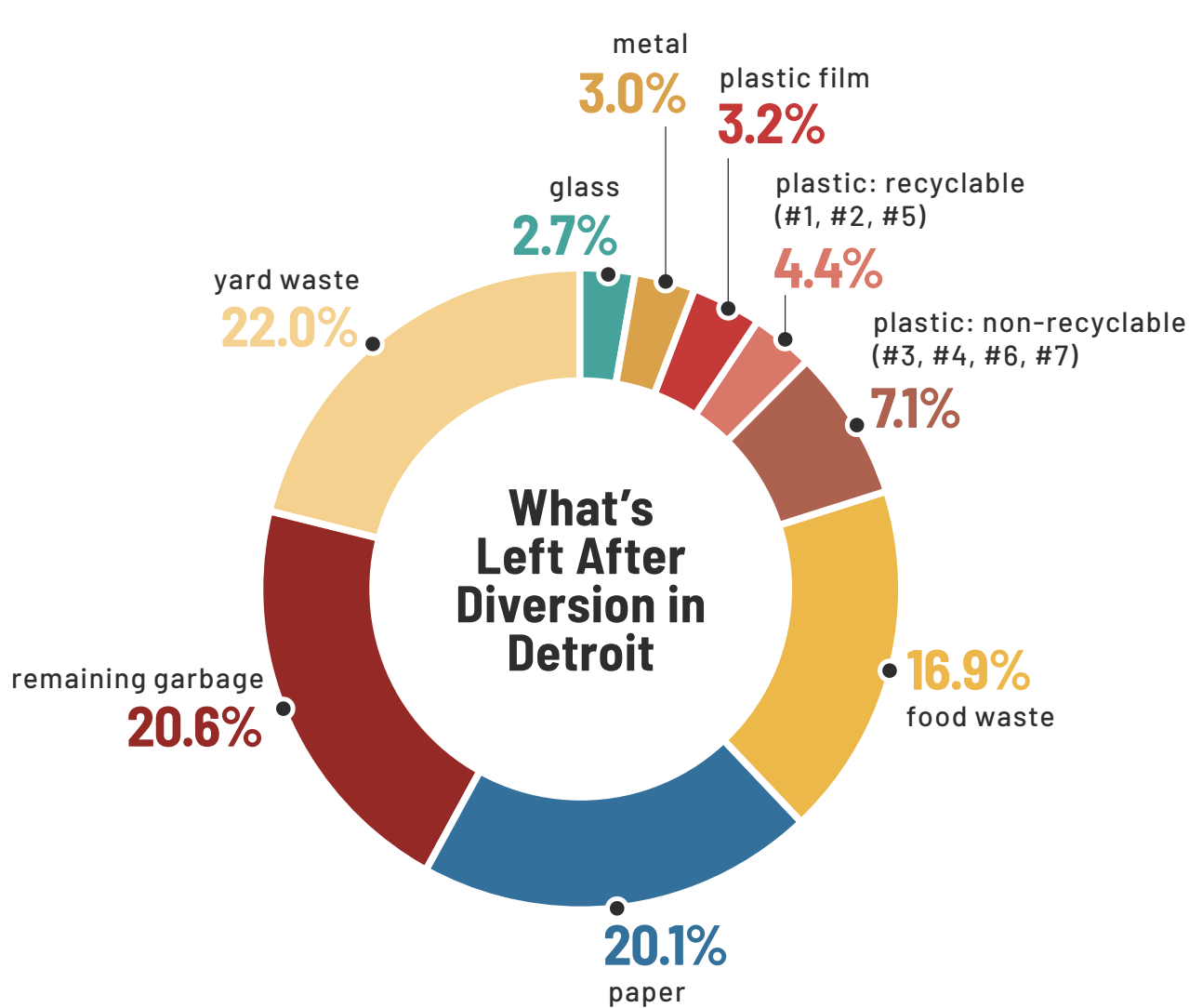

This chart shows the composition of what is left after diversion in Detroit.

Key Points of What's Left After Diversion in Detroit:

- Food waste $(16.9 \%)$ and yard waste $(22.0 \%)$ make up the largest fraction of what is left after diversion, totalling almost $39.0 \%$ of the remaining waste in Detroit.

- Traditional recyclables of paper $(20.1 \%)$, glass $(2.7 \%)$, and metal (3.0\%) account for over $25.0 \%$ of the waste stream

- A small fraction of plastic in the waste stream (4.4\%) is potentially recyclable plastic.

- Plastic, including film (3.2\%), non-recyclable (7.1\%), and recyclable packaging ( $4.4 \%)$, makes up $14.7 \%$ of the waste stream

- Plastic film makes up about one-third of non-recyclable plastic.

Data Sources can be found in the Appendix II: Methodology and Data Summary. 


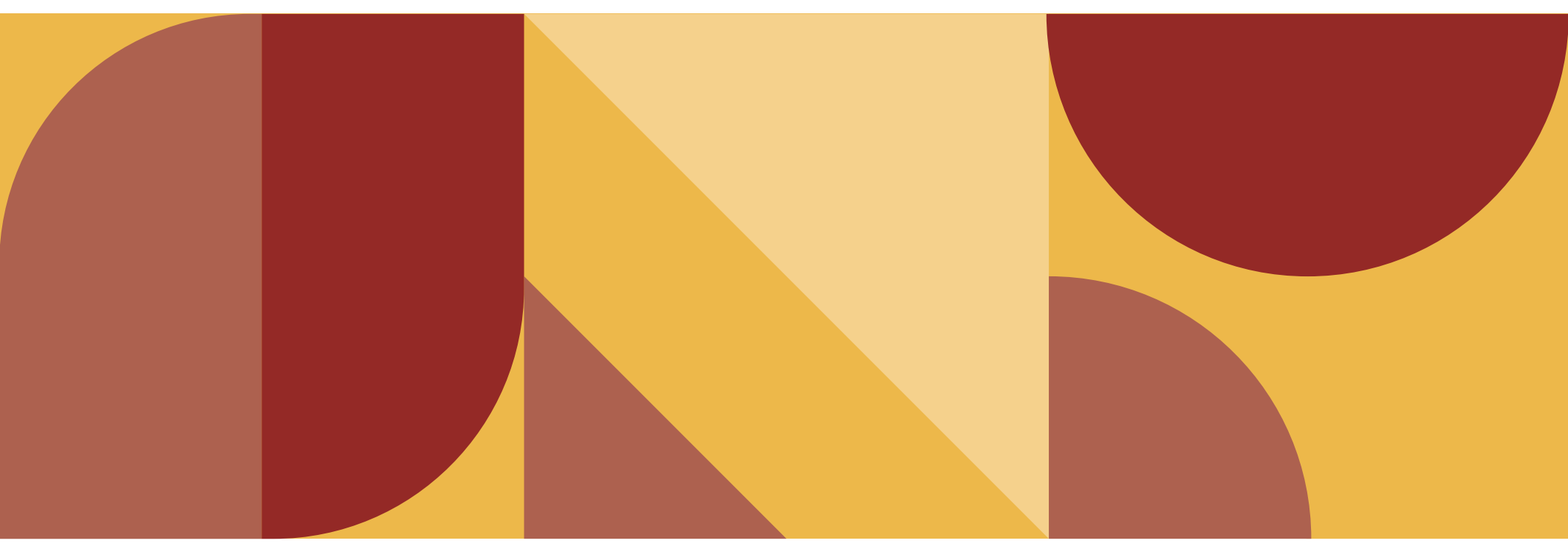

A Tale of 5 Cities: Plastic Barriers to Zero Waste

(C)2021 Global Alliance for Incinerator Alternatives 1958 University Avenue, Berkeley, CA 94704, USA 